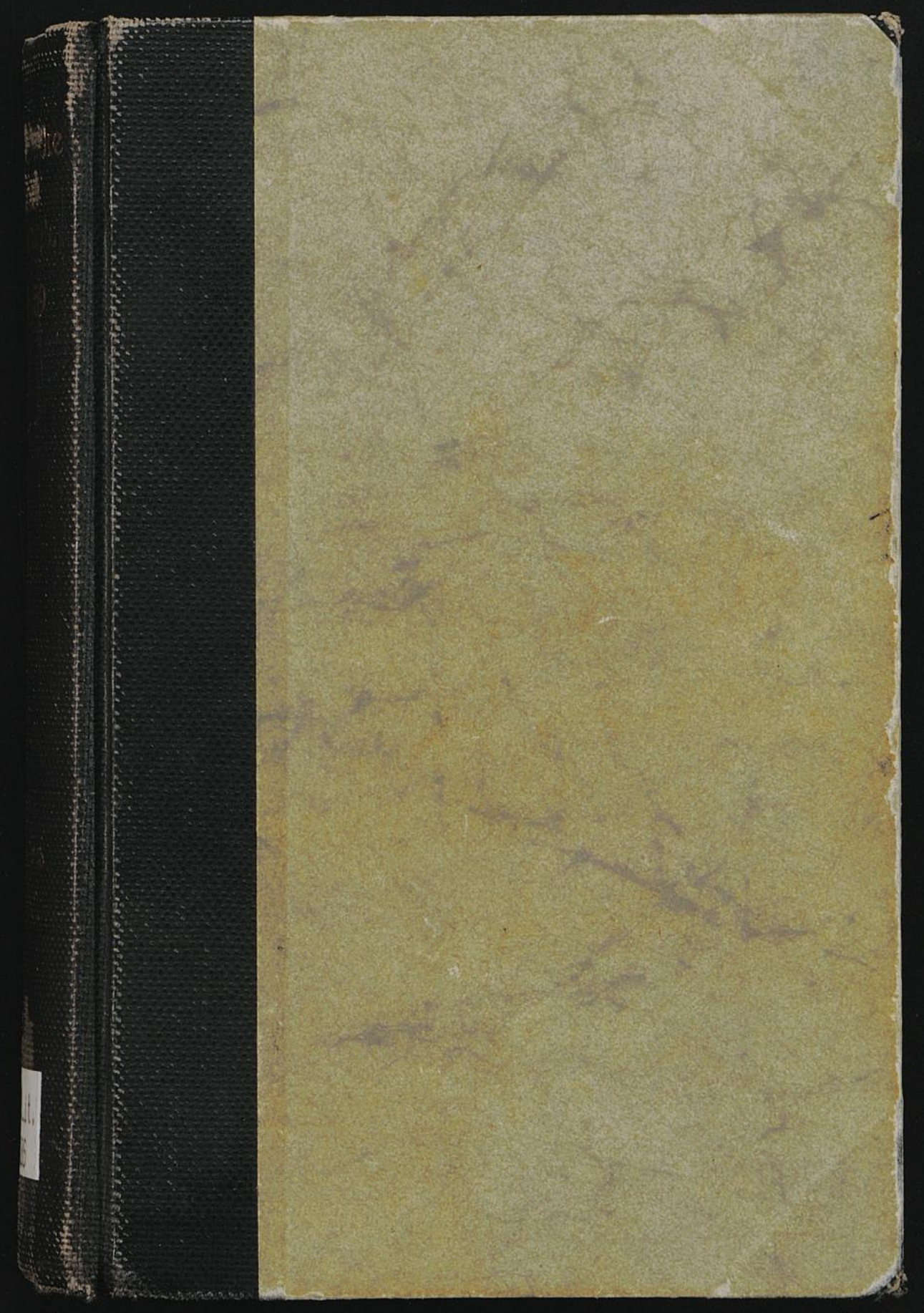




$$
\begin{aligned}
& 50 . v \\
& 51 / 52 v \\
& 53 / 54 v \\
& 55 / 56 \checkmark \\
& 57 / 58 \checkmark \\
& 59 \checkmark
\end{aligned}
$$

ULB Düsseldorf

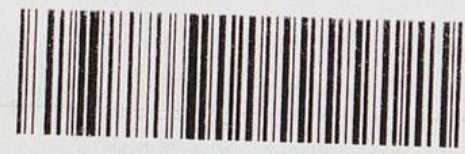

$+4012400 \quad 01$ 


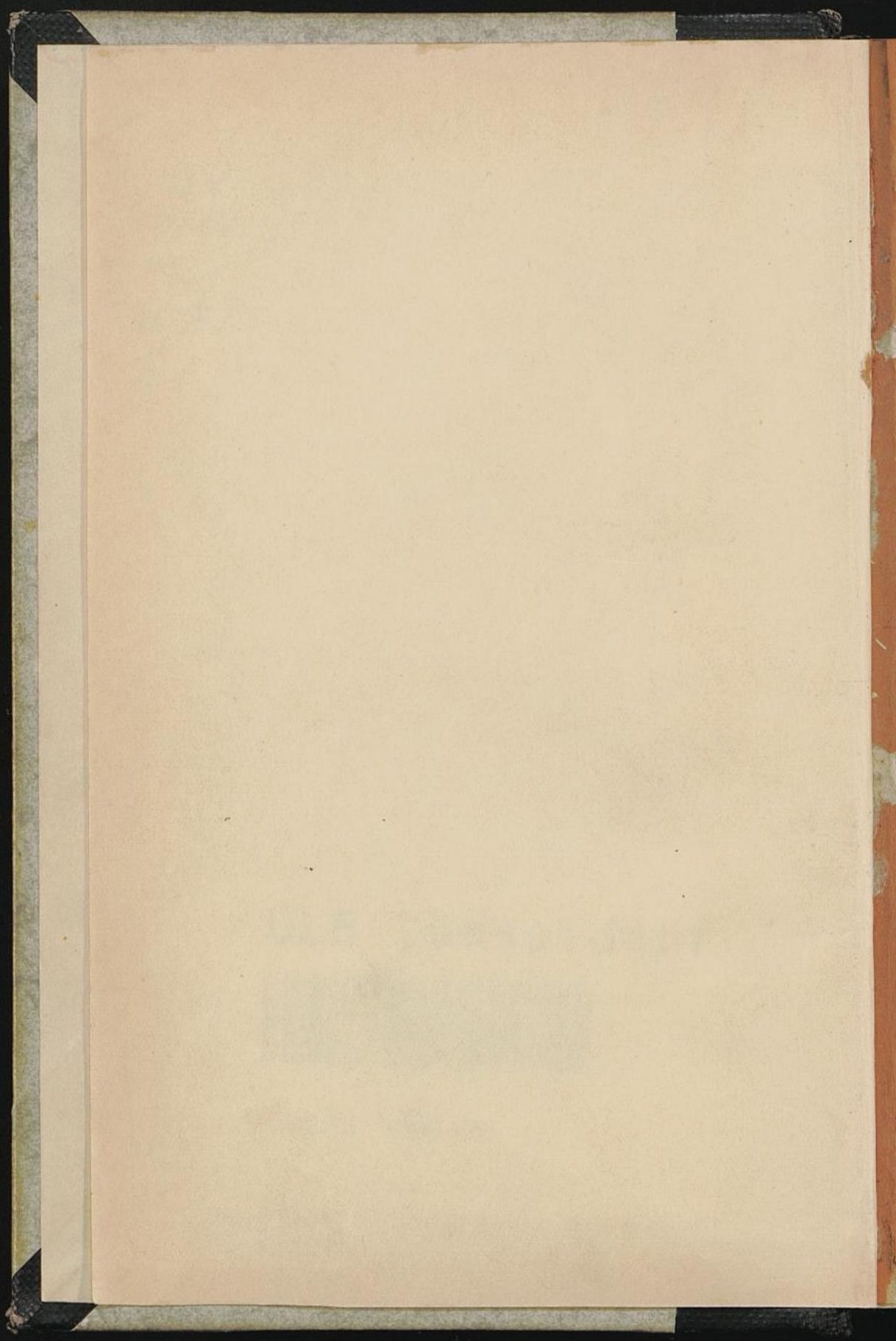


No. 50.

Preis $60 \mathrm{Pf}$.

eudrucke deutscher Litteraturwerke

des XVI. und XVII. Jahrhunderts.

\section{Von der \\ Winkelmesse und Pfaffenweihe \\ von \\ Martin Luther.}

Abdruck der ersten Ausgabe (1533).

Halle.

Max Niemeyer.

1883. 


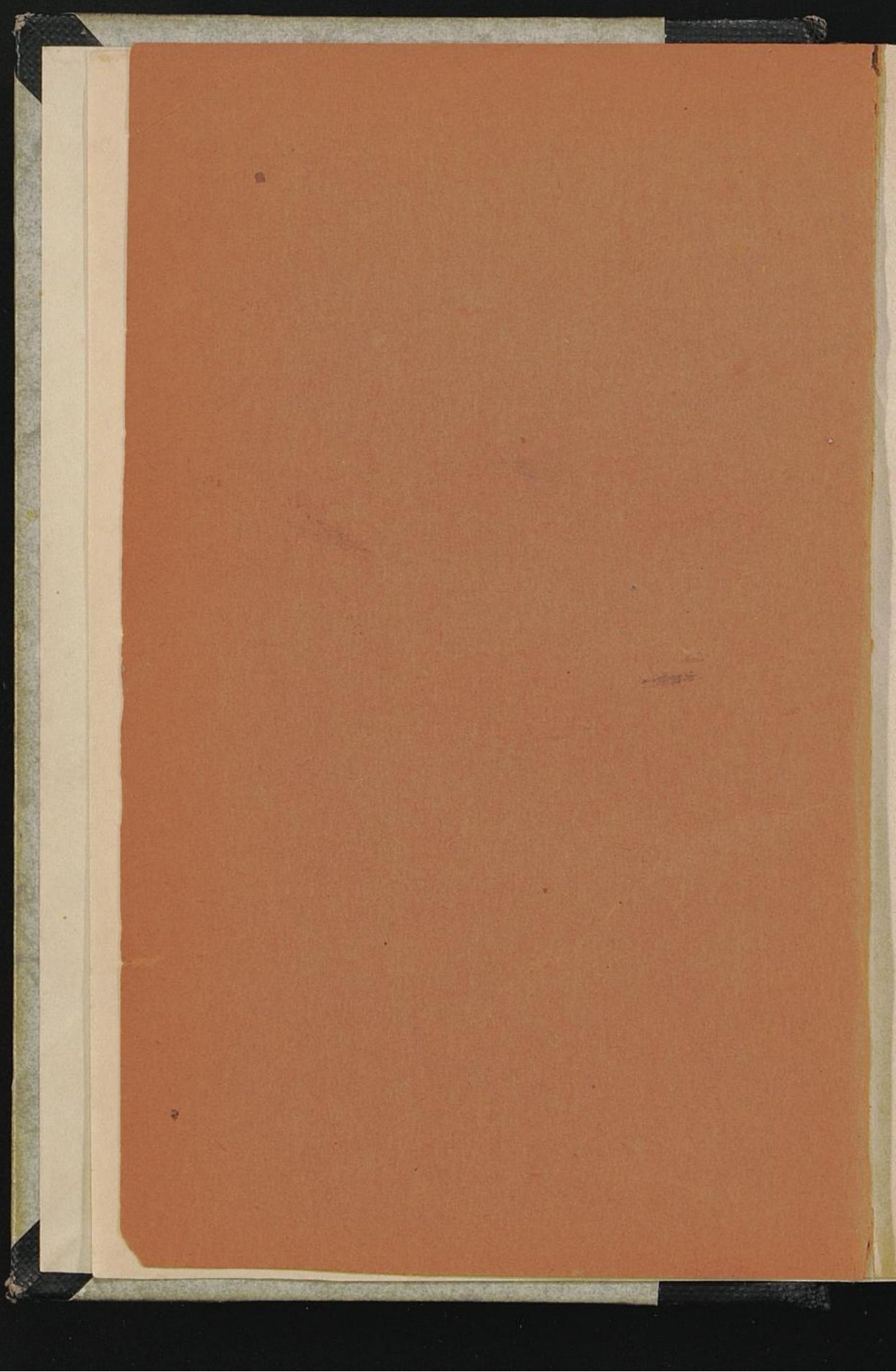




\title{
Von der
}

\section{Winkelmesse und Pfaffenweihe}

\author{
YOII
}

\section{Martin Luther.}

Abdruck der ersten Ausgabe (1533).

Halle.

Max Niemeyer.

$18 \$ 3$. 
1. Lit. $_{\text {...je }} 386$ 


\section{Vorbemerkung.}

Am 26. October 1533 schrieb Justus Jonas an Feorg Spalatin: "Lutherus iam scribit utilissimum fortissimum arietem, quo quatietur ut ferreus murus papatus, si quis adhuc est: Von der Päbstischen Weihe vnd Winckel oder privat Messen ". $\left.{ }^{1}\right)$ Damit erhalten wir die erste Nachricht iiber die Beschäftigung Lnthers mit einer der geistesmächtigsten und einschneidendsten Streitschriften, die er im Kampf mit Rom hat ausgehen lassen. Seiner Gewohnheit gemäss vollendete er die Ausarbeitung in kurzer Frist. Zu Neujahr war der Druck bereits beendet und die Schrift in die Oeffentlichkeit gelangt; denn am 3. Jan. 1534 wendet sich der Reformator an den vertrauten Freund Nicolaus von Amsdorf mit der Bitte: "scire cupio, quid sentias de meo libro von der Winckelmess“. ${ }^{2}$ ) Die Veranlassung für Luther, sich in jenen Tagen mit so scharfem Angriff gegen die Grundlagen des katholischen Opferkultus wie der katholischen Hierarchie, gegen Messopfer und Priestertum zu wenden, ist noch genugsam erkennbar. Sie lag für ihn in gewissen Vorkommnissen in seiner nächsten Nähe. 'Einmal war grade in jenen Tagen der ehemals lutherisch gesinnte, dann wieder zum Katholicismus zurückgekehrte Eiferer Georg Witzel in Luthers Geburtsstadt Eisleben, wohin ihn Graf Hoyer von Mansfeld als Pfarrer an St. Andreas berufen hatte, mit offenem Angriff gegen "die lutherische Secte" hervorgetreten;

1) Ko'de, Analecta Lutherana, Gotha 1883 S. 198. Bei Köstlin, N. Luther 2. Aufl. II, 665 ist irrig diesem Briefe das Datum , 15 . October“" beigelegt.

$\left.{ }^{2}\right)$ Luthers Briefe herausgegeben von de Wette IV, 500. 
am 18. October 1533 hatte er sein neues Amt mit einer heftigen Streitpredigt gegen seine ehemaligen Glaubensgenossen eröffnet. Und dieser Abfall eines evangelischen Geistlichen, dieses aggressive Auftreten eines neuen, mit dem ganzen Fanatismus des Convertiten den Streit anhebenden Verfechters der katholischen Lehre hatte die Wittenberger tief erregt. Luther nennt in seiner Schrift zwar nirgends Witzel mit Namen, verschiedene Stellen derselben werden aber nur durch Bezugnahme auf ihn recht verständlich. Ferner fanden in denselben Tagen in dem benachbarten Fuirstentum Anhalt sehr ernste Verhandlungen über die kirchliche Stellung dieses Fürtenhauses und ihres Landes statt. Cardinal Albrecht, Herzog Georg von Sachsen und andere katholische Fiirsten benutzten eine Zusammenkunft in Dessan, um die jungen anhaltinischen Fürsten Johann, Joachim und Georg, welche im Gegensatz gegen die von ihrer streng katholischen Mutter Margarethe bisher beobachtete Haltung, der Reformation sich offen anschlossen und durch Berufung evangelischer Geistlichen an der Neugestaltung der kirchlichen Verhältnisse arbeiteten, von diesem Wege wieder abzulenken und bei der alten Kirche festzuhalten. Der bekannte katholische Theologe Joh. Cochläus in Dresden versuchte eine briefliche Einwirkung auf sie in gleichem Sinne (vgl. Scultetus Annales II,399 f.). Den neuen Widersacher abzuweisen und die befreundeten Fürsten in ihren Entschliessungen zu stärken, zugleich den Beweis zu fuibren, dass er noch nicht mïde geworden sei, um den Kampf gegen Rom in der ganzen prinzipiellen Schäıfe und Entschiedenheit weiter zu führen: das waren die Beweg= griinde, denen diese neue Streitschrift des Reformators ihren Ursprung verdankt. Aber er hat ihr eine besondere Bedeutung dadurch gegeben, dass er sich in ihr gar nicht gegen einzelne Personen, es seien katholische Fürsten oder Theologen, wendet, sondern dass er sich hier nur mit dem System des Romanismus zu schaffen macht und dieses an zwei Hauptpunkten angreift. Dadurch hat diese Schrift eine Bedeutung erhalten, die weit iiber die Geschichte der Conflicte jener-Tage hinausgreift; sie bleibt bestehen als eine der mächtigsten prinzipiellen Auseinandersetzungen des 
Protestantismus mit dem Romanismus. Zugleich ist sie von Interesse um des Einblicks willen, den sie in die innerliche Arbeit des Reformators gewährt, Gewissheit in den Grundpositionen seiner religiösen Anschauungen zu gewinnen, und um der Reminiscenzen willen, die in ihr aus Luthers ehemaligem Leben im Katholicismus (Romreise u. a.) widerklingen. Auf die Bedeutung, die dieser Schrift zukommt, um die Anschaungen der Reformatoren vom geistlichen Amt und speciell der Ordination kennen zu lernen, ist kiirzlich von Rietschel in seiner Schrift, ,Lnther und die Ordination“ Wittenberg 1883 hingewiesen worden.

Im Fürsteutum Anhalt erzielte diese Schrift unmittelbar den Erfolg, auf den ihr Verfasser gehofft hatte. Im Frühjahr 1534 erschien der Mentor nnd Freund der Fürsten Georg Helt (Forchemius) in Wittenberg als Ueberbringer der frohen Kunde ,abrogatam esse missam papisticam et restitutam communionem ac synaxin reram juxta institutionem Christi“" (Archiv zu Zerbst). Der Sieg der Reformation war jetzt dort entschieden. In katholischen Kreisen zürnte man begreiflicherweise heftig: „libellus d. Martini Lutheri de missa privata videtur durus esse papistis et quibusdam magnis etiam principibus" - so meldete Jonas in eínem Briefe vom 9. April 1534. Besonders erregt zeigte sioh Johann Cochläus. Hatte dieser schon seit einer Reihe von Jahren es als seine specielle Mission betrachtet, möglichst jeder Schrift des Reformators seinerseits eine Gegenschrift entgegenzustellen, so versuchte er diesmal eine ganz besonders kräftige Abwehr. Er fand, dass diese Schrift Luthers „longe immanior virulentiorque" wäre als seine friberen Angriffe; laut jammerte er iiber diesen, ,tam impius ac plane diabolicus liber Lutheri." Er trat den Angriffen auf die Messe und Transsubstantiation sofort entgegen mit der Veröffentlichung zweier Schriften des Mittelalters, einer des Papstes Innocenz.III. und einer des Erzbischofs Isidorus von Sevilla:

Innocentij $\Re a=\mid$ PAE, HOC NOMINE TER= $\mid$ tij, Libri lex, de facro Altaris mylte- / rio, ex uetulto Codice nuper ex $=\mid$ cripti, \& nune per Typogra- $\mid$ phos excufi. | LIPSIAE. | - M. D. XXXIIII. 100 Bl. $4^{0}$. (Lipsiae in aedibus Nicoloi Fabri). 
und:

BEATI ISIDORI | HISPALENSIS QVONDAM ARCHI $=$ | EPISCOPI DE OFFICIIS ECCLE- | SIASTICIS LIBRI DVO, ANTE / ANNOS D CCCC. AB EO EDITI 1 - M. D. XXXIIII. I - 45 Bl. $4^{0}$. (Lipsiae excudebat Michael Blum).

[Eine dritte Publication des Cochläus ähnlicher Art, die des „Liber de contemptn mundi, sive de miseria conditionis humanae, a domino Innocentio papa tertio compositus', (Lipsiчe, Michael Blum, 1534, mense Martio) stand zu Luthers Schrift nur in losem. Zusammenhang.] Aber diesen Zeugnissen des Altertums, „quibus merito rectius creditur, quam furiis Lutheri", musste auch noch sein eignes deutsches Wort bekräftigend zur Seite treten; er klagte ja darüber, dass Luther darauf aus sei, „allein den Deudschen vngelerten pöfel einzunemen, vnd durch listig vnd lügenhafftige Sophisterey zu vberreden, Gott geb, die gelarten schreyben zu latein dargegen was sie wöllen." (,Von der heyligen Mess" Bl. A ij $\left.{ }^{b}{ }^{1}\right)$ ). Daher ,ne Germaniae populos negligere videretur, Teuthonice quoque respondit Cochläus" - so meldet er selbst in der ihm eigenen Autoreneitelkeit sein Auftreten gegen Luther in deutscher Sprache (Commenta. de actis et scriptis Lutheri Moguntiae 1549 p. 264). Diese Schrift führt den Titel:

„Bon ber|Geyligen Mejs|und Friefter weshe, Ebrift= licher beridyt D. So. | Eocleus || M. D. XXXIIII-

Randl. $4^{0} .38 \mathrm{Bl}$. [Bogen $\mathfrak{\Im}$ hat nur zwei, nicht vier

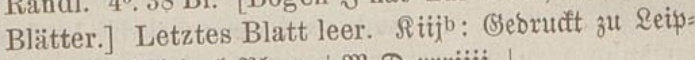

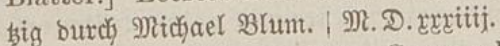

Aus den ersten Sätzen dieser Gegenschrift verdienen folgende besonders herausgehoben $\mathrm{zu}$ werden:

"Schrifft hin, f drifft her, bie furch beritebet bie Schrifft biel beffer sno gentffer burdy ben beyligen geyft, weldien byx c5riftus zugejaget wno gejanst bat, benn Suther burch ben bijen gesft. Das ift ein wort jo gut, als Taujenbe ynn biel zandbúdjern, Dabey

1) Vgl. Bl. A ij: "Eutber Blebbt ein Deubjajer farresber, ber bem ongelerten pifel " gofixt, bno allen lujt exlaubt." 
mus es endelicy bleiben, wenn wir fajon Iaujent jar bisputirten."

In sieben Capiteln handelt Cochläus in dieser Schrift ,1) vom Ablass, 2) von der wandlung Brods vnd weins im Sacrament, 3) vom Opffer der Messe, 4) von der Priester weyhe vnd Cresem, 5) von der Tauffe, 6) von dem Predigampt, 7) von beyder gestalt des Sacraments."

Auch später noch hat katholische Polemik mit besonderer Vorliebe auf die hier zum Abdruck kommende Schrift Luthers Bezug genommen und zu wiederholten Malen den Versuch gemacht, aus ihr das Eingeständnis Luthers herauszulesen, dass er in intimem Verkebr mit dem Teufel gestanden habe. Es genügt hierfïr des Jesuiten Nicolaus Serranus „Oratio, utrum verum sit, Lutherum .... Diabolo magistro et doctore usum esse" Ingolstadii $1603 \mathrm{zu}$ citieren und daran zu erinnnern, dass V. L. v. Seckendorf sich seiner Zeit veranlasst fühlte, einer französischen Schmähschrift gleichen Genres (Recit de la conference du Diable avec Luther, 3. Edit. Paris 1684) seine „Dissertatio historica et apologetica" entgegenzustellen, deren Inhalt er in seinem "Commentarius de Lutheranismo" I, 166 kurz recapituliert.

Aber auch von befreundeter Seite wurde Luthers Schrift misverstanden. Einige Aeusserungen derselben gegen die römische Transsnbstantiationslehre konnten so gedeutet werden, als stelle er seine eigene bisherige Abendmahlslehre, wie er sie den „Sacramentirern“ gegenuiber verfochten hatte, damit in Frage; er hörte den Verdacht äussern, , als halte er es, oder möchte es wenigstens mit der Zeit halten mit den Schwärmern oder Sacramentsfeinden." Daher liess er 1534 einen offnen Brief nachfolgen "von seinem Buch der Winckelmessen, an einen guten Freund", in welchem er seine Abendmahlslehre nach beiden Seiten, in ibrem Unterschiede ebenso von der Messopfer- und Wandlungslehre der Römischen, wie von "Carlstadts, Zwinglis und ihrer Gesellen irriger Lehre" auseinandersetzt und verficht (Erlanger Ansgabe 31 S. 378 f.).

Von seiner Schrift von der Winkelmesse giebt es folgende Einzeldrucke:

A. Bon ber win=| delmefje und $\mid$ Bfaffen Weite. $\mid$ D. 
Miart. Ruther. ${ }^{1}$ ) || SBittemberg. | DMXXXIII. | [Randleiste: der bekannte Holzschnitt der Schirlentzschen Officin, der die Enthauptung Johannis des Täufers in den Seitenbildern darstellt.] 56 Bl. $4^{0}$. Letzte Seite leer, vorletzte Seite [0 4]: Bebructit zu $2 B i t t e m=$ berg | burd) ridfel Styir=| Ienţ. M. D. XXXIII.

Von dieser Ausgabe giebt es jedoch, was die Bibliographen bisher nicht beachtet haben, verschiedene in geringfiigigen Dingen von einander abweichende Abzüge. Die ältesten Abzüge

a) sind daran kenntlich, dass Bogen $\mathrm{H}$ in ihnen einen andern Satz hat als in den späteren Exemplaren [erste Zeile schliesst mit "Gulffe" ]; ferner sind hier folgende Druckfehler uncorrigirt: $\mathrm{G} \mathrm{ijb}$ Z. 9 v. u.: Bonarentura. I Z. 19 v. o.: Teuffet?. I 4 b Z. 1: geruftr. K iijb Z. 4 v. c.: berufft statt beruff. L iij Z. 16: an elffen. Dann finden sich Abzüge

b) in denen Bogen $\mathrm{H}$, der in der Druckerei wohl beschädigt worden war, ganz neu gesetzt worden ist, daher oft mit andern Zeilenabbrechungen [Z. 1 schliesst, "Kúffffe mit"]. Ferner sind hier die Druckfehler zum Teil verbessert, nämlich: Bonauentura, Deuffe[s, gevirt, beruff. Endlich giebt es aber auch Exemplare,

c) in denen bei sonst völliger Uebereinstimmung mit b) auch noch der Druckfehler "elffen" in "elffiten" corrigirt ist.

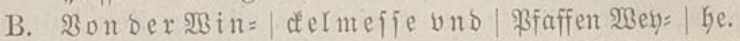
D. Marti. \&utber. || MBittemberg. M X XXXIIII. | [Randleiste wie in A.] $56 \mathrm{Bl}, 4^{0}$. Letzte Seite leer; vorletzte Seite $[04]$ : „Bsebructit zu Wittemberg | burch ritelel Edjit=| Yent. | IN. D. XXXIIII. -

Diese Ausgabe weicht in der Orthographie vielfach von A ab. Sie verbessert eine ganze Anzahl Druckfehler, die auch noch in Ac stehen geblieben waren, bringt aber zahlreiche neue Fehler hinein.

1) Das \& in Luther sieht einem lat. L so ähnlich, dass in bibliographischen Angaben es häufig als ein solches wiedergegeben wird; ebenso in B. 
Einige Varianten von B sind im Neudruck unter dem Texte angemerkt; die übrigen sind grösstenteils als Druckfehler zu betrachten. [So fehlt S. 8 Z. 6 v. u. "ou" vor "bolnbradjt", 14 Z. 2 v. o. "fie" vor "fan", 40 Z. 11 „wno" nach "Euangelio", 63 Z. 4 fehlen die Worte "wno mein" 68 Z. 8 v. u. "won" vor "beiber geftalt"; nur als Druckfehler sind ferner zu betrachten: 20 Z. 10 "inen" statt ,ikenen", 35 Z. 9 v. u. "Des" iterbenden, 36 Z. 5 v. u, "Iernet", 43 Z. 4 v. u. "ift" statt "ir", 66 Z. 8 v. u. "Das" statt „als", 74 Z. 16 v. o. "angreiffen" statt "angegriffen"; S. 39 Z. 5 v. o. findet sich der Pluralis "Die \$Bindel Bjaffen", 53 Z. 6 schiebt, ber" nach "inn" ein.]

C. Auf Luthers Wunsch veranstaltete sein Freund Jonas 1534 eine lateinische Uebersetzung, fuir welche jener den Canon aufstellte, ,ut libere sententiam meam reddas." Sie erschien unter dem Titel '):

„DE MISSA / PRIVATA, E'T VNCTIONE Sacer. libellus D. MAR. LV'IHE | RI ¿̇ Germanico in Latinum | translatus, per | Iuft. Ionam. [Hans Lufft'sches Signet.] VITEBERGAE. | M. D. XXXIIII." $76 \mathrm{Bl}$. so. Das 75. Bl. ist ganz leer, das 76. auf der Vorderseite gleichfalls, auf der Rïckseite das Luff'sche Zeichen. $74^{\mathrm{b}}=\mathrm{K} 6^{\mathrm{b}}$ [Bg. I besteht nur aus $4 \mathrm{Bl}$.] : ,Witebergæ, per Ioannem | Lufft, Anno. 1. 5. 34" Auf der Titelriickseite steht Luthers Brief an Jonas $=$ de Wette IV, 535, dem jedcch die Unterschrift und [Z. 13 bei de W.] "doctrinam" fehlt.

Die Uebersetzung ist - der Ermächtigung Luthers entsprechend - sehr frei, oft erweiternd und den Gedankengang des Originals weiter ausfïhrend, mitunter auch noch verschärfend und ibbertreibend, iiberall aber rhetorisch ausgeschmiickt. Beispielsweise lauten die wenigen Zeilen S. 48

1) Das Titelblatt habe ich vicht selber gesehen, da :sselbe in dem von mir benutzten Muinchener Exemplare hr stark beschädigt ist. Vgl. Panzer, Annales typographici
ol. IX S. 94 No.264. 
Z. $8-14$ bei Jonas: „Mox post textum Euange alienissima $a b$ Euangelio decantabant, et repen abducebant animos auditorum, nescio in quas i anissimas et uanissimas disputationes, Alij Arist telem et Ethnicos libros, Alij - ex consutili i farragine Decretis perorabant, Alij propositionn quaedam plaustra ex B. Thoma et scholastic inuehebant, Non deerant, qui Legendas sanctort recitarent, qui nunc Dominicum, nunc Franciscu supra omnes coelos eueherent, Ibi his uocibr ordo sanctus, ordo Seraplicus, omnia plena era: Franciscani ridiculo et blasphemo mendacio fin: runt sic Franciscum, uiuorum et mortuorum futur iudicem, totius scilicet ordinis Minoritani, sic Christus Judex futurus esset aliorum omnium, E tant de hoc ipsorum seripti libri, ut taceum inter Stationarios, et mare illud mendaciorum, reliqu fictivias sanctorum; lac Mariae, uinum ex nupt in Cana Galileae etc. Sed quis haec omnia enumer [Bl. F 8b]." Als Uebertreibung ist zu bezeichn dass er Luthers "ettliche" S. 41 Z. 4 v. u. „plaerique“ [Fijb] wiedergiebt. Luthers „rips $\mathrm{ra}$ S. 23 Z. 12 v. u. uibersetzt er mit der aus Suet entlehnten Wendung: ,citius, ut aiunt, quami as ragi coquantur."1) - Diese Uebersetzung wu iibrigens auch in die Wittenberger Ausgabe Opera latina Lutheri aufgenommen.

Dem nachfolgenden Neudruck ist ein Exemplar A a zu grunde gelegt, nur sind nicht allein die bereits A b und c verbesserten Druckfehler berichtigt, sondern a noch folgende, welche allen Exemplaren von A gemeins sind: S. 8 Z. 4 v. u. fanitn $=$ fanjtu; 19 Z. 17 v. u. \$jaff \$faff; 22 Z. 7 v. o. Dend (d) = Deubid); 34 Z. 1 v. o. Ebif beit = Ebriftenbeit; 37 L. 10 v. o. Biff $\mid$ fichoff $=$ Biffd 38 Z. 13 v. u. WibDerwetiger $=$ Wioberwertiger; $47 \mathrm{Z} .11$ v aufferweleen = aufferweleten; $49 \mathrm{Z} .10 \mathrm{v} . \mathrm{u}$. Euangelon $=$ Eua

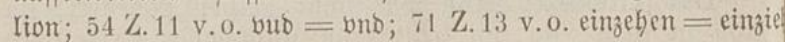
Magdeburg.

Gustav Kawerau.

1) Vgl. hierzu Erasmi Adagia Basil. 1574. 617b. 


\section{Bon Der min=}

delmetie viti) difffenturilse.

7. Altart. Puther.

mittembera D M XXXIII. 


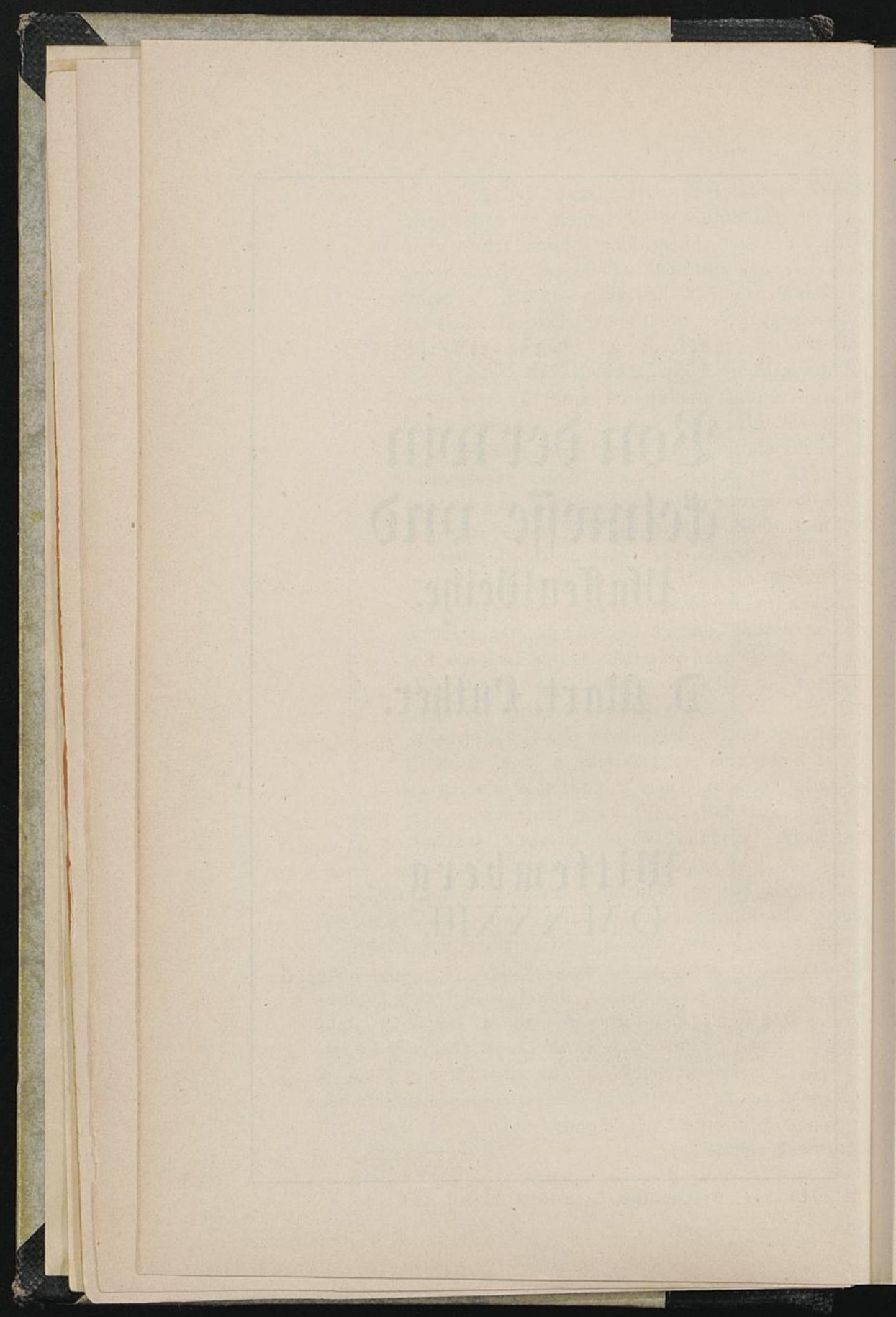




\section{[2. ii.] Soll Der Wintelme= tie und $\mathfrak{P}$ faffen $\mathfrak{B e r}$ he,}

D. Martini Ruther.

213 Ir haben vns bis ba her allezeit, vno fonder=

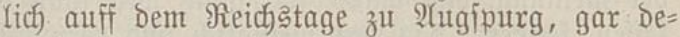
mitiglich exboten, Dem Sapit uno Biffichouten, Das wir nicft roolten ir Rircjen rechtel) bnto gemalt

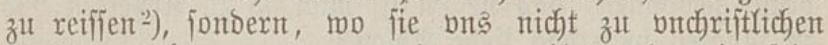
2(xtifeln zmuingen, gern von inen gemeih)et vnt regirt jein,

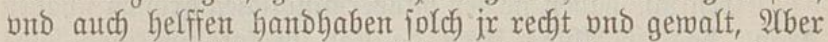
wix babens nicht mitgen exbeben nod) exlangen, Sondern, fie roolfen bns von ber warheit zu jren litgen vno gremeln Dringen, odber wollen vnts tod haben, Went jnen mu (meil fie jolche veritocte \$harannes find) mit jrer gemalt uno wenhe, ein mal gehen wird, wie es jnen mit bem 2lblas gangen ift, Rieber, wes wird als benn bie idfuld fein? Dem ba ich mich erbot bom 2 (blas ftilf zu ichtweigen, ip fern bie andern auch von mir itifl jchmigen, ba molt mich meder Bapit, (Eardinal noch Biffichoff horen, Sondern iff)

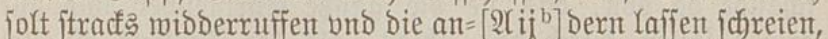
Waas habent fie bran gemonnen? Da ligt bas 2lblas, vno fint brieue vnd fiegel zu ftoben ond zu flogen. nichts veredfters inn ber welt, benn bas 2 tblas, aljo, das fie auch jelbs zu 2̂ugipurg Dent Seijer baten, Er jolte ben Bapft vermögen, das ex fein 2 tblas mehr jun Deubich Yano fchicfen rolte, angejeben, bas es jun abfall vno verachtung fomen were.

1) Ausg. B: recht.

2) Vgl. Augsburg. Confession Art. XXVIII, 69. 77. 
Diejer bitte ward zu Alugsipurg wol gelact, als fie aud marlich Yecherlich ift, meir Die \$apijten ibst jelba bittent widber Das 2 blą, Daruber fie mich vorhin zu Rebert, verbampt, verflucht, verbrant vno mit alferlen plage ver:

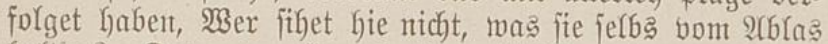
balten? Dent to fie es fúr nutblich ond gut bielten, múrben fie nicht aus ber vrjachen ba robsoer bitten, bas es jun abfall bno verachtung fomen ift, Sonjt mijpte man

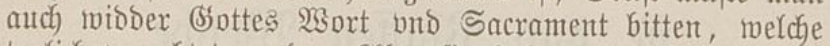
teglich werachtet werben, afber fie baltents jelbs fúx einent lauter betrug vito Yígen, Bno ich muite boch ber ergeit Reber heiffen wno bes tods jufurlsig jein, ba ich aflein vom 206las zmeituelte ond bijputirete, gar nicht (zu ber zeit) ber meinung, bas mans folt gants weg thun obser faren Iaffen, jondern, das mant meffiglich vno vernunffitig ba von jolt presigen und halten, Nut twas haben fie (fage icf) Dran gemonten, Das fie [9 zu plagten vmb dą liebe 2rblas?

(Eritfich), haben fie bent vnibermindficken grofien fichadent bran, Das ir 246 las fram da ligt int fot von jnen felbs veracht, vno nidyt mehr geld vno gut tregt, wie er zu bor vber alle mas gros gut ond geld trug, Diejen ichaben Gabent fie von mix, wno fonmens boch mir nicht ichuld geben, Sonden mifjen befennen, das es jres veritodten,

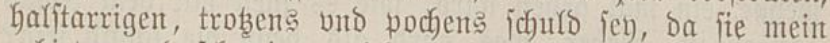
erbietent bno ichimeigen nicht wolten antement, Sno ift in recht gejchefen, wo afle welt lacht vno ipottet jr billich ztt foldbem ichaben. Bum andern haben fie bie emige fanande da bon, das fie bie ganke Egriftentheit bnd alle arment ieelen, burch das 24blas, als bie Teuffels 2Ypoiter wno betrieger, io ichendich verfitret, vito omb folds uniag= Yich) gelo betrogen Gaben, Sho wenn ber Bapit mit feinent Bapiften, fein ander lígen vno triegeren inn ber Ofriften= heit getrieben Getten, Dent allein Das 2Ublas, So Getten fie boch ba mit wol berbienet, das man fie fír bie grófie= ften feber bno reuber fichelten folt, fo bie erben jhe ge=

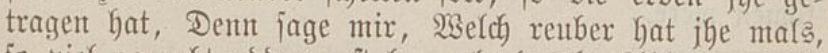
fo viel geraubt obser geitolen, als burchs stblas geraubt vno geitolent iit? Weldy Reberet) hat jo viel jeelen ver= 
furt ond betrogen, obser ift jo weit vno fern gelauffen,

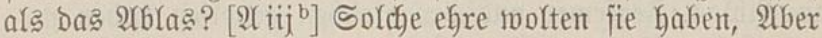
ment geben fie joldhen raub vno biebital miboer? bringen fie foldye verfitrete Ehrijten zu recht? Sa wol, Sie jeuffizeten nicht ein mal brumb, wolten wol lieber, bas jie joldhe verfürung vno renberet) etviglidy treiben

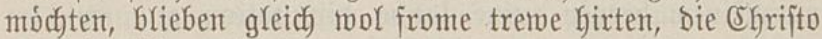
jeinte ichefflin tweibetent.

Wie? wents mit ber zeit ein mal eins jnen auch mit juer Sirchen gewalt wito Wethe aljo gehen wurbe, Das gleich, twie die 2 (blas briente zu ftoben bnto zu flogen finto, alfo aud beide (Erejent ${ }^{1}$ ) bni ßlatten, zu jtremet mitront,

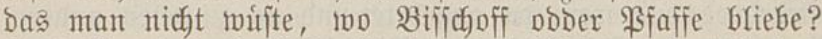
(Sott ift wumberbarlich), (Ex hat bas 2 (blas gelegt, ${ }^{2}$ ) Da? Fegfemr geleficht, bie $\mathfrak{B a f f a r t e n}$ gedempfft, vnd viel ander Des Mammons (Sottes Dienft vno ab́gótterey Der Papiften, niobergejclagen, burch jein toort, ob ex auch jo viel marcf jun feinen henden noch hette, Das er einen garjtigen Erejem, Ginder feintem roillent, burch lauter menjchent getidyt ein gefurt, finte aus fteubern? Wolan, fompts ba zu, lieben Sapit vno Biffichoue, fo burfft jr mir bie fdunllo nicht geben, jondern ewrem veritocftem, harjtarrigen fopff, Der nidyts wil jun ber zeit zun fachen thun, jonbern ftractes burch alles Gindurch brechen vito reiffen, Dem Utblas fumo jr nicht mehr helffen, Es ijt zu lange gebarret, Shie fundtet ir noch et $=[\mathfrak{A} 4]$ was jchaffen, meil wir lebent, Nach) vnjerm tod, jo exfaret benn, toas euch etwer Sct)reier

1) Chrisma.

$\left.{ }^{2}\right)$ Cochläus antwortet darauf: , Das des Bapst Ablas bey viel Deudschen ynn verachtung komen sey, kan ich nit laugnen, dazu Luthers schriften viel geholffen haben, nicht aus eygner krafft (denn sie selbs widder einander waren, vnd schluge eine die andern, so hart, das Lnther selbs offentlich begeret, man solt sie alle verbrennen, vnd schlecht sagen' Ablass sey der Römischen heuchler schalckheyt [vgl. Opp. lat. var. arg. V, 16.]) Sondern aus misbrauch vnd leychtfertigkeyt der Ablassführer vnd prediger, die $v \mathrm{mb}$ gelts willen solche gnad vnd mildigkeyt der kyrchen, mit viel ergernis vnd missbreuche, gemein vnd verechtlich gemacht haben." Von der heyligen Mess Bl.B. 
mit jrem ichelten vnd Yejtern Gelffen, gleidy wie fie euch ant 2 bblas, Fegfetwer vnto ber gleichen gefolfen haben.

sch wil an mir antheben, ond fur end beiligen Betern eine fleinte beicht thun, gebt uir eine gute abjolu= tion, bie euch felbs nicht icheolich fer, Jch bin ein mal zut mitter nacht auffermacht, ba fieng ber Teuffel mit mir junt meinem herben, einte foldhe difputation an, (twie er mir bent gar mandbe nacht bitter ont jaur grutg madjent faut) Şoret jrs, hodggelerter, wifjet jr auch, bas jr funff= zeben jar lang babt, fajt alle tage, mincfel Mefijen ge= halten, Wie toent ir mit folder Meefie bettet eitel $a b=$ gótterey) getrieben, vno nicht EGriftus leib ond blut, fondern eitel brod bno wein ba angebetet ono an zu beten andern fúrgebalten? $\Im$ ch) antmort, Bin ich bod ein getweyeter \$faff, habe Crejem vno \$eike vom Biffichoff empfangen, ba zu jolchs alles aus befelf ond gehorjam gethan, wie folt ich bent nicht haben (Eonjecrirt, ${ }^{1}$ ) weil ich bie mort mit ernit geiprochen, wno mit aller muglichen antoacht Mefie gebalten, Das weiffeitu fur war, sa, ipract) er, (ss ijt

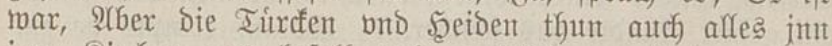
jren Sitchen aus befelly ond exnjtlichem gehoriam, Die \$faffen Jerabeam zit Dan nno Berjebe thet $=\left[24^{\text {b }}\right]$ tent alles, vieleicht mit grófier andacht, meder bie rechtent Friejter zut serujałent, Wie ment bente $\mathfrak{s e n h e , ~ E r e j e m ~}$ vno (conjecrim aud vectyriftlich ond falich mere, wie ber Titrcten wno Samariter?

Shie bract) mir marlich ber idfweis aus, wno das Gerb begonit mix zu zittern vno zu pochen, Der Teuffer meis jeine argument mol an zujeben ono fort zu oringen, wns hat eine ichnere itarcfe iprache, Bno gehent foldhe bifputation nicht mit langen vno viel bebenden zu, Sondern ein augen blicf ift ein antwort ombs ander, 2Bno ich babe Da twol exfaren, wie es zu gehet, bas man des morgens bie Yeute. im bette tod findet, Er fan Den Yeib ermitrgen, Das ift eints, (Ex fan aber audd) ber jeelent fo bange madyen mit bifputixn, das fie ausfaren mus jun einem augenblicf, wie ers mir gar offt faft nahe gebradyt bat,

1) B: gewandelt. 
Nu, Err hatte mich jut biejer bijputation ergriffen, SBto

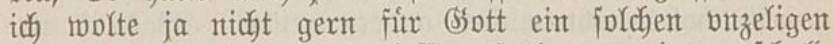
Gauffen gremel auff mir Iaffent, jonbern meine onjchuld verteibigen, wno horet im zu, was ex firr vrjachen hette,

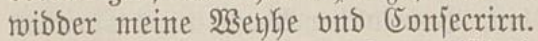

(Exitlich, iprach ex, Du tweiffit, das du nicht recht an Ebriftum gegleubt hait, wno bift bes glaubents halben, io gut als ein Tirref gemejt, Dent Der Tircef, ja ich felber

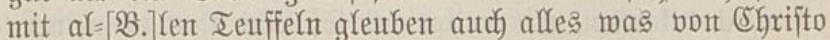
geichrieben ftehet, Jacobj am. iij. $\left.{ }^{1}\right)$ bas ijt, wie er geborn, gejtorben, gen bimel gefaren, ift, Afber bujer feiter tröftet jich jein, odber hat zuterficht zu jm, als zu eintem şei= lanbe, Sondern wir furchten in, als einent jtrengen richter, Soldben glauben hattejtu aud b, wnd feinten andern, ba bu getwenhet wurbejt vno Meefie Gielteit, vno alle ander, beibe

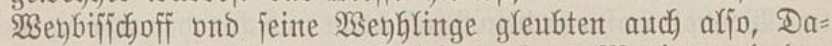

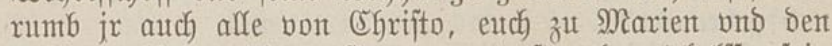
Szeiligen Gieltet, bie muiten ewer trojt voto not Gelffer jein gegen Efriftum, Das fanjtu nicht Yeugnen noch einiger Bapift, Darumb jeio jr getwenget, vno habt Mefje gebalten, als Seiben onto nicht als Ehriften, Wie Kabt jr bent

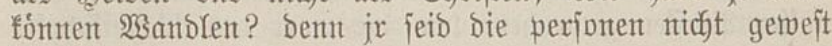

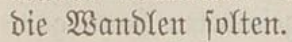

Bum 2Andern, jo biftu gemenget, vno hajt gewandret misoer bie oronung ono metnung Ehrift, Dent Ehriftus meynung ijt bie, bas man for das Sacrament obder bie Meffe aljo halten, das es jeinen Ehriftent aus getenlet vno ben andent gereidyt merbe, Denn ein \$faffe jol fein ein Dienter ber Rirchen, bas er bie Sacramtent aus teile vno prebige, wie bas alles bie wort Cyrifti im abenomal, vno jut ber eriten zun (Eorinthern am elfften Eapi. flerfich forbern, $\mathfrak{D a}$ her es audf) won ben alten $\left[\mathfrak{B}^{\mathrm{b}}\right]$ Setern, Communio, gemeinjichafft heiffit, bas es nicht Dex \$fraff allein jolfe nemen, jontbern, bie andern jun gemein auth mit empfaben, Nu hajtu misber jolche meinung EGrifti, bie funffzebent jar Yang, alle mege das Sacrament alfein

1) Jacob 2, 19. Das falsche Citat (Cap. 3) auch in der Ausg. v. 1534. 


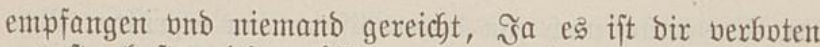
gemeit, Gaits nicht miffien andern reichen, $\mathfrak{S a}_{\mathfrak{s}}$ ift mu

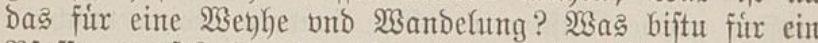
\$faffe gewejt? Der bu bir allein, und nicht ber Rircbent zum biener getwethet bift, \$on jolcher $\mathfrak{3 e n h e ~ m e i s ~ E b r i f t u s ~}$ nicht, Das ift gemis.

3um Dritten, Éfrijtus meimung ift, ' Das man bey Dem Sacrament folle bon jum vno jeinem tod prebigen, vnto offentlich befennen, wie ex ipricht, ธ\$ऽd) s thut zu meinem gedechtnis, bas ift, verfintoigt (mie es Sanct \$aulus rebet) meinen too, bis ich fome, Afber ou Wincfelmeffer baft nie fein wort geprebigt noch Egriftum befand jun affen Deinen

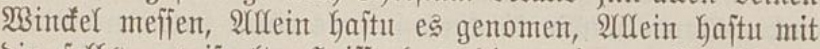
Dir felbs gemifpelt, Sceifit das die meinung Chrifti ge= Galten? Seifijt das ein rechter \$faffe? Sit bas bie hei=

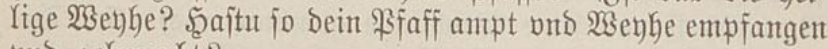
vnio gebraucht?

3um Sierden, Cyriftus meinung ift, bas es jolle ein gemein Sacrament fein, Den andern Shrijten mit zut teilen, 2lber bu bijt ge $=[3$ ij $]$ wenhet, das bu es jollejt (5jott opffern, vno bift nicht zum Sacraments \$Faffen, jondern, zum

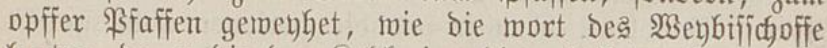
Yauten, Da ex bix ben fielch) jun die gejalbeten hand gab, bul iprach, Âccipe potejtatem conjecrandi et facrificandi pro biuis et mortuis, Das mag mir eine verferete $\mathfrak{B}$ ebge heiffen, das du bir einzelen perjonen, ein opffer gegen (S)ott braus machit, das doch fol eine gemeine ipeije fein, vou Cbott Durchs Bfaffen ampt, Den Ehriften zu reichent verorbent, $D$ gremel bber gremel.

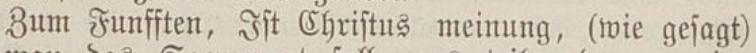
bas man bas Sacrament folle aus teifen ber gemeine Egrifti, jren glauben zu ftercfen, ond Egriftum zu Yoben offentlich, Du aber hait ein eigen mercf braus gemadyt, bas bein jey ond du volnbracht hajt on zutfun ber andern, ßno jolds s rercf andern mit geteilet bno bmb geld ver= faufft, $\mathfrak{W a}$ fanjtu bie leugnen? $\mathfrak{S}_{0}$ zu biftu mu gervenbet, ber bu feinen rechten glauben gebabt, Da zu wiober alle Dromung bno meinung Shrijti, gemenhet bijt zum eigen opffer $\mathfrak{B}$ faffen, zum eigen twerct $\mathfrak{P}$ faffen, nicht zum ge= 
meinen fiuchen Bfaffen, Der bu niemant hajt bas Sacrament gereicht, nichts ba bet geprebigt, wno gar nichts gethan, barumb es Ehriftus eingejebt hat, jonbern, das mibder ipiel gethan, Bno bijt ichlecht wiober (Ehriftum geweyhet, zut thun alles [B ij"] was piober jn ift, Biftu aber wiober

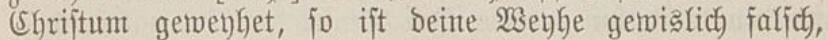
Wibderdfriftifich, vno lauter nidfts, Darumb hajtu auch ge= wislich nicht getwandet, jondern ichlecht brot vno wein geopffert, empfangen vno angebetet, vnto andern an zu beten fúr gefalten.

Gie fiheitu, das inn beiner Meffe, zum exiten nidgt die perjon da ift, jo $\mathfrak{B}$ andlen fol und fan, Nemlich, ein (Shriftgleubiger menich, Zum andern, ift nicht ba bie

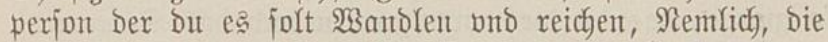
Chyriftlich gemein obder voldf, Sondern, Du Ssottlojer vn= gleubiger \$Sfaff fteheit da allein, ond meineit, Ehrijtus habs vmb Deinen wiflen georbent, vno jolfe bir alfein auff hupffen, vno jeinen Yeib vno blut Wandren Yafjen, jo ou boch) nicht jein geYied, jondern jein feind bijt, 3um Dritten ift bie endich meinung vno frucht obser brauch nicht $D a$, Die Efriftus Gaben twil, Dent es ift eingejebst, Die Ehrift= lidge gemeine da mit zu ipeijen nno jercfen, vno Chrijtum zupredigen vnd preijen, Nu weis bie Chriptliche gemeinte von beiner Meffe nicht won bir nichts, Sondern Du jhrweigeit bort im mincfel bub friffeft es alfein, ber bu boch vngleubig vno vnmirbig bijt, vno ipeijejt niemano ba mit, jondern verfeuffejt es, als bein vbrig gut mercf, Weil bu bent bie perjon nicht bijt, bie es thun [Biij] for, vnd bie perion nicht ba ift, bie es haben jor, vnd bie endriche meimung verferet ijt, bie Chriftus ba geordent hat vnd haben wil, $\mathfrak{B}$ nd bu Doch) zu feinem anbern, benn zu foldhem ichenolichen ver=

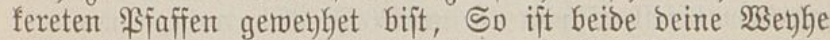
vno Wandelung Yauter nichts, Denn CBottes Yejterung vno berjuchunge, vno biftu meder Pfaffe, noch bas brod ber Yeib Ehrijti jun Deiner Meffe.

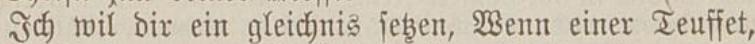
ba fein Berfon mere, bie fich Teuffen Yieffe, obser ment 
ein Fladent wet)er ${ }^{1}$ ) eine Shlofent teuffete, bie nicht jeint fant bie perjon, fo getauffit mag merben, Sieber jage mir, were bas auch einte Tenffe? Shie muftu fagen, Nein, Dent wer fan bas Ieuffen bas nichts ift, obder bie Teuffliche perjon nicht ift? Was were es fít eine Tauffe, wem idf junt ben wint hin (precke, Isch Teuffe bich int namen bes Baters 2c., vnd witrffe twaffer hinach? Wer emtpfehet hie bie vergebung ber funden, vnd Den Seiligen geift, vnd andere tugent ber Tauffe? Die lufft obber bie glocfent? Da mujtu ja greiffen, bas hie feine Iauffe jein fan, ob gleich bie wort ber Tauffe geiprochen bno das twaffer ge= goffen wird, Darumb das feme perjon da ift, bie ber Tauffe empfehig ift, Wie menn birs jun beinter Meffe auch fo gienge, das but bie mort pprecheit und bas Sacrament

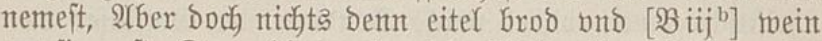
empfiengeit, Dent bie perion bie firche ift nidgt ba, So bijtut vngleubiger zum Sacrament geichidtt eben mie bie

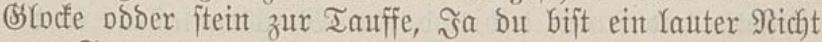
zum Sacrament.

Şie miltu vileidft fagen, ob idy ber Sitrchen nicht reiche das Sacramtent, So gebe obder neme idfs boch mir felber, Empfebet boch mancher im hauffen bas Sacrament,

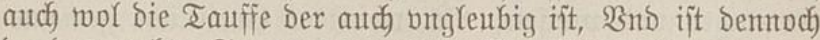
da bas rechte Sacrament uno tauffe, Sarumb jolt Dent

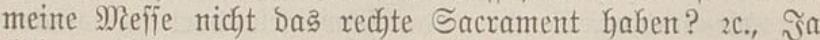
Yieber gejelle, Das ijt nicht gleidy, Denn jun Der Tauffe find alle rege (wents gleich) einte jah Iantfe ift) zum mentigftent zwo perjonen, Der teuffer und Der Teuffling, SHo offt viel mefre da bey, vno ift ein ampt, bas von fich gift jun ber gemeine, als einem andern gelied, nicht zu fich nimpt, ond anderen uichts gibt, Wie du jun ber Meffe thujt, Sno wenn alles feblet, jo gehet hie bas merct aus wnd jun bem befelf Chrifti, Deine Mefle aber nicht, 3um an= Dern, $\mathfrak{W a r u m b}$ leret jr nicht audf), bas fich einter folle

1) Spöttische Bezeichnnng der Weihbischöfe; so z. B. sehr häufig in der Schrift „Klàg und antwort von lntherischen und bebstischen Pfaffen" 1524 bei 0 . Schade. Satiren und Pasquille III, 149 f. Luther erklärt in einer Predigt (Erl. Ausg. ${ }^{2}$ 8, 176) Fladen als Abkiirzung des Wortes Oblaten. Jonas übersetzt [Bl. Bij] Fladenweyer mit Suffraganeus. 
Doer mitge felber teuffen? Waarumb iit bas jelbe feine tauffe? Waarumb ift das feine Jermelung, wo fich einer felbz

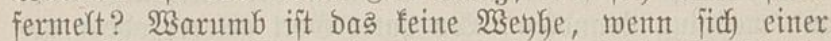

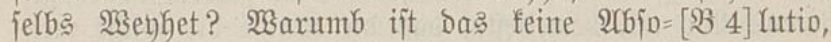
ment fich einer abjoluint? Warumb ift das feine Shung, wo fich einer jelbs Dlet? Warumb ift das feit Erebe, ment fich einer jelbs wolt zur Ëhe nement Sobder molt beid) laffen eine Dime mit gemalt vno iprecken, (5) mus einte Ehe jeint on jrent bandf, Denn bas fins ewer fiebent Sacrament, So mu bas war ift, das fein Sacrament fan non bir felfer gemadyt werben, Wie fompt Dent bas einige vno hókejt Sacrament ba zu, das du birs aflein vits felbeit machen mitgeit?

Waar ifts, bas (wie man jagt) Cryrijtus mit bent Singern aud fich felbs genomen hat im Sacrament, Sno ein \$Farrer fampt ber gemeinte felbs autc) bas Sacrament nimpt, Uber ex madjts bno nimptes nicfit allein fíx fich), fondernt empfehets mit ber genteine, odber mit andern, $\mathfrak{B}$ mo gebet alfes jun ber ordming wno befelf Egrifti, 2Aber idf

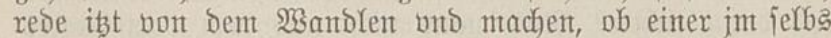
muge $23 a n d$ len vno machen, Dent to es getwandlet ift, weis idh wol, bas mit ben andern ein.iglicher jelbejt mitge nement vno effen, Dent es ijt eine gemeine fpeije, Shleich

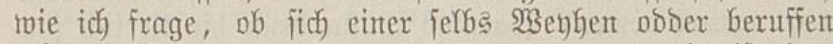
mitge, weis rol, went er beruffen obder getwenhet iit, bas er bax ntack foldfs beruffens brauchen mitge. Sttemt, ment einer bet) einer Dimen idjlieffe, bie nody nicft fein, nody jut $\left[\mathfrak{B} 4^{b}\right]$ gelobt ift, obs gmug iet), das ers allein ono jelbs eine ehe heiffe obser helt, meis fajt mol, ment fie ja jpridft buto jein ift, bas barnach bas bet idflaffen eine ehe ifit $2 \mathrm{c}$.

Jint biejer angit ond not molt idy Den Tenffel bon mir weifen, ergreiff ben alten harnifich, io ich im Bapitum Gatte Yernen anzigen vno furen, Scilicet intentionem et fibem Ecclejie, bas ift, idy Gette jolche Meffe gekalten im glauben vnt meinunge ber firchen, Dent ob idf) gleich) nicht recht gleubete nod) meinete, fo gleubts uno meinets doch) Die Sirche recht, Darumb mifte meine Mefie vnto Wethe recht jein, Da wiober fties ex mich aljo, \&ieber jage mir, 
wo fteht bas gejdyrieben? Das ein (sottlojer, glaublojer, menich mitge ba her tretten, bno auff ber ̊ircben glaubent

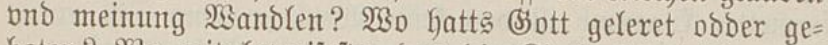
boten? $\mathfrak{B} 0$ mit bereijeitu, bas Die Rirche bir jolche mei= mung bar ftrecfe bno leble zu Deinem eigen wincfel merd? fabens aber menjoden gejagt, on Bottes mort, fo ift? alles exlogen, эa jo maujet ir im finjtern vnter bem namen ber Sirctsen, Sno for barnach alfe etro gremel, ber Sirchen meinung heiffen. Bum andern Yere bu mich nicht, was ber Sirchen glaube vno meinung fer), Die firche gleubt bno meinet nicfts auffer efriftus meinung vno oromung, biel mentiger, twiober feine meimung bno promung, won weldger ich broben ge=[(ㄷ] jagt habe, Denn Baulus fpricht jun ber exiten zun Corintbern am oritten (Eapi. $\left.{ }^{1}\right)$ Wir Gaben ben fynn obder meinung Chrifti.

Wo ker jol man aber miffen, mas bie meinnng Ehrifti vno feiner Sirchent ift, on aus feinen bno ber Sirchen eigen worten? 230 fer weiftu, bas ber Rirchen meinung ift, wie (Egebruch vnd mord funde fer), bas vnglaube berbampt, vnt ber gleichen? Mats mans nicht aus Dem wort (s)ottes Yernen? So man bent von Den werfen mus bie meimung Der Sirchen aus bem wort \&sottes nemen, wie viel mehr muङ man von ber Yere bie meinung ber ßirchen aus Dem mort Bottes nemen? Warumb thujtu benn bie flerfich inn Deiner $\mathfrak{B}$ indfelmeffe, wibder bie Kellen mort ons oronung Ehrifti, vno Yeugejt Darnach auff Die Rirche, ons wilt bich ferben mit jrer meinung, als jey ir meimung mibber Shriftus wort bno oromung? Wer Keifit bich fo jchend= rich) Yiegen auff bie firche? $\mathfrak{B}_{\mathrm{eil}}$ bu benn nicht ander: gemenhet bijt, benu zur Wincfelmeffe, bas ift, zu thun mibser bie wort vno oronung Ehrijti, mibber bie meinung vulo glauben ber Sirchen, jo biftu mebr entwenget Dent gewenget, vno ift beine weybe viel nichtiger vno erger Denn ber glocfen tauffe ond itein weybe, Darumb wirftu aud gemislich nicht gemandelt, fonbern eitel brob ond mein (mie bie Sceibent) geopffert, bno Den fromen Shriften als ein gut werd ber $=\left[\mathcal{C}^{\mathrm{b}}\right]$ fauffit bno mit geteilet haben,

1) 1. Cor. 2, 16. Auch B u. C haben das falsche Citat. 


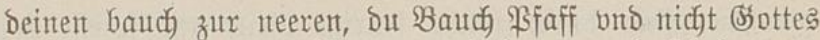
\$Sfaff, wer hat ihe groffer gretwel, betrug vnd jodaben ge= Gort jun Gimel obder auff exden $2 c$, Das war bie Dij= putation fait jun ber Summa.

Şie werben die Geiligen ßsapijten mein ipotten und jagen, Bijtu Der groffe Doctor, bnd fanjt Dem Teuffer

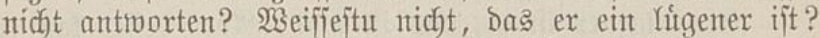
Dand habt lieben Gerrn emer troftriçen 2lbjolution ond antmort, Denn bas bette ich nicht getwuit, Das ber Teuffel ein litgner ijt, two jr mirs ibst nidht fagtet, Wentu idf eint Bapift twere, wno ber Ieuffer Yiefje mix frieben, wie ex fie Yefit im jauje bno ficker Yeben, So roifite ich jut auch fein zu antworten, Dent ich and ber finen belden einer bin, sex fich nidgt fitr zeben furcht to idy alleine bin, Uber folten fie ben Teuffel Goren bijputirn, fie jorten mix nicht lange von Sirchen, bon altem braudy ond ger

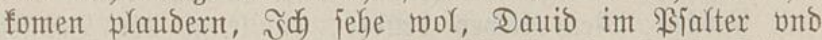
bie lieben Bropheten, wie fleglidy jie vber joldhe Dijpu= tation idfreien, Bno Shrijtus jelbs, mis (wie tool omb vniern millen) manth bitter jufffizen ono engiten lajien eraus faren, burch des Ieuffers jedgen bno orengen, Sno ich Galt, das (Emier ${ }^{1}$ ) vnd Ecolampabius, ${ }^{2}$ ) und ber

1) Hieronymus Emser starb am 7. (oder 8.) Nov. 1527 plötzlich zu Dresden. Cochlaeus beschreibt sein Ende folgendermassen: „obiit, si forte nondum audisti, VII. die Nov. Dresdae, suffocatus (ut mihi scriptum est) fluxu pectorali, quum tertio ante obitum die sacrificium missae peregisset. Vir profecto, qui ut amicitia tua non erat indignus, ita in asserenda fide catholica omnium fidelissime diutissimeque ac fortissime pugnavit, cujus animam non dubito nunc super glorioso labcrum ejus fructu gaudere ipsamque veritatem, pro qua hic dimicavit, clara visione intueri." Heumann, docnm. literar. pg. 56. 57. Dagegen erzählt Marcus Wagner, Einfältiger Bericht von Nicol. Storck, Erfurt 1592 Bl. 33 b: „Als box Emser zu Dresden mit Etlichen ein Banket gehalten und wohl bezecht heim kommen, setzt er sich auf einen Stuhl, fiihret schreckliche Lästerworte und greuliche Gebärde, fährt der Gotteslästerer Emser des jähen Todes plötzlich ins Teufels Namen dahin."

2) Oekolampadius starb am 24. Nov. 1531, schwermütig: seit dem Untergange seines treuen Kampfgenossen Zwingli. Ueber seinen wie Z wingli's Tod schrieb Thomas More an Coch- 
gleichen, fint burch jolche feurige pfeile unto fpieffe bes Tenffels, io plóblich [S ii] geitorben, Denn es fan fie fein menich extragen, on jonderliche (sottes huifffe vitb ftercfe, Er ift fajt fitrb meilig, ment ex bifputirt, Dent ex jpielet bes furben ond madbt nicht lange meile, wo er ben man alfein ba heim findet.

Ein litgenter ift er, Das ijt twar, 2(ber befīer fant ex Yiegen, Dent jonjt ein idjlechter Yingener, vno funjtlicher, mebder ein menich veritehen fan, Denn ex nimpt fúr fich eine warkeit, bie man nidft lengnen fan, vno juerfft ba mit jëine litgen, Das man fich nicht weren fan, (E) war bie Yauter

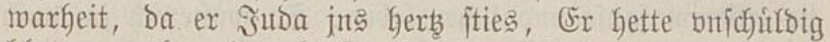
blut verratgen, bas funte sithos nicht Yeugnen, (Es toar bie marbeit, 2lber bas mar erlogen, bas ex jn verzmeyueln

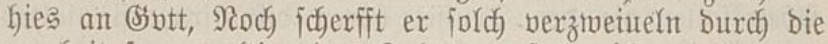
warkeit io gemaltig, das গubas mujt baritber babin ond fich Gencfen, Nein lieber bruber, Da leugt Der Teuffel

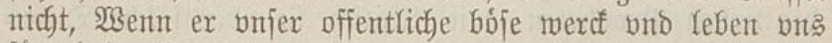
firr helt, Da hat ex zween zeugen, Die niemanto ftraffen fan, Nemlicf), Srottes gebot vnto vnjer gemiffen, Shie ijt mix nicht mugfich, Nein, zu jagen, Sol ich bemt, Ja, jagen, als ich thun mus, jo bin ich bes tods vno bes Teuffels, 2lber ba leugt er, ment ex Daritber mich treibt,

läus: „Quorum nunciata mors laetitiam mibi attulit. Quanquam enim dolendi causas reliquere nobis seu nimium graves propter multa, quae neque sine horrore eloqui possum, et nemini sunt ignota, neque audire homines pii sine profundo gemitu debent: sublatos tamen e medio esse tam immanes fidei christianae hostes, tam accinctos ad ecclesiae excidium, tam intentos ubique in omnem perimendae pietatis occasionem, jure gaudere possumus." Comment. Cochlaei de actis Luth. p. 232. Reformirterseits hat man es natürlich sehr übel vermerkt, dass Luther hier Oekolampadius' T'od als vom Teufel bewirkt bezeichnet hat; vgl. z. B. Sculteti Annales II,355. Es liesse sich aus der Reformationszeit ein langes trauriges Register derartiger Urteile über den Tod von Männern, die einer andern religiösen Partei angehörten, als der Urteilende und Richtende, zusammenstellen, namentlich in Fällen, wo ein plötzlicher Tod eingetreten war; eine Beispielsammlung zu Christi Wort: Richtet nicht, auf dass ihr nicht gerichtet werdet. 


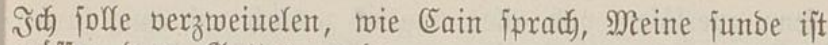
groffer, benn Csottes gnabe.

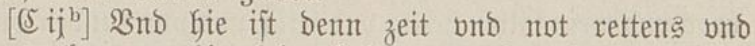
helffens oben vom fimel herab, das entmeder ein bruber bet bir (et) mit einem eufferfichem wort (S)ottes, obder ber Seifige geift felbs im Kerben mit eximnerung folcher eufferlicjen mort, bno ipreche, Du haít befant vno nicht geleugnet, Der Teuffel fat bas ja mort gemonnen, bas bu gejundigt

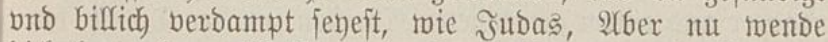
bich herumb zu Ehrijto, wie Sanct $\mathfrak{B}$ etrus, vno jihe was er furt bich gethan hat, Egriftus hat folch dein ja mort burch fein blut lotboerrumb verbamt vno zu nicht ge= madyt, ond for bir nicht ichaden, 2Aujer (Egrijto hette ex wol recht zu Dir, 2Aber weil bu inn Egrifto bift ond in anruffeft, fo ift folds bein ja mort ribserumb zum Nein morben, vno fanjt trotzen vnd rhimen wiober ben Teuffer, Bin ich benn ja ein funter, jo bin ich Doch ja fein junber, Ein funber bin ich jum mix jelbs aufjer Ebrifto, Siein

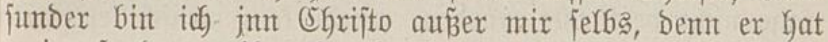
meine funtoe vertilget burch jein heiliges blut, da zmeinel ich nicht an, barauff habe ich Tauffe ond 2rbjofution bno Sacrament, ars gemiffe fiegel bno brietue.

Summa, rix fint jolcher $\mathfrak{B}$ indelmefie bno Exejem los, vnd wolfen fie laffen vertendingen jue herm bie Bapiften, fo ibst viel bucher idgreiben fonnten mit eitel litgen vno Yejtern exfifflet, von forn an bis zu ende, Sie

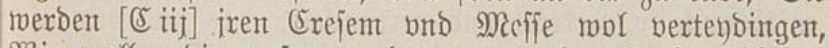
Wir wollen die mijern vno wer es begerb, jun biejem ftud vnterrichten, twarnten vno trojten, $\mathfrak{S}_{5}$ erhalten mu bie Papiften odoer nicht, das jun jrer 23 incfelmeffe eitel brod vno mein, odoer ber Yeib vnd blut Egrifiti jeb), (ba fúr wir fie Yaffen forgen) sijt eitel brod und mein ba, wie es fajt mislich ono ferlich ijt, So mus joerman jagen, bnt fie jelbs aud befenten, bas fie bie groffiejten betrieger vno verfiurer auff erden fint, bie den Egriften eitel brod

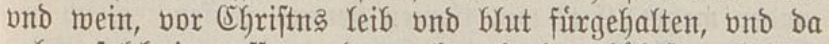
neben joldh jr opffer vno mercf, als den hóbeiten Bsottes Dienjt auff exben, mit geteilet vnd verfaufft haben, ba Durch bie jumber fúr (s)ott zu verjumen, bie jeelen im Feg= 
femr zuerlojen, vno alfes vnglinf zeitlicf) bno emig zu ver: treiben, als were Chriftus gar nichts, und wir burch eitel brod vnd wein jolten Keilig vnd jelig, bno von jundent bno too erlofet werden? Sieber wie wolten mir einten jolchen Bfaffen jun jeinem Meigetwand vno vber bem 2urtar anjefen vito nenten, anders, bent einen Yeibigen Tenffel felbs, aus ber Selfen grumb heraus? Bno was were als bent feine Weyhe, da er zu joldyer Meffe gemenhet ift, andera, bent das er auts einem gemenheten (Shriften jun Der Tauffe, Durdf jeine Biffichoff und Exejem, zu einem Teuffel entwenket were?

Şie bilffft nicht bas fie ichreien, Sirche, [尺 iij ${ }^{b}$. Rirche, ßnto viel Beter, Sanct Srregorits, Berntbardis $x$, Gaben jolche Mefie gebalten $2 c$, Dent auff Der Beter Yeben ono thun fonnen wir nicht tratoen noch batwen, Sondern auff Sottes wort allein, meil Shriftus uns jelbs gar tremlidf getwarnet hat, Matthei am vier vno żmenzigiten [v.22.24] Das joldjer jrthum fomen folfe, bar ein aud bie auffermeletent

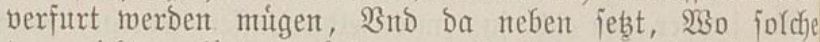
tage nicft verfitrbet mutroen, wurbe fein menich jelig, Da zeigt ex ja flerlich an, bas vnter Den Efyriften bas mort vno Sacrament bno Iauffe (Durch) welche mir múfien felig werben, und jonjt nicht) jolle jo jun ferfigfeit geraten, Das niemand ba burch múge felig merben, Nu haben mir onter bem Bapitum foldye zeit erfaren, Dent ob wir wol bie Tauffe, Sacrament und 3 ort gehabt, fint fie bodf (twent wir gros bno alt roorden) burch menichen lere ond misbrauch jo verferet vno vertundelt, bas wir vnt nidft: mehr dex jelben Gaben fómen rhumen, Sondern Gaben

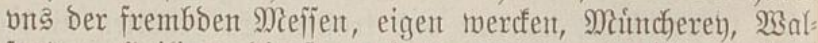
farten, Şeiligen bienift, uno ber gleichen, muffen tróften,

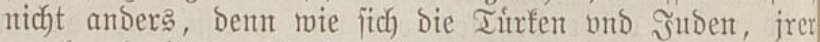
mercf und Bsottes bienjt tróften, Bno ift auff joldfen bes Bapitumbs verferung vno gremel, aller melt gut gangen, Sb mu bie auffermeleten fierin mit verfuret morben fino, hat fie Sott an jrem ende (mie Sanct Bernthard buto ander mehr) [ङ4] wol fónten heraus reifjen, gleich wie Sot aus Sobom, bno bie fieben taulent zur zeit EFlias, Darumb auff ir thun bno reben, on (3)ottes wort, nicht? zu wogen ift, jun foldjer hohen emigen jachen. 
Sit aber ber leib vnd blut Egrijti da, So mus jeder= man fagen und befennen, das fie die groffeiten Sottes diebe vito Sirdgen reuber find, jo auff erben ibe tomen fint, Denn das Sacrament (wie oben gejagt) ift nach chriftus meinung da zu geordent vnd eingejest, bas mans jol bent andern Shrijten reichen obser mit teilen, als einte Communio vno gemeine ipeije zux ftercfe ond trojt jres

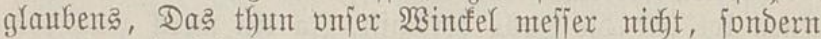
nemens ond behaltens allein, ond teilen nidgt einem eintigen Shrijten etroas mit, ond menn ite es arjo ber Sbriftenbeit geftolen vno geraubt Gaben, geben und verkenffen fie bar nad) Da fix, jr opus operatum, ir eigens opffer vnto toercf, gleich als fie vns auch, toent roir gros morben find (Denn bie finder find fur jnen Durch Ssott ficher blieben) die tauffe, als nu Durch folgende junbe verloren, geitolent vno geraubt gaben, Da fúr ons lemen eigene wercf thun, Mainch werben, vnd beiligen bienen $2 c$, wie ธ. \$etruts jagt, 2. \$etr. 2.1) jagt, Den jhenigen, die recht entrinnen (Durch) Die Tauffe bni Sottes toort) bno nut int juthum wandeln, verbeifjen fie frengeit, jo jie jelbs fnechte Des verderbents find.

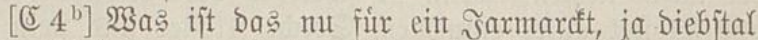
vnd raub? da man mix ben leif vnto blut Efrifti, fo mix geburt vmb jonjt mit zu teilen, raubt, vno vmb mein gelo bno gut gibt, eines gottlojent elenden menichen opffer bno wercf? Das mag Geifjen, mix mein narung rauben, bno

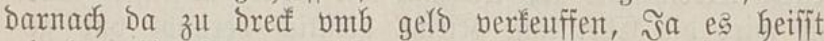
mix das gimelreich rauben, ond ba fiur, nody bmb mein geld, bas şellijuche feur verffenffen, Welchs ich Yeider zund, on geld, verbientet bno zu eigen hatte, burch meine junbe,

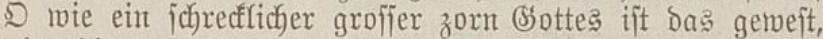
vber bie vndanfbarn welt, wie Sanct \$aulus getweifiagt, $\left.{ }^{2}\right)$ Darumb bas fie die marbeit mit Yieb ons band nicht an= nemen zux feligfeit, miro in S5ott freffige jrtbum fobicfen zum verbamnis ber vngleubigen, Wie gar billich nentet ex am andern ort, joldse zeit, gretwliche ond ferliche zeit, sa freilich, gremlich bno vber gremlich, Darinn joldyer
1) 2. Petr. 2, 19 .
2) 2. Thess. 2, 10.11.
2. Tim. 3,1 . 
Geubt gremel bber hanto gebabt, wno fait alle welt verfirret hat, wno noch gels vno ber welt gut ba fiur zu lohn ge= noment hat.

Whie fol man joldjen \$faffen vber feinem Alltar, int feinem Sriejterfichen ampt aniehen vno achten, anders, Dent einten (S) ttes bieb vno Sirchen reuber, Da zu einen vnerforeten verrether vno teuficher, ber vmb ber welt gut,

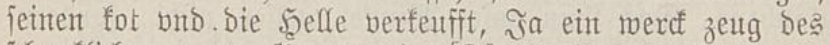
ichrectfichen zorns Şottes, Da [D] Durch ex frefftigen $\mathrm{j} x=$ thum fichicft Denen, jo jein mort nicht mit lieb ond bandf angenonmen haben, bas fie jelig wurben. ßno wie jor man jeine 2 senge, ba burch er zu joldjer Mefie gerwenbet ift, anders beuten, Denn das jein Webbifickoff Gabe vnter Die Cryriften gerwethet, einten offentlichen Ssottes dieb und Sirchen reuber, Der Den Grottes zorn und itraffe vber bie vndantffarn vno verechter folte ausrichten? Sho hat aljo ein Sottes bieb Den andern, ein Rirchen reuber Den an= Dern auggeidjift, bis fie bie Rirche da mit exfitflet bno alfes verwíitet Gaben, was Ssottes ift vno heifit, wie Dantel verfimsigt hat, Spie jolten Die Fapiiten fich bey Der najen nemen, went fie ichreiben bber firofter brechen vno SIlofter gutter einnemen, Soldhe flofiter find ftein bno holb, Die giter fint zeitlich) bing (roie tool ber Bapft, (Earbinal, Biffictgoff ond \$faffen joldbs autch am aller meiften treiben, ba zu auch vor hin, als bie biebe nno reuber be= jeilien haben, wie ich ein mal wil weiter anzeigen) 2(ber Gie wird bie Shriftliche Sirche geiftlich beraubt und ge= plintort, Sacrament ond Wort zeritóret, Soldys Yadjent fie noch ba zu, ond fol twol gethan heiffen, 2Aber Brott hat angefangen ji midberumb zu Yachen, Das mird bas beiffent, Denn ir lachen, 2 (men.

Sie hilfft aber mal nichts, bas fie icfretyen firche vno Seter, Denn rie gejagt, ber $\left[D^{b}\right]$ Menichen thut vno reben, auffer vond on Sottes wort, ficht vns inn fol= chent hoken jachen nichts an, wens gleid) ein (Engel bom himel were, Wseil wir wiffen, das nicht alfein bie \$ropheten,

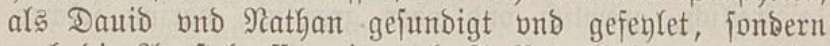
auch) bie 2(poitel offt, wie auch ङ. \$et. Šal. 2. gejuntigt vnt gefeylet hat, Sno bie heilige Rirche felbs teglich beten 


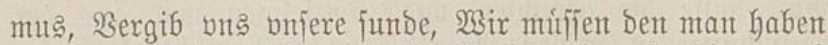
bon bem allein gejdyrieben ijt, (Er hat nie gejundigt, noch) vnredjt gerebet, $\mathfrak{W a s}$ ber jelbige thut ond rebet, das goren wix nach jeins $\mathfrak{B a t e r s}$ gebot, Mat. 17 [จ.5]. Da mit vrteilen

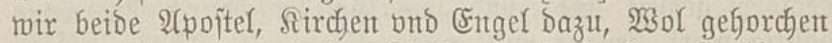

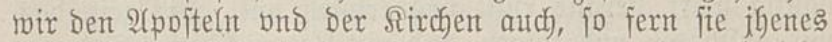
mannes marzeidsen mit bringen, Da ex zu jnen pridgt, Ego mitto vos, ite et prebicate Enangelion, $\mathfrak{B} n \mathrm{D}$ aber mal, Docete ens, que mandaut vobis, $\mathfrak{S}_{\mathrm{D}}$ fie das zeidgen nicht bringen, fo boren mir fie nicht weiter, benn ऽ. Faut. (Bal. 2. \$setrum Girete, Da Giffft fein jchreien furr, Wir tyun bem nicht anders.

Şilfft auds nidgt, ob jie furrgeben, Sie rauben oder ftelen bas Sacrament niemands, meil es joermant jut feiner Bfarr tool befomen mag, jonberlich einer gejtalt $2 c$.

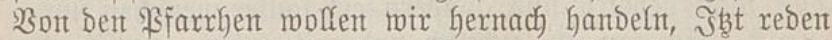

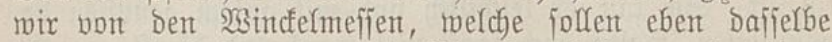
Sacrament Gaben, Das die \$fFarrben Gaben, ond teilens bod) niemanto mit, Denn es heifit ja nicht Sacrament Der Bfaffen, Son=[D ij] Dern Sacrament ber firchen, $\mathfrak{S}_{\text {nno eint }}$ ßfaff jol ein bienter ber firchen bno nicht jein eigen berr jein wiber Die Airchen, Na friegt bie firche ir Sacrament nicht jun ber Wincfelntefie, wie es bod jein jolt, So Dientet obser reichts ix audy Der Mindelmefjer nicht, wie ex zu thun jouldoig, Sonbern begelts allein, ond beraubt alfo bie Sirche jus Sacraments, bno gibt ix ba furr die

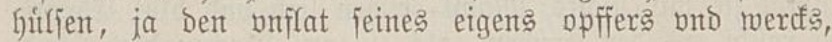
bmb geld ond gut.

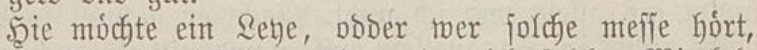
fragen, Was jol ich denn thun, ber idf foldjer Winder= meffen viel gebort, uno nod) boren mus? $\mathfrak{W a s}$ baben Denn gethan onjex vorfaren, Die joldye Mefie geftifftet bno biel Da zu gegeben haben? Untmort, Sntjer vorfaren muiffen mix Ssottes gericht befelgen, ber fan tool ettliche Gaben exhalten, wie ex die finder Sorah erfielt, Da Die

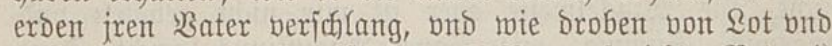
(Elias zeiten auch gejagt ijt, Denn S. Betrus ipricht 2. \$et. 2.1)

1) 2. Petr. 2, 9 . 
(5)ott twiffe die gerechten wno Sottjeligen ror aus Der veriuchunge zu erlójen, 2(rber bie vngeredgten bebalten zum gericht zैt peinigen, Weil wir Den im Bapitum mit folchen greweln ber $23 i n d e l$ mefien vnd viel andern veriudgt vno belabent gerwejt finto, ond ons (sott nu burch jein war= haffitig wort, heraus rufft wno erlófen wil, sits zeit, bas wir auffisiren vnto forgent, bno mit Rot aus biejer Soboma fliehen, Ssott gebe, es bleibe da hinden Sdymager, Endam

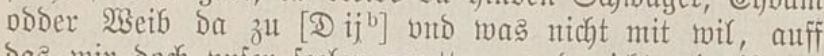
bas wir boch vnjer feelen erretten, wno nicjt mit jhenen verberben, Dent wir fonmen vits mu burch) SSottes toort, wie Sot Durty bie Engel, wol heraus machen.

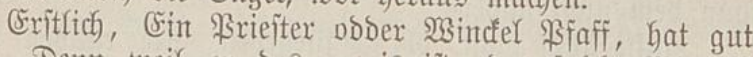
thun, Dent tweil ex bes getwis ift, Das folche rsindfel= meffen, went gleich) Egrijtus Yeib bnd blut ba mere, von Giott nicht geboten fint, fondern ein lauter menichen fund= Yin ift, So fan ex Yeichtlich vno mit gutem gewiffen ba von lafien, Şaitu Doch jonjt viel mercf bno bienjt, da but gemis bift, bas fie S5ott geboten hat, Die felbige thue vnto lafie bas ungeboten ond bngemis mercf faren, $\mathfrak{s e r}$ wil bich) bazu żwingen? weil Du weifiejt, Das (Sott nicht Darumb zurnet, fo du Daunu Yefiejt, Ja wer wil bich pober mich zwingen, bas wix miffien gleuben, es jer jnt ber

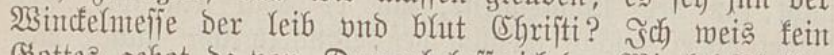
Sottes gebot Da von, Darumb Yaffe idy Dent 2 indfer \$faffent machen, was ex macht, Seine Mieffe giebt mix nichts, jo nimpt fie mix nichts, Macht er Den Yeib ond Glut Cryrifti, jo raubt exs ber Rirchen, als ein erbs Rirchent bieb, vno nimpt exs alfein wno ich nicht, Macht ex nichts, jo gehet michs nichts an, So taug iein opffern vno mitteiln auch nichts fiur midh, Silffit audf nidbt, das fie geiffern, $\mathfrak{B S i r}_{\text {genteffent }}$ Des reibs vno bruts Chrifti jun [Dii] Der खsindelmeffen geiftlich), Durch ben glauben, Soldy geiftlich genteffeu, wil ich beffer finden im himel, Da Ehriftus leib und blut fitht zur rechten (S) ttes, bas ift mir geboten, gemis vno feiret nicht, Die wincfelmefie aber ijt mix nicht geboten ond vngewis, Sumnta, wie Sanct 2luguftimus ipricht, Tente certum, bimitte incertum, Spiel du Des getwiffen, bno las das vngemifije faren. 
Sa, ich jage noch meiter, weil es vntgewis ift, of jint ber Wincfelmeffen, Der Yeib vnto blut (Ehrifti fet), vno ge= rislich ein Yauter menichen thand ift, io joltut ben Yeib vnd Yeben, nicht gleuben, Das Shriftus Yeib vnt blut da jey, Dent ber glaub fol feinter fachent gemis jein, vno einen getwiffen grumb haben, Darant mant nidgt ztweituelnt mus noch fol, Sch fitr meine perion fants nicht gewis Galten noch machen, Darumb wil ich meinen glauben nicht bran mogen, bis ich feke, das es bie \$apiften gemis

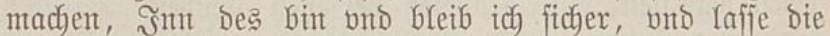
Wincfelmeffen faren, pampeln vno idyeben, wie fie pant= pelt vno fichebt, Dent Sott hat mir nichts geboten, fie zu Galten, Da bey zu jein, obser etroas da zut thun, rebent obber gebenten, Doch wil ich gern horen, wie fie es wollent getwis machen, Sie merben frenlich getroflet fomen mit

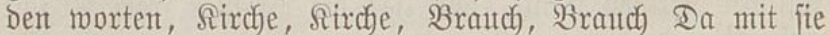

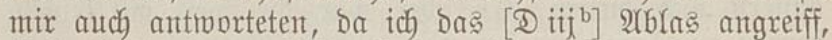
Sito fie body mu jelbs finten, bas weber firche noch Brantch das Arblas exhalten fan, jo wentig als andere mebr jrthum, vntex Dex Sirchen namten getrieben, Sant $\mathfrak{B e t u n}$ jagt aber, W̧ex jun ber Sirchen rebet, Der folle Şottes

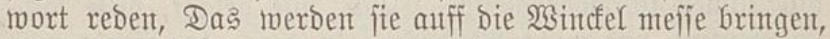
went ber Teuffel mu gen himel feret, Machent fie es nut nidjt getwis, jo jage mix, was ijt bent ber Exejem vnto

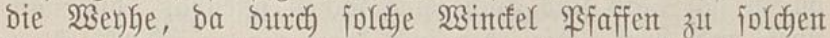
wincfelmefien gewenget werben? Teuffels brect mirds ex= funden werbent.

Bum andern, Ein Rebe obDer gemeiner SGrift, obser wer bie Wincfelmefije Goret, hat vber joldye vrjachen bie

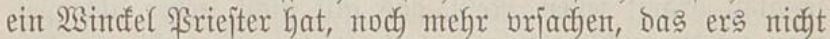

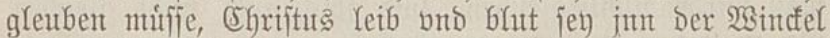

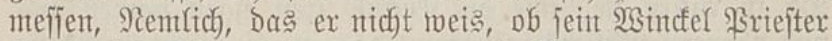
Eonjecrirt odoer (twie mans nemtet) Wandet, fants aud

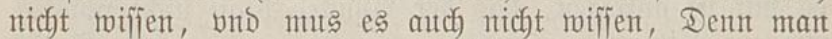
Yefit in bie wort nicht horen, melche Der \$riejter fol vber Das brod und wein prechen, So fan ex Dem ßrfaffen ins herbs nicht jefen, twas ba fur ein glaube jet), vnto muts aljo im jact feuffen, Ja weil es ein menichen thanto ift, fol ex nichts brauff bawen, twie SGriftus Matthei. 15. [v. 9] 
(pricft, Bergeblich) Dienen jie mir mit menichen Yeren. Bnto ob Der \$rieiter gleich befentet obder jagt, Er gleube ond habe die [D 4] roort der Wandlunge geiprochen, So mus bno thar jm doch niemanto glenben, Dent Grott hat ge=

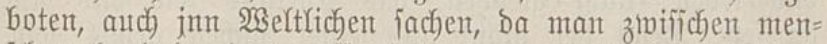
fchent hanbelt, bas auff eins mans munt nichts jol ge= urteilt werben, wie wir benn audh jagen zu Deubich, Ein man fein man, Wie viel wentger fan obser thar ein

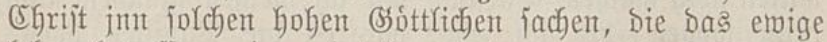
Yeben betreffen, einer einbelen perionen gleuben? Darumb mag ex wol von foldyer Meffen bleiben, Sober nus ex Dienjts halben Dabei) jein, jo (afje ex Den \$faffen machen,

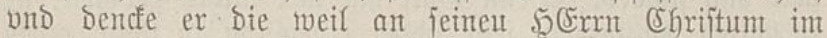
fimel vnd fpreche jeinen glauben pober \$falmen, gleich twie Saeman Suruts. 4. Regum. 5. ${ }^{1}$ ) bei feinem Sónige jun Der Sirchen ftund, und Yies die \$riefter jrem 2Obgott Dpffern wno bienen, Er aber mar bie weil mit feinem Gerben zu seruifalem bey bem rechten (sott.

(E) gilt aud nicht, of mant hie wolt fintwentoen, Ein Wincfelpriefter fey eine offentliche perion, offentlich geweenhet $2 c$, Der man gleuben jolle, wie man einem Siotario odser Dffentlicken ichreiber glenbt, Denn, wie gejagt, bieje fache ift (Seiftlich vnd nicht $23 e$ eltlich), 3u Dem, fo gleubt man aucich 23 eltlich) feitrem Notario allein, two er nicht zeugen Da zu hat, So find audb) feine jachent offentbar, Die man, figet bno Gort, Şie aber find feine zengen $\left[D 4^{\text {b }}\right.$ ] Son= Dern eine einbele perion, welche im tuncfeln muncfelt vno vnter sem huitlin ipielet, wno ipricht barnady, fie habe es fo und io gemacht, bem folle man gleuben vno vitjer

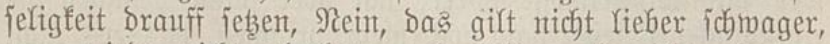
mant wiros nicht gleuben, wnto jols and hicht gleutben, Da zu ruffen fie, (mie ber ภ̂ufuf) jren eigen namen aus, vnd nentens Mififam pritatam, Das ift, eins einbeht Mrefie, Da mit fire anzeigen, das ber $\mathfrak{B i n c f e r}_{3}$ faff nicht publica, wie ein Notarits, Sondern, pritata periona iet), So es bod) bie alten laben genentet, Eommunionem, eine ge= meine Mefie, oa viel jum gemeine zu fomen, vno nicht ein

1) 2. Kön. 5, 17. 18. 
einbeler afleine das Sacrament nimpt, ond bie andern lefit lebig ba bon gehen.

Bnd mens Ssott gleich nidbt gebotent hette, Das mix eines einbslen mants toort bns wercf nidgt jolten gleuben, So ztounge ons Doch die exfarung bnt not jelbs bazu,

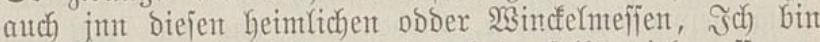
zul Rom gemejt (nicht lange) Gab da jelbs viel melje ge= harten, ons auch jeben biel mefje Galtent, bas mix gratwet ment ich Dran bencfe, Da Goret ich onter andern guten groben grumpen, bber tiffiche, Surtijanten Iachen bno rbit= men, wie ettliche meffe Gielten, bno ober bem brot bno wein iprechen, Dieje mort, \$anis es, panis manebis, Binum es, vinum mantebis, bno arjo auff gebaben, Nu ich twar ein junger [ङ] ons redgt exniter fromer Mcind), Dent jorche wout webe thetten, $\mathfrak{W a s}$ jolt idy bod, Dencfen? $\mathfrak{W a}$ fonbe mix anders einfalfen, Dent jolche gebanden? Rebet man hie zu Rom frey, offentlich vber tiffch alfo, Wie? ment fie alzumal, beide Bapit, Cardinal, fantwt ben Cur= tijanten aljo meffe bielten? wie fein twere idf betrogen, ber ich bon jhnen io viel Meffe gehort hette, ßno zwar efelt mir jeer da neben, Das fie jo fidfer ond fein rips raps funoten Sefje Galten, als trieben fie ein gaudfel fpiel, Denn ehe ich zum Euangelio fam, Gatte mein neben \$faff jeine Mefije aus geridgt, vno jdyrien zu mix, \$afia, \$afia, jmex toeg, fom Da von $2 c .{ }^{1}$ )

SAt twifjen toix, Das ber Eurtifanten tugent ond glau=

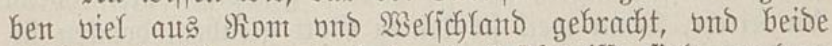
Stifft ons Bfarren tool bamit bejchmeifit fint morden, Dent wir haben viel nuchlojer Ihumbherwn, Bicarien und artariften gejeben, bie fait eines toildens, wititent Yebents, mit ichroelgen bnd hureven tag vnd nacht zu bradjten, ond Dentod des morgens Mefie gebalten haben,

1) Cochläus bemerkt in seiner Gegenschrift "Von der heyligen Mess “ Bl. A iij hierzu: „Nu ist es wol möglich, das unter so viel Tausenden aus allen landen, etliche solch verzweyfelte buben befunden werden. Es ist aber nicht recht, das Luther dadurch die fromen andechtigen Münch vnd Priester wil vervnglimpffen, vnd bey dem volck verdechtig machen, auff solch Zwinglisch vnd Pickardische meynung." 


\section{4}

Wiser wil hie burge da fitr fein, vnto vns getwis machen, bas fie nidft aud Gaben auff jolch Romifiche ond Cur= tijanifiche meije Meffe gebalten, bno bus lafien eiter brob vnd wein anbeten? Jch wil idfweigen, was fie gegleubt, gemeint und gemadft, Went fie gleich bie mort ber $\mathfrak{B a n d}=$

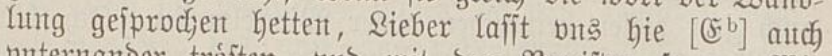
pnternander tróften, vno mit den \$apijten fagen, $\mathfrak{S i r}$ jollen jolche Mefile, jun ber meimung ond glauben ber beiligen Sirchen hóren tno fehen, Ja mein Freund, bebalt bu folchen glauben ond meinung, Mir nicht, ich wil einen glauben vno meinung Gaben, bie keifit aljo, sch bin butrd jolche exempel, gebrant, getwibigt uno gewarnet, bas ich nimer mefyr wil bey joldger 2 sincfelmeffen jein, oder mus ich ba bey jeit, io wil ich boch jr nichts achten noch

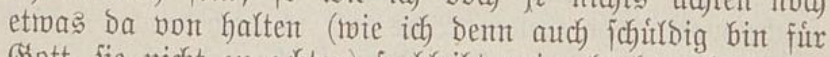
(5)ott, fie nicht zu adgtent) fo bleibt mein glaube vnbetrogent, Des bin ich gerwis.

Stem, Man jagt, Das ibzt ettliche \$apiften 3winglijech fitto 1) bno balten auch, bas im Sacrament ichlecht brod vnd wein fet, ba zu audb rbumen, Sie wollen binfurt Deite Yieber Meffe halten, weil bie jorge ond fahr mit Dem reibe bno blut Ogrifti tweg ift, Da zut fint ibst Der Epicuri, Sceptici, ono Suciani faft viel, bie vmb ber zinje willen mefie Galten, vno dem Sapit vits Biffichouen beucheln, ba zu bie Sutheriffichen fait ichelten, ichrweren auch, fie rooffen itch) zu reiffen Yafjen, ehe fie aubers gleuben worten, Dent Die Sirche, Denn weil fie feinen Jistt glenben, Dendfen fie, jolcher eio thu juen nicht ichaben, Spotten gleich) wol ba neben, ber ganben (Shriftlichen religion, wno halten ons fur groffe ntarren, bie twir jolche [eij] felbame ond mimberficke $2 \mathfrak{A}=$ tifel gleuben, 2no find buter juen, auch Bifichoue vno hochgelerten jut breien jprachen geubt, $23 a \mathfrak{s}$ hat ber arm menich Thomas Munber gethan, da er im lanbe vmbher= itreich bno jeinex ontugent eit neit fucht? Ex Gats befanto

1) Sicherlich ein Hinweis auf Georg Witzel, über welchen Melanchthon am 22. Oct. 1533 schrieb: "Noti sunt mihi jpsius

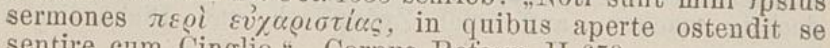
sentire cum Cinglio." Corpus Reform. II, 679. 


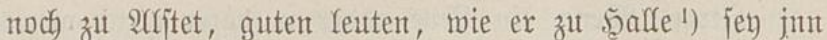
einem Rlofter Caplan getweit, vno habe bes morgens bie

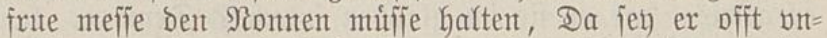
willig gemeit, vnto habe bie wort ber Wantoelung auffent gelaffen, vno eitel brod vno wein behalten, $2 \mathfrak{s o l t}$ ba zu noch gar twol gethan haben, Sint rhimet fich zit exfitet

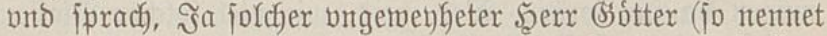
er bie Dblaten) habe idf twol bey ztweylundert gefreffent.

Was Gabent wol antoer Schleidfer vnd itreidjer vmb= Ger gethan, bie Gin wno wiober zur Eriten mefie bettelten, buto waren boch vitgetwebhete, boje butben, ber ettlicke auth mefie Gielten, bno gatten teller im ermel, went fie Dent Selch wiboer eintunten, ftolen fie bie patena, vno legtent Den teller an bie itet, $\mathfrak{S}_{\mathfrak{3}}$ Gatte ber arm menjch gemogt,

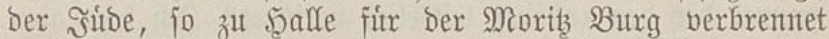
ward? ${ }^{2}$ ) Was wird joldyex gremel melyr gejcheben jeit jum alfen Yantoen, ba wir nichts bon twiffent? Dent es wol zu vermuten ift, das twir bas menigeft erfaren haben, Bno jolche exemtpel gutugant vns jolten toarten, ond alfe rincfelmeffe $\left[\& i^{b}\right]$ versechtig halten, ja gar nichts achten, Bns ift aber recjt geidjeben, da wir jits Teuffels namen wolten flutger feit Dent Sott, vnto die Meffe beffer ord = nen, bent ex fie georbent hatte, wno an S'ottes ftat, vnjer eigen buncfer vno meinung jeben, bas twir jum joldben abgrunt alfer gremel fallen muften, vno ein blinder ben andern nach fich zithen.

1) Luther irrt hier wohl und meint Münzers Anfenthalt in Kloster Beutitz bei Weissenfels, wo er 1519 Beichtvater der Bernhardinerinnen war, vgl. Erbkam, Gesch. der protest. Sekten im Zeitalter der Reformation. Hamburg und Gotha 1848 S. 492.

$\left.{ }^{2}\right)$ Luther meint die Verurteilung des getauften Juden Johann Pfefferkorn, der am 3. Sept. 1514 vor der Moritzburg an langsamem Feuer verbrannt wurde, angeblich weil er ca. 20 Jahre lang ,priesterlich Amt gepflogen und doch nicht geweihet noch ordinirt gewesen", ferner weil er drei geweihte Hostien gestohlen und dieselben teils gemartert und gestochen, teils an die Juden verkauft hatte u. drgl. m. Vgl. Dreyhaupt, Beschreibung des Saal-Creyses Bd. II Halle 1750 S. 513. 


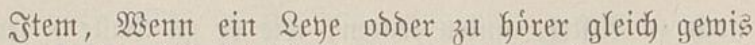
mere, das jein Winder \$ffaffe die mort ipreche, wie meis ex gewis, bas er fie im glauben ipreche? Dent es fan

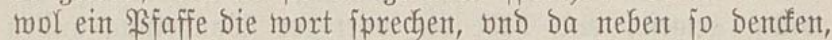

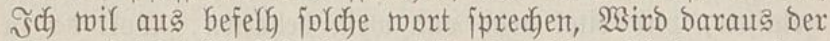

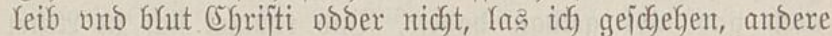
mitgen ba fúx jorgen, ßex meis, twie viel joldyer \$faffen geheit bno noch finto? gleich, wie anch ein mal ein gutex gejell fragt, obs nidyt gnug were einem Ebriften, twent ex gleubte und gonnete crorijto fajt wor, bas ex (siott jer), ex were es obDer nicht, Urfo diejer Bfaffe leijt es mol

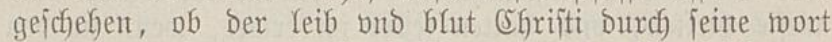
merben, on das ex joldys fteiff zu gleuben wil unbejdweret

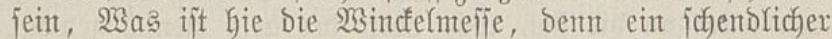

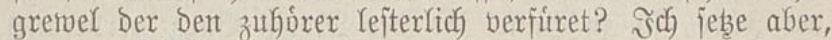

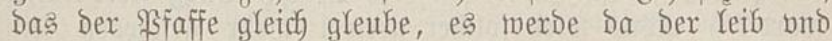
blut, Noch fants ber Sebe nidht wifjen vno mus ztweiueln und jorgen, ex bete [ङiii] eitel brod wno wein an, jck rede ibst von Dem Bepftifichem glauben, bas ift, bon Dem glauben, Da mit fie gleuben, (5s jet) Dex Yeib und blut Sfrifti im Sacrament, weldyen glauben die Siottlofen vnto farliche shriften ond alle Seuffer aud baben, ond ift nichts, benn ein menjoblidjer gebanden bno mabn, ${ }^{1}$ ) Denn Dent

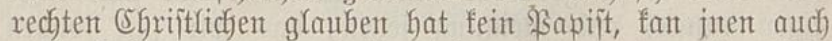
nidgt baben, Sintemal fite nidft gleuben, bas fie allein

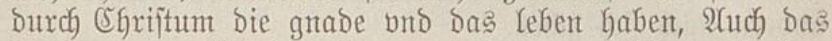
Sacrament nicht brauchent jut oboer zu joldsem glauben, jonbern als ein opffer bnd mercf, bas fie audf andern

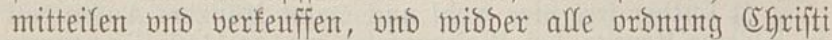
da mit vmbgeben.

Denn mex Den rechten Ehriftlidgen glaubent hat, bex fan feine Winfelmefie Goren, viel weniger jelbs Galten, Denn ex fans nicht Yeiben, Das die Mefije jen ein opffer bnto gut roercf, ba mit auch ein (Sottlojer fan beibe fich) jelbs bnt andere, Gsott veriunen bno gnabe exwerben, Sondern meil ex meis, das jun joldger Meffe der \$faff

1) Diese und ähnliche Stellen brachten Luther wohl besonders in den. Verdacht, dass er es jetzt mit den Sakramentierern halte. 
feinten rechtent glauben hat noch haben fan, fo ift er nicht fajulbig won foldyer Melie zu halten, bas ba nidyt eitel Grod und rein jey wno bleibe, wie ich broben gejagt labe, Denn wo nidjt glaube ift, ba ijt Der Keilige geift vnto fein wercf audh nicht, So wiro bon foldher meffen, Dent Ehriften obser ber $\left[\digamma_{i i j}{ }^{b}\right]$ Sirchent nichts gereicht, noch mit geteilet, ba mit man Doch jagen fimste, ob ber Yeif vnd blut Egrijti, nicht da were umb des \$faffens willen, fo ift er bod ba umb ber willen bie das Sacrament empfaben im red)= ten glauben.

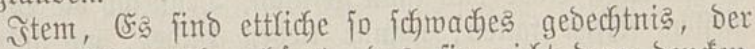
ich tool gejefen ond gehoret, bas fie nicht bran bentenen, ment fie die wort iprechen, ond offt nicht wifien, of fie bie wort geiprodjen Gaben obser nicht, thuren jie Dods nicht eimmal fprechen, Şie war antgit ond not, Shie lyatten bie Theologen zu flicfent vnt zu Yappen, ßer virtutem in= tentionis primte, Snot trofiten fich alio, Ess were gumg, bas ein \$riefter, da er anfahen toolt mefie zu halten, einen furiab bnts wilfen gebabt hette, die wort zu ipredjen vnd zu $\mathfrak{B a n b l e n , ~ D a r u m b ~ o b ~ e r s ~ h e r n a c h ~ v e r g e l i e ~ o b s e r ~}$ vilfeicht nicht iprecken mitroe, jo were es boch jein mifle

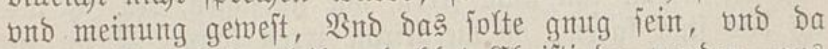
mit gleich rool ber Yeib wno blut Chrifti ba merben, aus

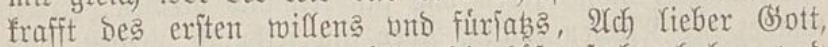
wie mancherley Gebelff mufijen bie bófen jacken haben, bno geboren jmex Dar fieben lúgen zu einer Yitgen, Das fie ber warbeit gleich) icheine, $\mathfrak{W a}$ s hilffits aber viel flicfen bno pleben am pelbs, ba haut vno har nicht gut ijt?

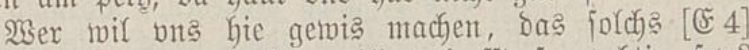
recht gejagt, und bes eriten willens fraffi, io medjtig, jet)? too ift hie Siottes wort obser grumb ber Sdyrifft, bie bas getwiffen ftercfe ond erbalte? Mienjichen rebe find es, Bno auff menichen rebe ift werboten vnjern glauben zu jeben,

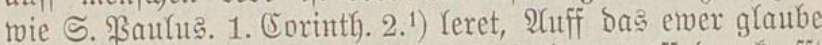
nicht auff menjichen weisheit fteke, jondern auff ber frafft

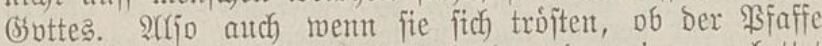
nicht Wanblet, ond fie eitel brod ond wein angebettet

1) 1. Cor. 2,5 . 
Getten, bas jchade jrem glauben nicht, Ia lieber, bas fageitu, Wer bes fiegel vnd brielte hette, dos war mere, Warumb thut man nicht anders ba zu, ba mit wir jolcjer vurichtiger, ferlicher, jrriger, wnjicferex, fcheblicher Yere ond wercf vberbaben weren? fan man boch die $\mathfrak{B i n d f e l}$ meffen wol lafien, als bie bns nicht geboten, fonbern ein Yauter, eigen, extichtet, jelbs ermelet, menichen lere ond fúnolin ift, Dent menichen lere pflegen zu leb̧t folche fruchte zu= bringen, das mant nicht tois, wo getwiffen, glaube obser

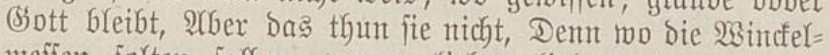
meffen folten falfen, wante rieben fintor, wo jolt bas Bapitumb fo bals auff einem bauffen Yiegen, mit Stifften vno 2rltarn, vnd allem bas fie find vnd haben, gleidy wie Soboma onter gieng mit allem das fie twaren ond hatten.

Sie baben einten pruch exgriffen, Darauff jx thum

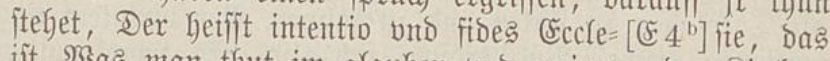
ift, Was man thut im glauben vno meinung ber Rirchen, bas ift recht, Darumb baltent fie es ba furr, fie formt fampt jrem Sapit nicht jrren, Denn mas fie thun, bas beiffen fie im glauben vno meinung Der Sirchen getban,

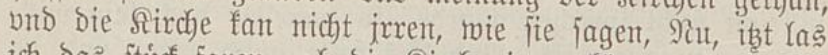
ich bas ftucf faren, ob Die Rirche jrren fömne, Denn fie vntericheiben nidyt, jrrent bno jun juthumb bleiben, Jrrent fchabet ber Sirchen nichts, 206er jun jrtbumb Gleiben, Das ift vumutglich, wie Egriftus ipricht, bas auch bie aulfer= welten jint jrthumb gefirret witroen, two es miglich were, Denn bie Sirche befentet in ßater vnjer, Daß fie junbige vito jrre, aber es wird ir affes vergeben. Darumb nicht zu batwen ift auff einiges thut obber werct, viel wentiger auff jre meinutg obder glauben, (mo fie auffer vnd ont Sottes mort etras meintet obser gleubt) Dent fie bleibt eine vnterthenige funberin fiur Sott, bis an Den Jungiten tag, ond ift allein beilig jun ogrijto jrem Seeifande, burch gnade vno vergebunge ber jumben, Solds) itud fage ich), lafje ich ibt faren, ba von idh etruas geritret an andern orten, wns hernach mals weiter reben wil, of Ssott wil.

2rber in biejem ipruch, wil ich fie verjuchen, ob ich Den Teuffel malen fóme bno jeine farbe anzeigen, SSlaube obder meinunge Der Sirchen ift zweyer(et), Die eine Keifft 
vnd |₹] ijt audf bie rechte marbaffitige meinung Der Sirchen, bie jelbige ift offenbar und iderman befanto, unto itehet vno ift gegrimbet jun ber Schrifft, als, Das die Tauffe wafiche bie funde ab, bas meintet vnt hellt bie Sirche fíx getwis, vnd gifbt auch aljo bie Tauffe, Arljo hellt vno meinet fie aucf), das im brod ond mein der Yeif ond blut Efrifti gereicht twerbe, fo man nach Der einjebung wo befelf Ehrifti da mit vmbgehet, Summa, Dieje meinunge Der Sirchen, fan nicht juren, Denn fie bellt fich ntach Dem wort Sonttes, vno ber meinung Efrifti jelbs im limel, Sach joldyer weife ond veritand ijts recht gerest, Was man thut jun ber meinung ber Rirchen, bas ijt redft ge= than, Denn es ift jo viel gejagt, $\mathfrak{x a s}$ man nach Dem wort Ssottes vno Dex meinung Cegrifti thut, Das ift recht getfan, Şie mit haben bie alten Seter vnto \&erer, getroftet

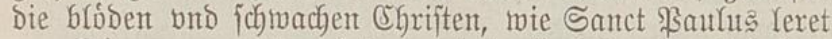
zut Roment ant vierzeheden vno funffzebeden Capitel, das man bie idfrwachgleubigen folle antemen, ont wir itarcfen

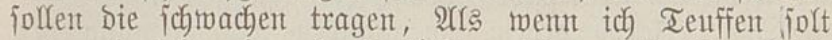

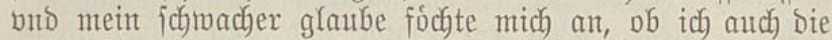
rechte Tauffe gebe, barin mein Teuffing bon funden Yos vnd rein ruitroe, weil es jo ein gros bing ift butb bie Tauffe, vnto ich ein geringer armer junbiger menjob, Şie

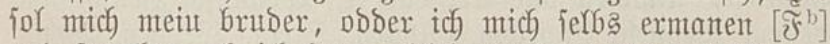
vno iprectyen, ob ich benn gleich vntwirdig bint vno fachwer= (idc) gleube, bas burch mein Teuffen joldhe groffe bing ge= ichelyen, So reis ich boch getwis, das bie firche foldha alles von ber Tauffe Gelt wno meinet, Darumb wil ich frólich Teuffen jutn jolcher meimung ber firchen.

Bno ijt, furbs ba von zu reoen, jolche meinung ber firchent, fajt fo viel, als das exemtpel ber firchen, Da mit ein ichwacher Egrift gejtercfet vnto gebefiert miro, Dent gleich twie ein boje exempel ben glauben ichmechet wnto ergert, aljo midoerumb bamet vno ftercfet ein gut erentpel, 2rls wenn viel Ehriften auff ein mal fich lieffen omb Cyrijtus wilfen martern, for tor ba felbs einer mitig werben, auch mit zu Yeiben, ber jonjt villeicht, allein zu blode were vno Ehriftum verlengntete, 2Urjo fan einter aud die Tauffe vno Sacrament vno alferley trojt empfahen, 
(ber boch idfwach) im glauben ift) went ex fithet, Goret obser gebenteft, twie fejt wnib getwis bie andern joldfes gleuben vno thut, vnd bie ganbुe Sirche nicht barant zweituelt nod) wancfet. (5) ijt aber bie wol zut mercfen, (mie gejagt) das joldhe meinung ber firchen jol offenbar fein, vno wol berwijt Dem fdyachen, ber fich bar nach richten wno ftercfen wil, Denn es jol ein exempel jein bes glaubens, Dex nicht in herben heimlich berborgen lige, jondern, eufjerlich erzeigt vno bereijet merte, Das rebe ich vmb ber ander meinung [₹ij] rillen, bie folget, ba mit wir nicht jun ber jelbent tundel bno finjternis irre gebent.

Die ander meinunge Der Sirchen ift, bie man auffer Dex eriten meinung jelfs machet und mit foldfem namen nentet obser heifint, Das der firchen meinung fet), vnd ifts boch nicht, Sondern find eitel menichen bindfel, auffer Der Sdyrifft exfunden, mit ber firchen namen gejdymitcft,

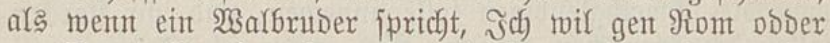
zu Sanct Jacob geben, in glauben vnt meinung ber firchen. Stem, went ber Saapft vno Biffchoube 21blas geben vno jagen, das fie es thun jun ber firchen meimung, Went fie bie jeelen aus Dem Jegfeur lofen, mit Meffen, Bigilien, 2Almojen bus jeel bad 2 , whent fie seiligthum meijen, Sצent fie Eapellen, Slocten, Stein, Wethen, Whent fie Matuch vnto Ronnen wethen obder merden, Went fie

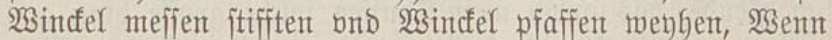
fie Wurb, Wein, Salb, Spect, Flladen, Balmen, vno Dex gleichen, wengen, Das mu joldhe ftucfe (Der vnzelich) viel ift) aflezumal im Bappitumb 2(rtifel bes glaubens roorben find, ift aus biejem ipruch fomen, bas man hat fomten jagen, sch thu es im glauben vno meinung ber Sirchen, WSer jolche roort hat fónten jagen obder Dentfen, Der hat troffen wno nidgt juren fonmen, Denn es ift getwis, Das bie Sirche nicht jrren fan, Şie ijt gar fein [₹ ij ${ }^{b}$ not ge= mejt, zu forjacen ond fragen, was bie Rirche jun foldyen itucfen meine obder nicht, fondern ift gmug, noch heutiges

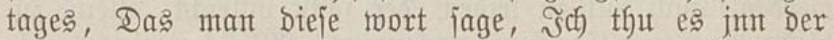
Sirchen meinung, als bent ift es alfes recht vni (shriftlich) wol gethan, vni fan nicht feylen noch jrrent. 
Sit bas nicht fein uno wol gebeutet vno veritandent Die Meinung Der Rirchen? Die rechte meinung Der Sirchent iit ein erempel, ja grunto ond pieiler ber warbeit im toort Sottes, Darnach fich. ein iglicher Elyritt, fonberlich bie idwacken uno bloben richten wno fterfen follen, Dieje aber ift ein eigen freber menichen bintefel, aufijer bnts on Siottes mort, nach welchem bie Sirche fich richten vnto halten jor, Das mag heiffen, Sus Mineruam ${ }^{1}$ ), hie leret (Ev) Das Sun, und Sachel Den Iopffer, Sirchen Meimung ift, was fie vns, aus Sisttes mort furbelt bno Yeret, bem

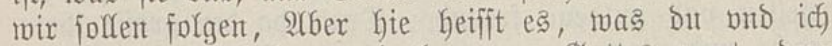
Der Airchen furthalten butb Yeren on \&sottes mort, Dem jolle fie forgen, wno gehet aljo baher, ber roagen fur ben roffen, wie folte joldye fuffre jrren, odoer bes weges gen fimel feulen? Sibeftu fidier die farbe des Teuffels und jeine Mummerey ber vnter ber Sirchen namen vno mei= mung, alfe feine grewel hat eingefirt ond geitercft, als ein ausbuntoiger Sophijt und [§iij] meifter, inn allex

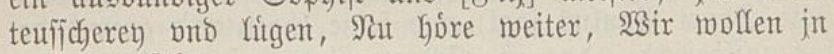
noch bas jeben.

Da fie jolchen ipruch), Der mafjen gebeutet hatten, futben fie Das redfte loch) zur Sirchen hinaus, vnd fament auff Den fichern freven plab, Den fie gern hatten. (Eritfich, Das fie nicht burfften forgent; wie fie glenbten ont from wirben, bno nach Siottes wort Yebten wno thetten, fur jre perjonen, Sondern, fóndten jagen, $\mathfrak{W a}$ i itg not, Das ich gleube, vito nach) Sśttes roort thute obder from werbe? Site boch gleid) gnug ono recht, wenn ichs jun ber

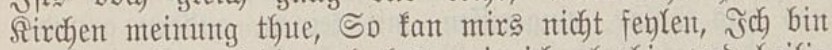
ber jorge fret), Yedig und Yos, twie ich) gleubig vno heilig merbe, Man mus boch wol alfes bon mix futr recht bno

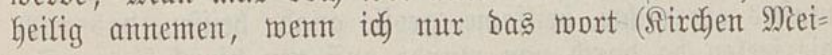

1) Sus Minervam (docet). Cicero de orat. 2,57, 233. famil. $9,18,3$. acad. $1,5,18$. Man braucht das Wort, ubi quis id docet alterum, cujus ipse inscius est " (Festus). Luther citiert den Spruch sehr häufig: z. B. de Wette III, 570. IV.112. 629. V, 316. 598. VI, 352. Vgl. O. Schmidt, Luther's Bekanntschaft mit den alten Klassikern. Leipzig 1883 S. 15. Sicheurls Bri sfbuch I, 53 
mung) furgebe. 3um antern, (bas nod) exger iit) Mach= tent fie nicht aflein bie mit fich jelbes fren ono los, vom notigen gehorjam bes Ssottlickent worts, fitr jre perjonen, Sondern, namen auch baraus joldye macht bno recht, alfe anber Efriften einzutreiben vno zu zroingen, das alles, mas fie nux exbencfen, jagen, Yeren bnto gebieten molten, mujte recfit vno fir 2rrtifel Des glaubens von Der Rirchen gehalten merben, Denn ber Rirchen titel vno jrex meinung, erichrecfte joer man, weil niemand gern, twisber ber firchen meinung thun rolte, Şie murben mix gute [尺 iij $^{\mathrm{b}}$ ] gefeflen vni guldone freunde, Denn da ber grofje tham brach, bno Siottes wort bie rechte meinung Der firchen meg war, wie jolte da nicht einreiffen eitel findflut alferYet) menichen lere, das ijt, litgen, juthumb, A(bgótteret) unto gremel.

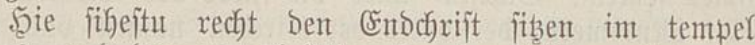
Gottes, vno Den gremel iteben jun ber heifigen itet, Der Durch bircfung Des Teuffels das wort (5)ottes veritoret (wie Sanct \$aulus jagt) bno jeine litgen bno gremel ba fiur auffgericht, (bas iit) fich) an (sottes itat gejebst, vno zum (s)ott gemacht lyat, wnd fich) exzeigt, als fet) ex (siott, WSas gibt dieje faliche exlogene, lejterliche Meinung Der firchen, antors bent bieje frenheit, bas fie mitgen, Dnt Sottes wort, ficher Yebent, wie fie wollen, bno ba firr Yeren bno gebieten jun ber firchen, was jnen treumet obser gut binctt? Dirffen nicht mefrr thun, Dent ber firchen namen furen, ond fagen, $\mathfrak{s i r}_{\text {thuts }}$ alfes jun ber firchen mei=

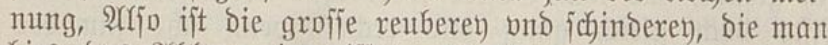
hies bas 21blas, eingeriffen, mit feinem andern grunde, Denn das es bie Geifigen ßeter verfaufften, vno die Yeute feuffen muiten, jun meinung ber firchen, Mit Dem namen muftes ein rechte, heilfame, grofije gnabe heifien, bas aud bie feelen ba burch von mutbe auff gen bimel fúren, $S_{0}$ boch bie firche, jun [₹4] bes, von jolcher meinung nichts muite, jonbern gleubte ond bachte, Durch fein wercf, es mere gethan, obder von andern gefaufft, (mie bas Yiebe 2(bYas war) fondern Durch) Shejum Ehrift, on berbienjt, viel mehr on geld, felig zu merben, Soldb ongeidnunge= ner, grewlicher, groffer beturg vnzelicjer jeelen, neben 
Dem vberichmenglichem raub uno biebital ber gitter, ligt Den Sapijten auff Der jeelen, Sno weil jie joldges wiffent, vno Doch fich nidft Demittigen noch) biffien, zeuget bas einige ftucf wol, was fie firt freutlin find, bie zut joldsem idfaben ber Efgriftentbeit, nod) Yachen vno frólich find, 2(ber ber (Enbechrijt mus (Endechrijtif(f) jidf) Galtent.

Stem, int joldfer Meinutg ftno auff fomten ond mit

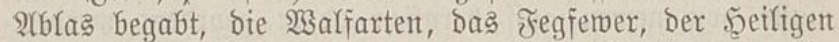

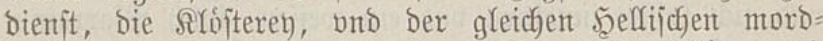
gruben on zal, ba Durch bie jeelen jemerlich verfitret vno Der welt gut gremlich beridjlungen ift, ß̧ber ber feinem thun fie buffe, Sondern, morden noch bazu, bie jo jnen

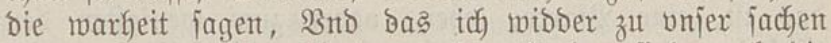
fome, Sntt foldber Meinung ber firchen fint aud bie Wintfel meffen auff fomen, gebalten, vmb geld verfauffit vno mit geteilet, als menidjen wercf uno opffer, 2tber wie jollen fie an ihentem tage beiteben, went $\left[₹ 4^{\mathrm{b}}\right]$ bie heilige Sirche fich-offenbarlich wirb Goren Yaffen, Das fie von jolder Meinutg nie nidgts gemuit habe, fondern ien eine Yeiterliche Yiggen des (Endodrifts, Durch wirchung bes Teuffels, frefftig morben, zur verfiumtg vno ftraffe der vntgleubigen vntbanfbarn melt, Denn, Esott lob, folche ritgen bebt bereit ant, offenbar zu merben aud bie auff erben bey ben rechten Cobriften, zum vorbrab bes Juntg= ften geridyts, ba fie gants auffgebecft vnto verbampt for werben, fitr allen augen, beibe ber Keiligen vno ver= Dampten.

Sie mixo mant mix furbalten, vno jagen, Mit ber weije wiritu uns auch feinen \$rebiger, Bfarber nodf Bfarrben Lafjent bleiben, und das Sacrament, jo bis Ger vnter bem Bapit gebrautcht, gar auff heben, vno eitel brod ond wein draus machen, Dent es ijt fein Bfaffe anders von Den Biffidouen getwenget on zu ben 2 sincfel mefien, bas ijt offentlich am tage, 5̧aben wix bent feine rechte \$faffe nodb Sacrament gebabt, jo ift feine Chriften= heit oboer firche blieben, Das ijt flar miboer Den 2 (rtifel,

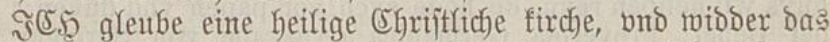

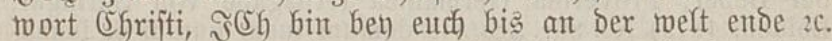
Darauff antworte ich) alio. Eritlich), bie firche odoer 
(5)riftentheit ift blieben vno mus bleiben, Das ift eins vno ift gemislich war. Bum andern, ift bas aud war, Das vnter Dem Bap[\$] ftum, nie lein \$ffaff zum \$farber

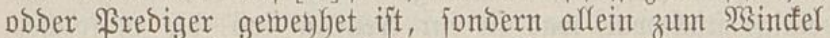
Sfaffen, Das fan niemand Yeutfen, Denn welcher folt ein

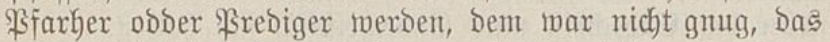
ex gewenhet uns Den Erejem empfangen hatte, Sondern, mujte von nemen auff beruffen obser geordent merben,

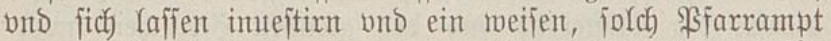
zu empfahen vno an zu nemen, odber muite es zunor fúr jeiner Weybe, als einen titel haben, Dent fie aud feinen Wincfel $\mathfrak{B f a f f e n}$ wenhen wolten, ex hette bent einen titel, das ift, eine Bfarre, Yeben, pober zum menigiten ben tifich bet einem edelman obser burger, die felbigen heufer heilig vno rein zu halten wiober bie feuldyeit, zucht vno ebre, wie Das fprich mort jagt, WSiltu rein beharten bein hauts, So laffe \$faffen vnts Miunche braus.1)

Sie rolfen roir mu vntericheiden vno fejen ben tempel Sottes, Darinn Der Endechrift jikt, vnto bie heilige ftete, ba ber gremel intent itehet, Das ift gemis (mie ibst gejagt) bas ber Biffchoff feinen \$farker noch \$rebiger

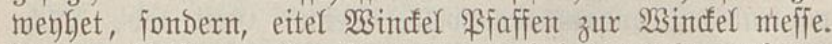
ja es bleibt jum eben jo hart, itach ber weybe verboten als ba vor, bas ex fich offentlichs prebigents jun ber Sirchen vnd Pfarrampts nicht thar vntermindent, on fon=

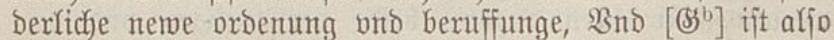
bie Senhe obser Erejem gar weit geicheiben bom orbinim obser beruff zu bem gemeinen Egriftlichen ampt bes pre= bigents unto \$farrampts, wie wol fie bas gebalten haben, das fie feinen vngemenheten zum Pfarber obder Prediger beruffen, fontbern allein aus Dem getwengeten bauffen etliche haben gentomen; siu joldc jr thun vno brauch, Das

1) Dieses Sprichwort lautet bei Tunnicius (Hoffmann v. Fallersleben, Tunnicius. Berlin 1870) No. 1275: „De syn huys wil hebben reyn, de hode sych vor papen vnd duuen;" bei Bebel, Proverbia Germanica (Ausgabe von Suringar, Leiden, 1879) No. 86: „Si vis domum tuam puram et immaculatam habere, caveas a columbis et sacerdotibus." 
fie on \$farme, Bfaffen menken, ynd boch on bie weylhe

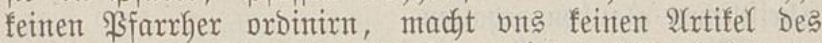
glaubens, bas drumb aljo jein muffje, Wsir haben ibst

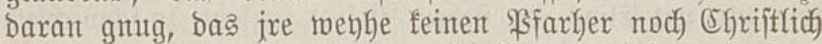
ampt vnter bie gemeine Der Chriften ordinint, jondernt

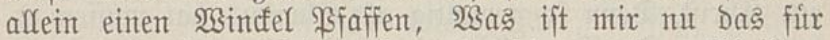
eine wenhe obder \$riefterthum, da bie gemeinen Ehriften, meder Tauffe, Sacrament, troit, 2Abjolutio, Frebigt, obser einiger(ey feelforg noch ampt von haben? Wem merben fie gemenhet vno georoinirt? Dex Rirchen? Ia wol, Sie merben inen felber bno affein jrem baudbe gewethet, auff bą fie ber gremel fein mutgen jum ber şeifigent ftete, Die Sirche exferets nimer mehr, of fie gemenget, obder wie fie gemenget merben, Denn fie friegt nidfts ba bon, on einen lefterfichen betrieger, ber jr mil jeine Meefie vno mexct verfentfen zux jeligfeit, Des mag jie aber nicht, vno jol fein nicht mitgen.

Die felfige Geilige Sirche iit nu bie heilige itete Des gremela, Dent ba hat (sott mit [Si ij] macht vito munber erhalten, das bennoch onter dem Bapit blieben ijt, Erit= lich bie heilige Tauffe, Darnach) auff ber (Eanbel Der tert Des beiligen Euangelij jun eines iglichen lanbes iprache, 3um britten, bie heilige vergebunt ber fundent vnt $\mathfrak{A b}=$ folution, beibe int ber beicht vno offentfich, Bum vier= Den, Das heilige Sacrament des 2utars, das man zu Ditern wno jonjt im jar Den Shriften gereicht hat, wie mol fie geraubt laben bie eine geitalt, Zum funfften, bas beruffen odber ordinim zum \$Farampt, \$rebigampt odber jeelforge, die jumben zu binden vnd lófen, vnt im fterben vno auch jonjt zu trofiten, Denn bey viefen ber braudc) ift blieben, Das man Den fterbenden, Das Crucifix furge= Galten, ond fie eximtert des Yeidents Shrifti, Darauff fie fich laffen folten $2 \mathrm{c} 3 \mathrm{u}$ Yeţt auch bas gebet, als Bialter, Bater vnjer, ber Silaube vno Beben gebot, Эtem viel guter lieber ond gejeng, beibe latinifach vno beubich, Wo mu folche ftucfe noch blieben find, da ift gemislich bie Rirche vnd ettlictye heiligen blieben, Denn es finto alles bie oromung bno frichte Ehrifti, ausgenomen ber raub ber einigen geitalt, Drumb ift fie gemialich (Shriftus bey Den 
feinen getwejt, mit feinem heiligent geift ond jun jnen ben Ehriftlichen glauben erbaltent.

Wate wol es alles ift idsmedflich zu gangen, gleidf

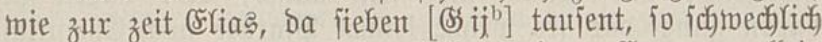
exhalten worben, das Erlias jelbs meinet, Er were allein ein Ehrift, Dent fo getwaltig als EGriftus hat mitifen er= Galten bie Tauffe, wiober fo viel exempel ber wercf vnto Secten, vnt ben text bes Euangelij vno die andern ob= gentanten itudf, wiober jo mandjerlet) neben Yere, von 5̧ei=

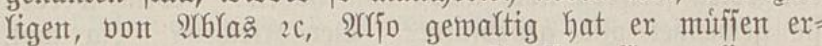
Galtent bie Kerben, das fie jre Tauffe, Eutangelion $x$, nicht verloren nod) vergeffen haben, bey fo viel erger=

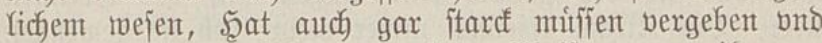
Durch bie finger jeben, two feine Égrijten zu weilen ge= fallen ond betrogen morben finto, wie er Santt \$etro vno Den Ipoiteln hat mififen vergeben jr verleugnen, Sonder= Yich) aber bat ex miffien feiner armen Sirchent zu gut halten, das fie on jren twillen hat emperen muifien, als mit getwalt ir geraubt bie eine geftalt des Sacraments, Bno went fie gleich jr gantzes Yeben weren verfurt ge= tweit hat er fie boch ant ende heraus gerifien, wie ans einem feur, als Sanct Bernthard, Sregorits, Bonauentura,

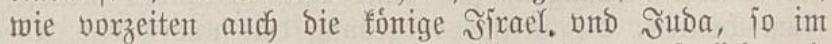
reben boje maren, Er befentet ferber, das es ferfiche zeit fein mirne bno ber gremel afles bermifiten, onto feine aus erweleten folten verfint merden, 2rber weil fie die auffermeleten fint, finto fie fintoer ber gnaben, vno mus jnen feite junde ichaben, fie feien wie gros, viel obder Yang, fie jmer fein mitgen, jr Şeiland Egrif́tus ift gro:

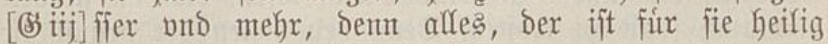
blieben, wo fie junber fint wornen.

Jnu folcher heiliger itete, itehet mu ber gremel bes Tenffels, vber alfe maffe gnam brein gemenget, bas on Den Şeiligen geift nicht mitgliç) ift fie von ber beiligen ftete zu vntericheisen, 2Aber an jren frudoten leret vns Der geift, fie erfenten, SHo bas wix zu vnterit anfahen,

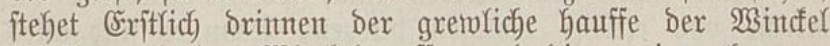

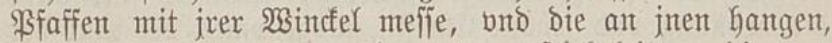
Dieje \$faffen bben ber obgenannten ftucf feines, bie zur 
Sirchen exhaltung Shriftus geordent hat, Sie Fredigen nidgt, Sie Teuffen nidgt, Sie reidgen das Sacrament nidat, Sie 2rbjoluirn nidgt, Sie beten nidgt (on bas jie bie mort des \$falters lorren vno mijpelnt) Sie finto jun feintem ampt Der feeljorgen, nach) bey Den jterbenden etwas thun, Sondern es ift das vonits, faul, mifjifg, gefintoe, bie allein bas Sacrament (mie fie meinen) Gandeln, vno fúr ein opffer ond wercf verfeuffen, freffen ba firr, beide Der Shriften vno ondfriften gitter, Darnach hat ein iglicher hauffe feinten Winctel Biffichoff, die jelben Biffichoue thun auch ber obgenanten fticfe feines, Sie \$rebigen nicht, Sie Tenffen nidht, Sie reidjen ber Sirchen das Sacrament nicht, Sie 2Abjoluiren nicht, Sie beten nicht, Sie jorgent fur bie jeelen nicht ond orbinim feinten \$farber noch

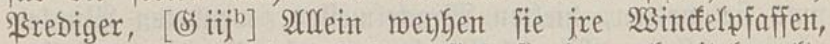
menn fie Das gethan haben, fint fie barnad) eitel relt= liche Finfiten wnd Gerrn, Geiffent fich gleich tool Biffichoue ber firchen, Bno jo viel fie groffer vnto hoher fint bent

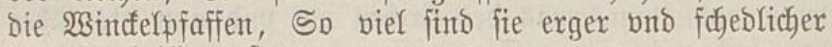
jun ber heiligen ftete.

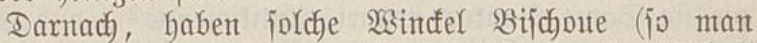
orbinarios loci nennt) ein iglicher teil jeinen (Erbijifichoff vber fich, Die Erbjoiffichoue einen ßrimatent vber fich, Die Frimaten einen \$atriarchen vber fich, 3u Yebst, obent auff

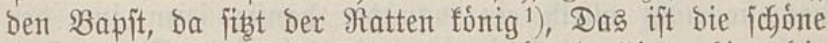
Monarcfia oder (rie fie es gern hórent) Şierarcfia, bie heifige Ehriftlidfe firche, Dieje affe thun autd) Der $\mathrm{ob}=$ genannten ftucfe feins, Sie prebigen nicht, Sie Deuffen nicht, Sie reichent bas Sacrament nicht, Sie Ilbfoluim nicht, Sie beten nicht, Sie jeeljorgen nicht, Dent joldye

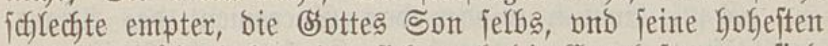
heiligen geitbt haben, Dex fich auch bie Engel fremen, finto foldjen grofjen serrn zu ichlecht vnd geringe, gleich tool

1) Dieser Ausdruck hat Cochläus ganz besonders in Aufregung versetzt: „Als solten Keyser, Könige, Fürsten, Cardinal, Bischoffe vnd andere herrn, die yhn als den öbersten Stathalter Christi ehren, vnd fur den obersten Prelaten der gantzen Christenheyt erkennen, fur Ratten zu achten sein"! Bl. A ij. 


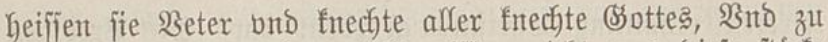
marzeichen das mefrer teil wijien nicht was bieje fticte vno empter find, ettfiche aud nicht bie 3eben gebot noch bent SSlauben fonten, als Dody bie finder fommen, (5) ift ein voldf fúx fitch, Das junt ber Geiligen ftete fikst, vno thut bock ber [(5) 4] firchen nicht einen einigen bienjt, wie fie von ampts vnd naments toegen fchüldoig finto, Dą mitgent bie goben firten Geiffen, die jr Gerde verfaffen, wie 3acharias am elfften ${ }^{1}$ ) jagt.

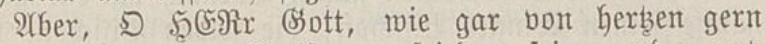
wolten wir armen Ehriften zufrieden fein, ond ganbs Demutiglich bancfen, Das fie ber firchen feinen mubs noch Dienit exzeigten, wenn fie nur Şern bno Furitent ono faule beucfe blieben, Yebten onto thetten fur fich jelbs,

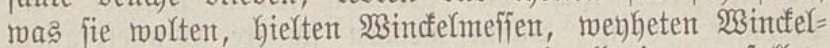
pfaffen, blieben Wincfel Biffichoue, nad alle jrem gefallent,

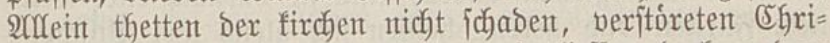
ftus orbuung ond mort nicht, ond lieffen boch andere Yeren vno thun, was ber firchen not bno nub ijt, 2Uber bas wil nicht fein, Sie muffen jrem namen gntug thun, wie fie Sanct $\mathfrak{B}$ anlus nentet, $2\left(\right.$ ntifimentos ${ }^{2}$ ), bnto Sanct

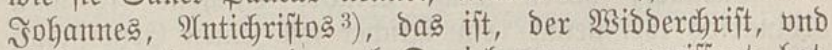
Wibderwertiger, ond auch Daniel zunor gemeifinat hat,

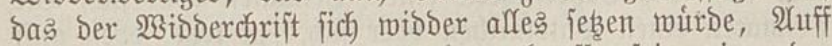
bas fie nidft allein ein vmtiber hauffe jeien jun ber firchen, fondern aud feinde vnd verberber, Das wollent wir jeben burch alle obgenante ftícfe, Sho anfahen bon jren bóbejten vol bejten wercfen, ałs ba find, jre 2 indelel= meffe vno wenke, Darauff fie ftehen bno troben, als gar fonderliche heifigen fír alfen andern EGriften.

$\left[\$ 4^{\mathrm{b}}\right]$ (Eritlich wiober bas Sacrament des 2ultars, fo Efriftus verorbent hat feiner Sirchen ond Ehriften zut reichen, zu ftercfen jren glauben vnto jein exfentnis, baben

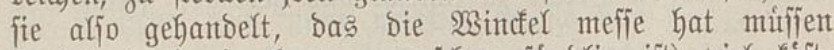
(welche sod) ein lauter menichen fundolin ijt) viel fóft=

1) Sach. 11,17.

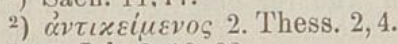

3) 1. Joh. 2, 18. 22. 
Yicher fein, weber bie empfahung bes Sacraments jun ge= mein (weld)s bod) Chriftus einjeb̧ung vno oromung iit) Denn wer zum Sacrament ift gangen, ber hats nicht fontmen opffern, nodh als ein wercf, fitx andere thun,

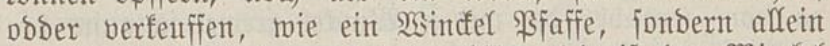
fitr fich jelbe allein empfahen múfjen, Şie ift ber 2 sincfel meffen ein grofier idjein bno hohe ebre zu gangen, ba gegen bem Sacrament vnd feiner empfahung, ein ge= ringes amjeben, vno faft gar kein anjeben blieben on was Chriftus munberbarlicf) (mie broben gejagt) jun jeinen aufferweleten exhalten Kat, Der \$apiften ond wincfel Bfaffen Galben ift hie mit bas Sacrament zu nicht wor= Den, Dent bber bas fie es geringer gemadht haben gegen jrent Mefien, Gaben fie die Yeute auch nichts ba bon bn= terricht, wie fie es jolten mit bem glauben empfahen, zum troit vno ftercfe des gewiffens, Sondern baben fie ge= engitet vno gebrenget, wie fie es nur wirbiglich empfahent jolten, ono ba mit jie geleret, auch ein mercf braus zu madjen, ba burch fie ber firchen gehorfam Yeiften, aber bod) nirgent gleicf), dem opffer bno wercf jrer Wincfel= meffen, auff [5] Das fie bie jelben ben armen Yenten zn Guirffe mit teilen vnto verfauffen módgten.

2urfo ift bie empfahung des Sacraments jun ber Sirchen worden (wo Efyrijtus bet) Den jeinen nidgt wut = berbarlich mit gemirft) ein flein werd bes geforjamts, ba mit ein Reve Der Sirchen (mie fie rbimen) gnug thut, Das boch ftracts mibser Shriftus orbitung vno meinung ift, Sie aber bie Kerrn von ber Winctel meffe, funt Ehri= ftus rorben, Gaben bie armen fundere fonnen Siott ver= funten mit jrem opffer ond mercf, Diejer Yeibiger grewel bno Teuffer ift am tage, ono fan niemand Yeugnten, 5 s zeugnen Stifft, Sirchen vnd aller brauch, wie gar herrlich bno jabon bie Wincfel meffe geachtet, vno da gegen wie gar nichts das arme merf ber empfahunge bes Sacra=

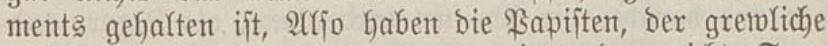
Gauffe, nicht allein bas Sacrament niemanto gereicht, Son= bern aud wibber bas reichen vno empfahen getobet, vno Den glauben im voldf gefindoert, vno junt ein veracht geringe Senen wercf verferet, vno fich mit jrem opffer vno mercf, 
Goch Driber bno ba wibber gejeb̧t, ba mit Dem Sacrament alle jeine frafft vno macht genomen, (Ehriftus hat bie jeinen erbalten) 2 nto das es ja volfómenlich ein veracht, tuncfel, geringe, wercf morbe, Gaben fie bie eine geftalt

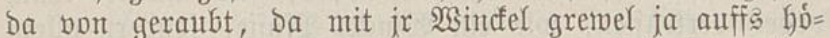
$\left[\mathfrak{G}^{\mathrm{b}}\right]$ heit im Yiecht vnd ehren ichmebete, Isch lebze aber, Das bie eine geitalt zu empfahen recht mere, (als nicht iift) wo fompt ber freulel her, bas fie beider geitalt zut em= pfahen auch vnrecht ichelten vito verbieten, als feberet), veriagen die leute, berbrennen vno morben fie da zu? So es body flar vno gemis ijt, jun dem Euangelio vno Sanct Baulo, das es Ehrijtus 23 ort vno vromung fer), Was jino bas furr lente, Die Egriftum felbs vno jein toort pffentlich bno vmuerichampt verbieten, verbammen, Rez̧er ichelten, vno aljo veritoren uno verwifiten, fampt ber ganben exiten (Érijtenheit, die eintrecftiglich, beiberley geitalt, nad) (Efriftus oromung, fíx recht wno shriftlich gebalten haben? Widserumb laffen jie won jnen joldyen, verbampten, verfluchten, verfolgten 2 rtifel Den Behemen zu vno went fie wollen, als recht vnd Ehriftlich, Sno mus EGriftus zu gleich ein Engel vnd Teuffel, vnd mas fie mollen, bey juen jein, Das futc zeugt affein gnug, Das auch itein ond holb fullen modht, wie bie \$apiften ber rechte ers gremel jey jum ber Geiligen ftete, vno bie eigent= riche firche Des Gellifichen Satans, zu bermuiften Ehrifum vnd feine fircfen, was jolten fie andern mefr fticfent nidft thun, meil fie hierin jo vnuerichampt midober Egrifum toben bno witen?

Sike bas ift bie erfte frucht, baran man ben wifften gremel jum Der şeiligen itete fen=[ร̧ii] nen fam, Nemlidh, bas fie das Sacrament zux Windel mefjen madhen vnd Der Rirchen nicht reichen, 3 um andern, das fie ein opffer bnto wercf braus machen, wnis ben Shriften vmb geld ver= feuffen, Bum britten, das fie ber beiber geitalt eine rau= ben vnd Daritber bie Ehriften verbammen, als fieber, vnd verfolgen, mibberumb ben andern, als recht, zu laffen, Zum vierben, bas fie ben Seyen bie eine geftalt aud zum wercf vnd zum geringen berachtent werct machen gegen jren Mefien, wno feinen glauben ba bey Yemen laffen, 
Das mag Geiffen, Das Keilige Sacrament vermifiten who

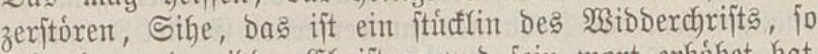
fich vber wno riober shrijtum vno fein mort exhofget hat, ond im tempel Ssottes jibt, fo meit bie Ehriftenbeit ift.

Zum andern, widber bie Tauffe haben fie alfo ge= miletet viti getobet, das fie ber jelben fait aud alle jre frafft wno efre gentomen baben (wil ibt ichmeigen, bas fie niemanto jun ber firchen Teuffen) wie torl fie bis auff biejen tag noch nicht veriteben, was bie Tauffe jey, and

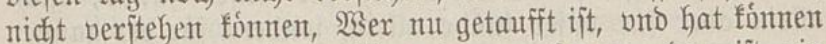
ba bey bleiben, ober wibber da zu fomen, ber ijt ein mundermercf shrifti gemeit, wie jeine aufferweleten alle find, Dem andent Gauffen ift Durch Den Bepitfichen gremel bie Tauffe mibbenumb genomen und zu nicht gemacht, (Exitlidf), Das $\left[\mathfrak{5} \mathrm{ij}^{\mathrm{b}}\right]$ fie den glauben vnd rechten braud obser veritand der Tauffe, nidft alfein verjdymigen, (alङ ba von bie blinben Yeiter gar nichts veritanden) jonbern auch) ba midoer geleret, mancherlet) Yere von mercfen, bon Rew, Beicht wnd gutug thun, Darauff fich bie getwiffen verlaffen vno jrer Tauffe vergeffen muften, Darnach bie

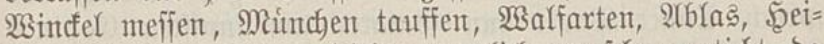
Yigen bienit, wno Der gleichen vnzelich menjojen geticht, ba burch) vergebunge zu erlangen, geleret haben, zu groffer

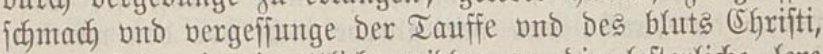
Da zu fahen ibzt jr ettlicke wiober an bie leiterliche Yere vmerichampt zu predigen, das ebriftus habe allein fur bie Exbjunde vnd vergangene funbe gnug gethan, fur bie folgenden múffen wir jelber grug thum, 1) Das heifft fein

1) Auch diese Klage bezieht sich wohl ganz direkt auf Witzels Predigt vom 18. Oct. 1533, vgl. Kawerau, Agricola, Berlin 1881 S. 153. Dieselbe Klage erhebt Hans v. d. Planitz gegen eine 1524 in Esslingeu gehaltene kathol. Predigt. Förstemann, Neues Urkundenb. I. Hamburg 1842 S. 198. Vgl. auch Plitt, Einleitung in die Augustana II, 77. Ein katholischer Leser der Schrift Luthers hat in einem uns vorliegenden Exemplare die Randglosse beigeschrieben: „Aber wer es thut, sagt Luther hie nicht" und ihn damit beschuldigen wollen, unbegründete Anklage erhoben zu haben. Die angefuhrten Predigten beweisen jedoch, dass seine Klage nicht aus der Luft gegriffen war. 
vno rein aus ben Chriften Turden vno Szeiden gemadyt,

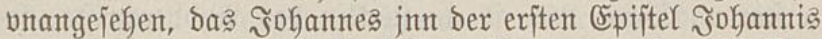
am erften (5ap. [v. 7] flerlich ipricht von alfen Ehriftent vno von fich jelbs, bas jo wir im liedgt mantoln, madyt

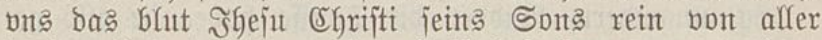

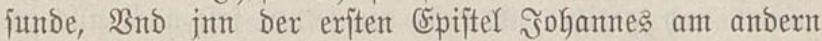
Capiter, [v. 2] $D b$ jemano juntsiget, fo haben wir einen

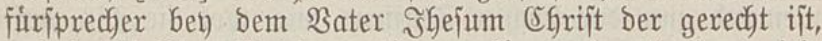
vno Der felfige ijt bie verjütung fúr vnjer jumbe, nicht allein aber fur bnjer junbe alfeint, jondern fúr ber gantzen melt, Bno bie Epiftel zun Esbreern [5iij] gar herrlich Ohriftus emiges \$rieiterthum aus jtreicht, wie er bey Srott fúr vns ftebe, Sanct ßaulus zun Romern am adjten Capit. [v. 34] ipricht, Efriftus bertritt vn's bey bem Bater, 2Uber was joltent jolche blinde Yeiter vnd Tauffe ichender von biejen Sachen veriteben?

Die alfer bejten vnter inen Gaben geleret wno Yeren nod), das dem glauben bie mercf obser bie liebe, fraffit vnto geitalt geben, wie fie jagen, Fities formata, Bno Charitas eit forma fibei, Bnd furen gar herrfich bent iprud) Sanct Bauli zun (Salater am funffiten (Eapit. ${ }^{1)}$ Jnt Chrifto gilt meder beichneittung noch vorbaut etroas, jonbern ber glaube, fo burch bie liebe thettig ift, $\mathfrak{B e r}=$ fteken da burch, bas ber glaube nicht vor ben werffen, jondern, Durch bie mercf, gnade ond jeligfeit ermerbe, So bod) Sanct gauluts bie nidyt rebet, was ber glaube fen obber thu jun feinem eigen mercf, (melch)s ex zunor burch) bie ganbe (Epiftel reidylich (eret) auch nicht, was bie liebe (et) obber thu, Sondern jafjet furb zu jamen, was ein gants (E)riftlich leben jein jolle, Nemlich glaube vno liebe, S)lautbe gegen Ssott, Der Crfriftum ergreiffet vno vergebung Der futbe friegt on alle wercf, Dar nady Riebe gegen ben neheiten, welche, als bes glaubens frucht, bereifet, bas Dex glaube recht vno nicht faul noch faljch, fonoem thettig vno lebendig ift, Darumb ex nicht jagt, das die liebe thet=

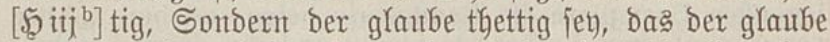
die liebe obe ond thettig mache, und nicht die Yiebe ben

1) Gal. 5, 6. Vgl. Lämmer, die vortridentinisch-kathol. Theologie S. $147 \mathrm{f}$. 
glauben, wie es die \$apiften berferen, vnd aljo ber liebe alles, vnd bent glauben nichts zu jajreiben, Sanct \$aulus aber alfes bem glauben zu ichreibt, als ber nicfst alleint bie gnabe empfehet von Şott, Sondern, aud thettig iit gegen bem nebejten wno die Yiebe obser merct bon fich gebirt onto twircfet, Nat ift ja affe Yere, jo bns auff mercf meijen, wibder bie Iauffe, barinn wir on wercf, bie gnabe empfangen, bno etriglich behalten jollen, wie das Sanct \$aulus alfentbalben gewaltiglich treibt.

Aber, Das ift afler erit ber rechten grewel einer, twibser bie liebe und felige Iauffe, Das fie fich rhimten, twie fie mit jrem Erejem bno $\mathfrak{s e n h e , ~ P f a f f e n ~ m a c h e n ~ j u n t ~}$ ber Keiligen Rirchen, Das iłt, einten weit, weit, hóbern bno Geiligen itant Denn bie Tauffe gibt, Denn ein gementheter bno mit Crejem gejalfter \$faffe, ifit gegen andere ge= tauffe gemeine Chriften, gleich wie ber Morgen itern gegen ein glummeno tocht, vno mus bie Tauffe, Darint wir mit Shriftts eigenem bhut gemafichen, bno mit jeintem Seiligen geift gejalbet fint zum ewigen Yeben, gegent Demt

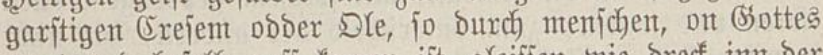
wort vno befelf auff foment ift, gheiffen wie breeff jun ber Qatern gegen ber Somen, vno mer $=[534]$ ben bock mit folchem Erejem nicht gejalbet zum emigen Yeben, fontoent zur Wincel Meefien, şie zu hilffit die \$latten vnd fonder= liche fleibutn, ber name Clericus, als jenen fie alleint Ehriftns eigenthum. Stem, wie fie ertichten, Der Caracter, das geiftliche malzeichen jut ber feelen, io fein gemeinter Orgrift haben jol, on allein bie gemenheten \$riejter. Sttem, bas geprenge io man einen \$riefter hat follen Degrabirn, Gaben viel Biffichoue, zu meilen mol fieben ba bey jein muffen, of ex gleidh bon einem alfein gemenhet ift, nock Gaben fie im den caracter nidft fonten nemen, mit joldjer prachtigen begradation.

Das fint bie rechten prechtigen wort ono freffige wircfunge bes Teuffels, ba mit ber Keiligen Tauffe jr

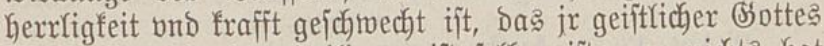
(creiem, welchs ber seilige geift jelber ift, gar nichts hat miffien jein gegen Dem Yeibfichen vnto zeitlichem Crejem ber \$apiften, Durch menjichen andacht exfunden, Die Tauffe 


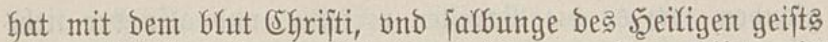
feinen \$faffen fonnen Wenthen vober machen, Stber ein

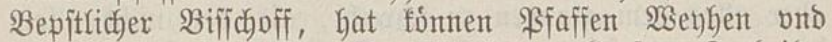
machen, mit jeintem ftindenden, garjtigen, Erejem, Jr heilo= jen verbampten narren vno blinben Yeiter, wie gar ichento= lich lejtert ir hie mit vnjer hei $=\left[54^{\mathrm{b}}\right]$ Yige Tauffe, bas blut Shrifti und Die falbung Des Şeiligen geifte, bno werfft vnts ba gegen auff, emer nichtige, jchentoliche, gremlidbe 23 incfer weyke zur 23 incfel meffen gericht, mit emrem Yeib= Yichem bno zeitfichem (Srefem, weldyer boch) ein lauter men= fiden thand ift, ond weser befelf noch gebot sottes bat.

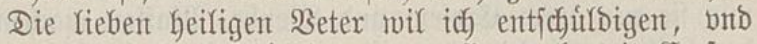
man jol jie aud) entichulldigen, two jie aud mit (Erejent geweyket obser georoinirt, und jre gemenketen, bie \$faffen obser \$riepter gentennet haben, Denn fie haben da mit

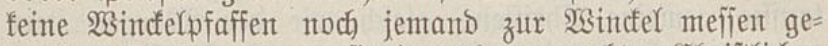
weyket, Sontoen ment fie jemanto zum rechten (E)rijtlichen Bfarrampt obber feeljorgen Gaben beruffen, Gaben fie joldgen beruff fitr bie gemeine, mit foldyem geprenge toollen zieren uno malen, zum vntericheio Der andern, bie nicht beruffen fint, auff bas jeberman getwis mitroe vno wiffe, meldje perion joldh ampt fúren folte ond befelf hette zit Teuffen, \$redigen 2 , Dent es fol vno fan im grumbe bie toubhe nichts antoers jein (jol es redbt zut gehen) Dent eit beruff obser befelf, Des Pfarrampts odoer \$redig= ampts, Die Apoitel haben on Erejem, allein sie hende auffe beubt gelegt vno gebettet ober bie jo jie zum ampt Gerieffen obser fambten, twie 9YActuum am neuntzehedent (Eapitel (1) Sanct $\mathfrak{B a u l u s ~ [ \Im ] ~ v n o ~ B ̉ a r n a b a s ~ g e i d j a c h , ~ v n o ~}$ Sant $\mathfrak{B a u l u s}$ jeinen Timotheon ${ }^{2}$ ) Yeret, (5r folle nicht bald einem bie Kende auff Yegen, Die Yieben ßeter Gaben jolche Eeremonten gemebret mit Dem Exejem vnto ber gleichen $2 c$, habens gut gemeintet. 2rber menjichen andacht vno gute meinung geraten affzeit aljo, bas hernach, erger= nis, jrthum ond $2(b g$ ótterey), Draus wiro, too der Seter

1) Act. 13, 3. Auch in der Ausgabe von 1534 ist das falsche Citat stehen geblieben, während Jonas dafür Cap. 16 einsetzt.

2) 1. Tim. 5, 22. 
geift nicht mit folget vno bleibt, wie jun viel ftitcfent mebr geidjeben ift, 2uljo ijt auch bieje gute meinung ber Beter vno jr wenhen ba hint geraten, Das die Tauffe und Chrijtus

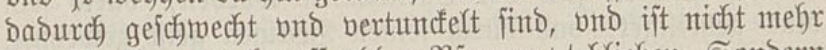
eine $\mathfrak{S e n h e ~ z u m ~ b e r u f f ~ o d b e r ~ P F a r r a m t p t ~ b l i e b e n , ~ S o n d e r n ~}$

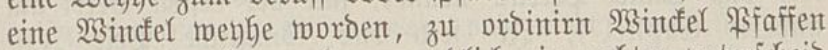
zur Wintelel melfe, vno mu endlich ein rechter vntericheio wno mercfmal, zwifichen den rechten Chrijten uno Des Teuffels Bfaffen, Dent fie bienten Der Sirchen nicht, jon= Dern find ber gremel ber jun ber şeiligen ftete alles ver= ftoret vno berwíftet.

Da gegen joltu beinte Iauffe midosenumb hoch hebent vend preijen, io viel bu vermagit, ben ichentolicjen gremel wioberumb auch zu idgrechen vnt zu nichtigen, Dent es gilt jun der (Shriftentheit nicht, Ffaffens machens noch wethents, Der Crejem (jage icf) vns Biffichoff werben wh

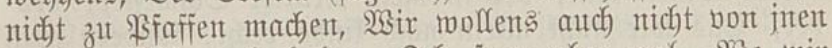

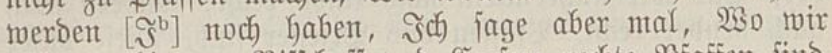
nicht vorbin on Bifichoff vnto Erejem rechte \$faffen finto So wird ons ber Biffichoff und fein (Exejem nimer mefr zu \$faffen machen, Zaruen bno Faftnachts \$faffen mag ex wol aus ons machen, gleich mie ex jelbs ein Jajt= nachts siffichoff vno Rarue ift, vno twie bie finaben inn

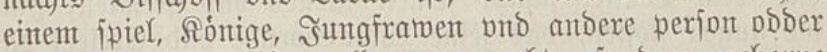
Qanten machen, $\mathfrak{s i x}$ wollen vitgemachte, jonbern, geborne \$faffen jein vno heiffen, und vnjer \$ffaffenthum exblich) Durch vnier geburt, von Bater vnto mutter her haben, Denn vnjer Bater ift ber rechte \$faffe ono hoher \$rieiter, twie geichrieben itehet, am hunberten vno neundent \$ialm ${ }^{1}$, (S)tt hat geichtworen, Das wirb in nicht geretwen, Dut bijt ein \$riefter inn ewigfeit, nach) der meije Melchijedech), Das bat ex auch bemeijet, vnto fich jelbs am Ereubs fitr vnts geopffert $2 c$. Der jelb Srieiter odser Bifichoff, hat mit eine Braut, eine \$riefterin ober Biffichoffin, wie ge= fajrieben itehet ฐohantes am britten ${ }^{2}$ ), $\mathfrak{B e r}$ bie Braut hat, Das ijt ber Brentgam.

1) Ps. 110,4 .

2) Joh. 3, 29. 
Bon Diejem Breutgam vno Braut, fint wix ge= boren, Durch bie heilige Tauffe, vnto aljo exblich zu

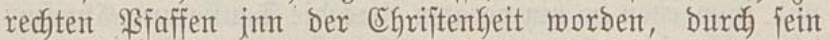
blut geheiliget, ono burch jeinen Seeiligen geijt gewenhet, mie vns Sanct \$etrus nentet, jun ber exiten \$etri am

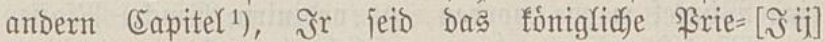
ftertfum, zu opffern geiffliche opffer, Bno Sanct Faulus

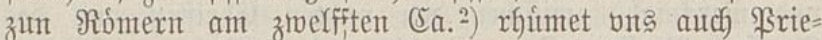
iter, Denn ex heifft uns opffern vmere Yeibe zum heifigen, rebendigen, antgenemen opffer, $\mathfrak{N u}$ ift Crotte opffern alfein ber Sriejter ampt, wie der SBapit jelbs mus befenten vnt alle welt, Da zut find wir nicht allein jeine finder, jonbern auch jeinte britber, wie er fpricht am ein bno

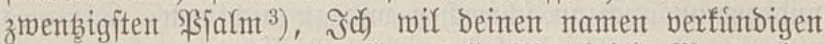
meinen britbern, $\mathfrak{B n}$ im Euangelio Mattbej ${ }^{4}$ ), $\mathfrak{W e r}$ meint vaters wiflen thut, ber ift mein Mitter Schweiter, bru= ber, Das wir nidat affein nach finds recht, jondern auch) nach brutber recht, Bfaffen vno \$riefter finto, Dieje vnjer angeborne vno erbliche \$riefterjchafft wollen wir vn= genomen, ongebindert vno vnuertuncfelt, jondern exfix gezogen, ausgeruffen, vno gerhimet haben, mit alfen ehren, bas fie Yeudften und jobeinten for twie bie liebe Sonne, vnd Dem Tenffel fampt feinen Yaruen vnd gremlen, int bie augen jtofien, Das jeine Wincfelmenhe bno Crejem ba gegen ichein wnt jtincfe, erger benn Teuffels orecf ftinctit, Da her auch ber beilige geijt im nemen Teftament mit vleis verfyitet hat, Das ber name Sacerdos, \$riefter ober pfaffe, auch feinen 2 (poitel noch einigen andern ampten ift gegeben, Sonbern ift aflein ber getaufften ober Chri= ften namen, als ein angeborner erblicher name aus ber Tauffe, Denn vnjer feinter wiro jnn ber Tauffe ein Ipoitel, \$re $\left[\mathfrak{S}_{\mathrm{ij}^{\mathrm{b}}}\right]$ Diger, Lexer, $\mathfrak{B f a r h e r , ~ g e f o r n , ~ S o n d e r n ~}$ eitel \$rieiter ond \$faffen werben roir alle geborn, bar nach nimpt man aus folchen gebornen $\mathfrak{B} f a f f e n$, volo be=

1) 1 . Petr. 2, 9 .

$\left.{ }^{2}\right)$ Röm. 12, 1 .

3) Ps. 22, 23.

4) Matth. 12, 50 . 
riffit obder ermelet fie zu foldhen emptern, die von onjer alfer megen, foldy ampt aus richten follen.

Das ift ber grund inn biejer jachen, Den niemano fan vmbitoffen, uns wo bie Bepitifiche Wenke recht molt thun, folt fie nichts anders thut, Denn foldhe geborne \$fFaffen beruffeu zu \$farrampt, vno nicht neme, Geiliger vnd befier Sfaffen madjen, meder bie getauffte Ehriften find, Sike, Das ift bas ander ftucf (wie gejagt) ba mit fie onjer Tauffe geichendet, vertundfelt vno gejchinecht, ba zu vnt joldge vnjer herrliche, emige, angeborne, erbliche \$riefterliche ebre, jo ichendlich vno refterfich beroructi uno verborgen, ba fuir uns jren tobten, garitigen, Erejem, fo hoch ond herrlich furgeitellet, haben, das wir Sot jelbs nicht io foch gefurcht vno geebret haben, als dieje jre nichtige laruen ond fajtnacht ipiel, Das aber bie Seter jre gemeyheten haben Sacerdotes genentet, ono aljo junt brauch ift fomen, Sol man (jage ich) jnent zut gut haltent,

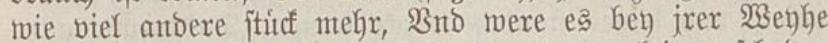
vnd ordinim blieben, io hette ber namen feinen ichaden gethan, Denn fie haben \$farber gewenget, 2rber Dex gremel hat ben namen behalten (meil ex fo herrlich mar)

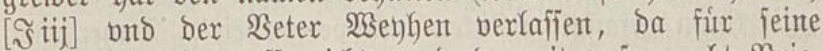
Wincfel menhe auffgericht, ond da mit vnjer recht \$rie = ftertfum wnd Tauffe gremlich berwiffet vno veritoret.

Mit Dem oritten ftucf, Das ift mit Der \$rebigt ifta aljo gangen, (Erjtlich, Das fie ben tert des Enangelij vnto bes leibents Erbrifti auff ber Canbel haben ba her gejagt, Soie mit ift blieben Der name vnd erfenntnis Egrifti jun jeinen aufjermeleten, 2(ber Durch gros Bsottes macht vno twunder, fint fie ba bey erbalten, wie wir hören werden an jren grewelen, fo fie ba midoer getrieben haben, ßno

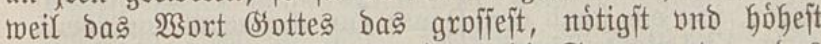
ftucf ift inn ber cogriftenkeit, (Denn bie Sacrament on Das 23ort nicht fein fómen, aber wol bas Waort, on bie Sacrament, \$nd zur not, einer on Sacrament, aber nidjt on bas Sort, fundte jelig twerden, als bie fo da iterben, ehe fie bie begerte Tauffe erlangent) hat Gierin (Ehriftus

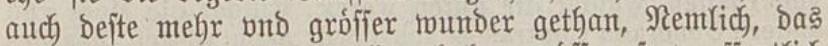
fie ben tert bes Euangelion haben muffen fret offentlich 
\$rebigen, ntidft alfein jun Yatinicher, Sontoent, audf junt eintes iglichen Lantoes ipractien, bas es ja von alfer twelt bnto int alfen ipradjen futo bliebe, bey ben aufferwele = tent, So jie bock das Sacrament vno bie Tauffe, jum fei= ner andern bent jun latinijoder iprackje, mit Keimtlickent worten, bie niemand horen muite Gandelten.

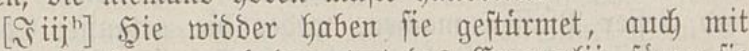
affer madyt, Dent nach Dem tert bes Cuangelij, firren fie ba fin jnt Schlautraffen Yanto, Einter predigt aus 2Ariftotele bnto Den Setonifichen Gitchern, Der ander atts Dem Decret, Ein ander bracht fragen aus Sanct Thomas vno Schs= Yaitern, Ein ander prebigt von ben Seiligen, Crin ander von ieinem heifigen Drben, Ein antoer von blatw entent, Ein ander von hitner milld), $2 \mathfrak{s e r}$ fant es alles erzelent das vnzifer? Summa, bas war bie fumît, das ja feiner bet) bem tert bliebe, da mit das vold hette migen das Eutangelion bebalten, Den Ślauben, Behen gebot, Bater vnjer, vno jeines itandes mercfe Yernen, Das mujte alfes geidhigigen jein, Sondern bie Yeute muit man burch joldhe gaudel presigt auff eigen mercf vno verbientit meijen, bno Efriftum int irem Kerben (io aus Dem tert des Cruan= gelij faum gefaffet) erfticfent vno vergraben ${ }^{1}$ ), Daher and

1) Cochläus replicirt auf diese Schilderung des katholischen Predigtwesens a. a. 0 . Bl. I ${ }^{b}$ : „Nu gestehen wir jhm dieser stucke gar keynes, ynn gemeyn durchaus. Das ich aber sagen solt, das vnter vns nicht vngelert odder vngeschickt prediger gewest weren odder noch sind, das weis ich nicht zuthun. Ich sage aber dargegen, das auch vnter den Lutherischen Predicanten der gröste hauff vngelerte Theologi, schwetzige ohrenkrawer, vnd bittere Bapstschender sind, Ein grosser teyl faule grobe Esel, die das Euangelion auff der Cantzel vor dem volck aus eynem buch lesen vnd aussagen, wie ein knab den Donat ynn der schul vor dem Locaten, Vnd nichts wissen zu sagen, denn was sie aus Luthers Postillen vnd Deudschen Catonichen gelernt haben. Der halben sie den Text nicht hart beyssen noch scharff auslegen, Sondern so ihre yhre seychte kunst bald aus gepredigt haben, fahen sie an die vbrigen zeyt der predigt mit schenden vnd lestern zu erfüllen, wider den Bapst, widder Müneh vnd Pfaffen, widder die guten werck, widder die Mess vnd andere Generalia Contra. - Ich dörfft auch wetten, das des Luthers schwetzige Postill viel weniger eynfïre Biblische 
alfe welt io vol Stifft, Ŝlojter, Rirchen, vno Cappelfent worden ift, bas mant ibt mit alfer welt gut vno madft, nicht bie helfft funote aufficichten, Welchs bie faljche lere gar Yeicht vno mit luift. Gat erbawet, So ein gewaltige, reiche, feiferin ift, bie litgen obser faljuge Yere jun ber melt, Daneben bie marbeit wno Euangelion nicht hatte, ba fie jr keubt modgt Ginlegen, ond fur durit bno hunger eifitg ond gallent trincfen, muite zu Yez̧t (Ereub ond id)mad)

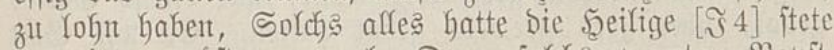
von jrem wifíten grewel, Dent folds weretent Bapit, siifichoue, Bfaffen nidgt, Sondern fahens gern, Gulffents treiben uno Gandhaben, Sage mix, Wer hat hie fonnen bey bem Enangelio bleiben odser widoer da zu fomen, on wer ein gros mumber mercf Shrifti geweit ift? als bent jeine aufierwelten alle finto.

Da mu folchs ftitrmen wioer Den tert bes Euangelij Dem Teuffel nicht gung, bno Da burch Dent tert bes (Euangelij nicht zugrumb vertilgen funo, Jur ex zu, vno febet feinen gremel nidft allein wibder, fonbern aud bber bas Euangelion, wie S. Baulus vno zutud Daniel verfint= biget haben ${ }^{1}$, bas fitch ber (Endechrift feben jolt im tempel Sinttes, wiber und bber alles was ba Gsott heifit dober geefret mirb, Welchs aljo ergangen ijt, Dent bie gebot vut Yere des Bapits (jo gar nidfts nom glauben Chrifti, wie bas Euangelion thut, fondern alfein feinen gehorjan jun Yeiblichen, Yojen, Yeichten jachen, als fleijch efjen, feyren, fajten, fleiden 2 prebigen) hat ex viel hofger getriebent ono gepreijet, meder alle Siottes wort, fino auch bof her gefitrdyt vnd gehalten, Gaben bie gemifien herter erichrectt vno gefangen, bie belle viel heiffer gemacht, Dent beide

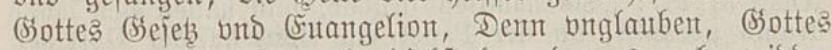
rejterung, egebruch, moro, biebjtal, vno twas mehr wiober Ebriftum bno jein Siebot ift, haben fie geringe geadjtet, bno ift bald gebriffet ond vergeben geweit, saber wo jeiner

schrift denn vusere alte Sermon schreyber gethan haben u. s. w." Vgl. des Herausgebers Zusammenstellungen ibel. das Predigtwesen am Ende des Mittelalters in Zeitschrift füir kirchl. Wissenschaft $1882 \mathrm{~S} .15 \mathrm{l}$ f.

1) Dan. 11, 36. 2. Thess. 2, 4.

L uther, Winkelmesse. 


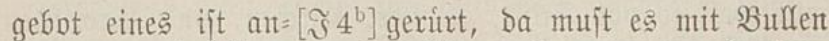
Domern vno bliken, vno heiffen verbampter vngehorjam, vno inn Des Bapits Bann, Şie multe zittern bno zagen fimel vno erben, aber jut ben junden wiber SSott, barinut jie jelbs erjeufft find, reget jith nicht ein Ejpenlaub, Son= bern battens jren fpot vnd lachtens da zu fúr groffer ficherbeit, wie fie noth Geutiges tages thun, da zu ver= folgen ont morben gremlicher weife, alle bie jo Siottes gebot, vber jres gremels gebot baltent. Er wil Sott vno fein mort viter fich) Gaben, wno er bríber fitzen, bas ift jeir regiment wno wejen, on welchs er nicht funde Der Endodrijt jein.

Şaben fie es boch ba fin bracht, bie reibigen tenffels meuler, bas fie nicht mit blinden worten, fondern fret offentlich rfumen, Der Bapit ond feine firche iet wher bie heilige Sdyrifft, 3no ex habe madht bie jelben zu en= Dern, auff Keben, verbieten vito Deuten, wie er molle, Sno mar bas fein handmercf, bas er als ber heifigen Schrifft, als ein tópffer aus Dem thon, machen mocht, eine Sacheln obser firug pdDex searmicherben, ßnt wie ers madyte, jo war es ein Artifel Des Ehriftlichen glaubens, twie fie noch heutiges tages thut, mit Den worten ono einjebung Shrift, von beiber gejtalt bes Sacraments, \$ber bie felben wort bno tert Egrift, Gerrichet ex, wie ein tópffer vber jeinten thon, wie exs macht, fo $[\Omega]$ mus mans balten, obder verbrant, ermorbet, obder veriagt fein on alfe barmberbigfeit, Denn fie Geiffen jynen einen jroijchen (sott $\left.{ }^{1}\right)$ ber nicht ichlecht menidy, Sondern aus (siott ond

1) Vgl. Luthers Schrift Von den Schlïsseln 1530, Erl. Ausg. 31, 15\%: „Sie handlen drüber, und haben sich lange drumb gezankt, ob der Papst ein Mensch oder Gott sei; haben aber endlich beschlossen, er sei Gottes Statthalter auf Erden, und ein irdischer Gott, eine Person aus Gott und Menschen zusammengeschmolzen, mixtus deus et homo." So wurde Julius Il. auf dem Lateranconcil 1512 als ,alter deus in terris" angeredet, Leo X auf dem Lateranconcil 1516 mit „Vestra divina majestas"; sein Ceremonienmeister schreibt von ihm: ",ipse jam non ut homo erat apud nos, sed ut semideus." "Vgl. die Belegstellen in Allgem. Luth. Kirchenzeitung 1883 Sp. 424 u. Gregorovius, Geschichte der Stadt Rom VIII, 197. 
menjich zu fament gemenget jey, wolten wol gerne jagen, das ex gleich trie Shriftus jelbs, warbafftiger Ssott vito

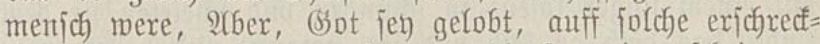
liche lefterung, Gat angefangen, bie font jren fobein zu= uerfieren, ber vorhang in tempel zu reifft, bie erbe bebet, die tobten greber thun fich auff, ond die feljen zu reifjen, 5es wil ein anders twerben, wnd das jun furb 2 . Int biejer frucht, wie fich Der Bapjt wibser nno vber Dent text Des Euangelij gehalten hat, fan man Den greme inn ber heifigen itete rol exfennen, vnd zwifichen bent Suangelio bni feiner lere (lefterung rolt ich fagen) wol vnterichied gaben.

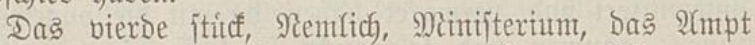
Des worts vno Bocationem, Den beruff zum \$Farrampt obber feel forge, (melchs fie die Wet)he obder Drbinitn Geiffent) meinen fie getwis, fie baben joldys aflein, vno

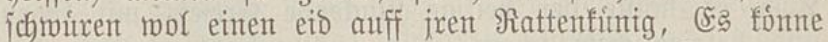
niemand on jre Wenge bno Erejem, das Sacrament mandlen, obder wie fie fagen, Timmen ${ }^{1}$ ), ex fet wie heilig obder gros ex rolle, Denn wie fie rhimen, Die engel in fimel, audf Maria jelbs, haben foldye gemalt nidgt, bie ein getwenheter Briejter hat, ja aud $\left[\Omega^{b}\right]$ fein beritorben

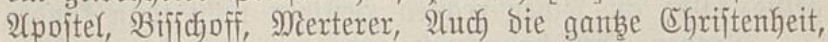
jo nicht Prieiter find, Nentlich), zut tirmen obDer twan= beln, wenn ex gleich onbeilig, ja ber exgejt burntreiber, (Ehebrecter, Morber, Dieb, Seber, Simpniacus, auff exDen were; foldse groffe frafft hat Der Srejem, $\mathfrak{W a s}$ meinjtu mol, das gute frijocje meyejiche putter thun jolt? ment joldy ein garitiger Srejem vermag? Da ber fie bent (5rejem auch) jo Geilig bnto herrlich Gielten, (ob twol die Priefters perjon mit ganben leibe ond jeele ein ruct)=

1) Ueber dieses Wort und seine Ableitung von terminare vgl. die Anmerkung bei Köstlin, M. Luther, 2. Aufl. II, S. 639 . Amsdorf schreibt: „Messe zu halten oder zu tirmen, wie sie sagen" in seiner Schrift "Das nie nöter gewest ist wider den Römischen Antichrist zu schreiben " Magdeb. 1551 Bl. A 4. Irrtïmlich wird das Wort von Turm abgeleitet in Unschuld. Nachr. 1715 S. 418. Auch Möller, Osiander S. 196 schreibt: ,Elevation oder 'Thürmung." 
Yojer bube war) went ein find obder Setje ongefer, bas Sacrament anritret im munbe, vnd rolts vom gaument

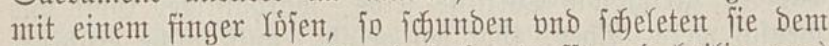
finde (bas Doch an Yeib ont jeel getaufft ond heilig war) Den finger onto bie haut abe, nomb ber grofien iuntoe willen, Das ein heiliger Efrriftlicher finger, vom Şeiligen geift gejalbet, bas heilige Sacrament angeritret batte.

Snd ift munder, warumb fie nicht aud alfen Leven, als Dent vngewerbleten, Das gants Sacrament vorpoten, Dober jnen bie zunge, gaumen vno fele, ba mit fie bas heifige Sacrament auritren mujten, nicht aud geichunben bno geichelet, obser boch zuuor mit jrem heifigen Erejem vnterfuttert ono verwaret haben, ba mit bie vngemenhete zunge, gaumen bno fele nicht io tieff fich beriundigten Durch) antrit=[ $[$ ij] ren Des Sacraments, wie fich ber arme finger gegen jeine ichinder vno icheler veriuntogent mujte,

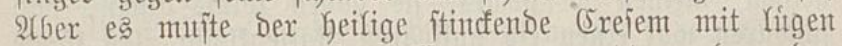
wnd betrieglichem ichein, alfo aus gepubt merben, Der Geirgen Tauffe zu fchmach vno vnebre, auff Das ber gremel ja alfein herrlich witrde jun ber beiligen ftete, vno bie getwalt óberfeme, Das ex einen bofen Yojent bubent fundte zu grofien efren heben, des gleichen bes Keiligen geifts jalbe an feinten rechten Seifigen nicht thun funtote.

Droben aber haben wir angezeigt, wie bie Erejems Bifichoute, nit jrer Wenge, feinen Bfarrer noch \$rediger

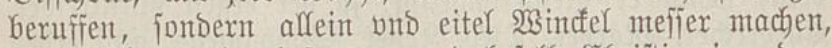
zut veritoren bie einjebung vno befelf Ehrijti, jun bem

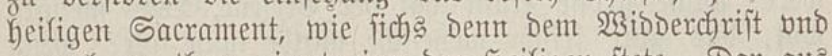
gremel zu thun zimtete jnn ber Seiligen itete, Dar aus folget mi flerfich, Das io wil an Dem Bapit ond feinent sifichouten gemeit ijt, Gaben fie im Sapitum ben beruff obser bas \$farrampt obber \$rebig ampt, gank Yaffen rigen bno feins nicht gefabt, Da zu haben fie es auff ge= haben vito zerftoret, Denn es hat fein gemetheter $W_{3}$ incfer Sriefter thuren ber gemeine das Sacrament reichen obser prebigen, wie es Doch (Shriftus befelf ond einjebung fobbert, Sondern hat da mujpen ftehen, vno mit grem=

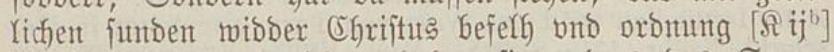
das Sacrament handen, haben fie anders das Sacra= 
ment, ond nicht eitel brod und rein gefabt, Dent idf broben aud angezeigt habe, wie es zu bejorgen jer, Das inn Den 2 sincfel meffen fein Sacrament, jonbern eitel

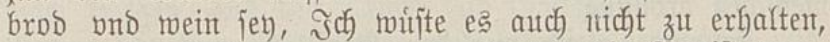
ment icfs gleich gern thun rolte vnto ein \$sapift were, Wenn nicht mefr jun Windfel meffe were benn misbraud obser junbe, fo wifite ichs mol zur halten, das Dennoch ber Yeib vnd blut Egrifti ba were, Suta abujus nou tollit jubjtantiam, Seb jubitantia fert abujum, Meisbrauch nimpt bas wejen nicht, jonbern bas rejen leibet bent misbrauch, 2Uls wer vntwirbig bas Sacrament empfebet, ob er rol ba mit junbigt ond miabraudjt bes Sa= craments, noch empfeget ex ben waren leib ond blut (5)rifti.

2lber jun ber Wincfel mefle ijt nidgt alfein ber mis= braucf obser junbe, bas ber \$rieiter vntwirbig Gandelt vno empfehet, Sondern menn jafon ber \$rieiter heilig vno wir= big were, tamen ipja jubitantia injtitutionis Egrijti jublata eit, bie wejentliche oronung vno einjebunt Chrifti nemen fie weg, vno madjen eine eigen orbinung, Nemlidf, Ehriftus oromung vno meinung ijt bie, das man bas Sacrament reichen jol, ond bon im prebigen, den glaubent zu itercfent, Dieje oronung Gebent fie auff vnd ferents alfes vmb, Sie befalten [ $\Omega$ iij] Das Sacrament alfein firr fich einbelen, ond reidgens niemano, So idfmeigen fie itifle bns prebigen niemanto, So jtercfen fie ben glauben feinem Efrijten, jonbern furen in vom glauben auff bas opffer und twert jer Mefien, welche fie inen mit teilen ober verfenffen vmb geld, Sibe, bas geifit nicht alfein jun= bigen ober misbraudfen ber oromung Ehrifti, fondern bie orbmung Egrifti an ir jelbs endern und verferen, Der Galben niemant gleuben fan noch jol, bas ba jey (Egrijtus leib ond blut, reil feine orbmung nicht ba ijt, gleich), al( menn bu jemand on waffer obber mit ajichen teuffejt, of bu gleich bie rechten mort iprecheit, ond boch joldge tauffe jolte nicht bie funde vergeben, fonbern ein malzeichent jein einer guten gejelichafft, Sifje, bas heiffit nicht allein toibber bie Tauffe gejundiget, fondern bie Tauffe jelbs geendert, ond Ebriftus meinung verferet, Darumb ift ba 
feine Tauffe, 2rrjo ijt jun Den waincfel mefjen auch fein Sacrament zu glenben, weil bie oromutg volo meinung EGrifti nicht da ijt, Sondern gar ein nem who eigen menichen orbunng.

Summa, gleich wie Dex Bepitliche mutiger gremel veritoret Kat Die Tnuffe, Sacrament, Frebigt Des Euan= gelij, aljo hat er aud Minifterium ond bie Socatio,

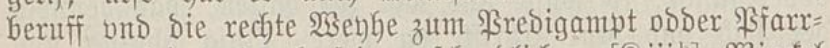
ampt veritoret burch jeinen ichendficken [ $\left.\Omega_{i j}{ }^{b}\right]$ Sincfel Erejem, âber bie ijt Ehriftus mit jeiner madjt vno mun= Der gemeit, und hat bentoch midoer ben Yeibigen gremel Das ampt ond ben beruff zum \$rebig ampt jun feiner Seifigen itete erfarten, Denn bie \$farrhen obser Frebig ampt, fint alfezeit, auffer vno vber ben (Erefem, Durch Firriten, Serrn, Steste, auch von Bifichouen jelbs, Epten, Eptiffimen bnt andern itenten verfiben, bno burch fordh ver(engen, ift Dex beruff bnd bie rechte $2 \mathfrak{s e n h e}$ zum Meini= fterio odoer ampt blieben, Da neben hat man foldye be= ruffene \$farker, jo jolche Leken ond ampt empfangen

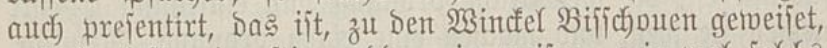
buto fie Yaffen intejtirn obder ein meifen, wie wol folchs nicht ber beruff noch \&eben, jonbern bejtettigung folchs beruffe, vno nicht von noten gemejt iit, Denn ber beruffent Sfarrber, wol an joldb bejtetigung hette fónnen fein Sfarrampt aus richten, gleich) wie bie Maccabej, fo ont bas geborne und beruffene Priejter waren, Dody vmb friedes wiffen fich Demitigten, vnto von Den 2Antiochis vno Demetrijs fonigen zu Syrien (melche Doch eitel Seetoen onto jire feinto waren) fich Yieffen beitettigen. ${ }^{1}$ )

Soldye Demut habent wir vnjern 2fntiochis ond Deme= trijs bis her auch angeboten, bas fie vnier Bfarrhern madyt forten haben zu [ $\{$ ]. Geitettigen, ob fie tool onjer feinde weren, Damit fie nicht zu flagen Getten, wix weren

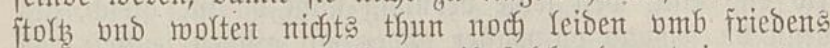
bns einigfeit roflfen, 2xber weil jolche demut juen ver= ichmeht ift, jonbern wollen vits jchlecht zu jrem (Erejent bnd andern gremlen vereibet vno gezmungen kaben, who

1) 2. Macc. 13,23 f. $14,23.26$ ? 
bnts oriber tobten bno plagen, fols jnen finfurt nicht mebr io gut merben, Sie follen jren gremel vnd Exejem behalten, wir wollen jehen, wie wir \$ffarrbern vno \$re $=$ biger friegen, aus der Tauffe ond Cisttes mort, ont jren

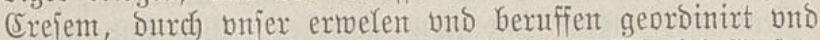
beftetigt, Bno wie mol wir bis her ben $\mathfrak{W}$ intefel Crejem Gaben gebuldot, wollen wix boch binfurt dem Bepitlidyen, halitarrigen, onbusfertigen, morbijchen, blutburitigen, gremel zu trob bno ribder, da fin erbeiten, das ein Bfarrber bey uns, zum vnteridyeid feiner 23 incfel 2 senge ond onjers beruffs, die gejalbeten finger mit laugen, falb vno jenffen fol reiben, vni des Endechrifts Caracter odoer malzeichen, abrwafichen, vnto jeinte platen wachjen Yaffen, Wollen bie Windel wenher odber Bifichoue, joldye vmier beruffene \$farrbern nicht fír gewenket halten, Das mitgent fie rol laffen, ber Teuffel bitte fie brumb, bnt gefen von ber want, io zu itofien fie Den fintoent nicht. Şat Doch Dex Bapit jelbs jut jeinen geift $\left[\Omega 4^{\mathrm{b}}\right]$ ricken rechten geboten (twie tool alt Den alten Setern ge $=$ nomen) Man folle Der Reber wenke Dober Drbinim fitr

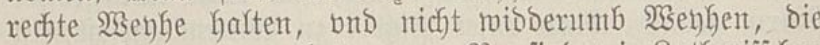
fo bon Rebern gemenhet waren, Na find wir \&utherifichen nicht Sieber, Das mufjen die Sapijten jelbs befenten, Darumb jollen fie unjer Wethen ond Droinim Yaffen recht jein (aud) nach jremt eigen Bepitfichen recht vnto gebot) ond follen feinten bandf da fur Gabent, Dent wir haben (Śbtt $\Upsilon_{0 b}$ ) Das mort Ssottes rein bno gewis, wie es ber Bapit nicht hat, $\mathfrak{S O}_{0}$ aber Sbottes wort rein und gemis ijt, Da mus es alles jein, (jottes reid), (Érijtus reich, Seiliger geift, Tauffe, Sacrament, Bfarrampt,

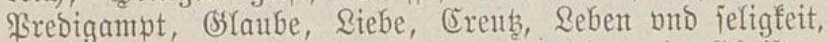
bnd alles was die Sirchen haben jol1), wie Chriftus

1) Cochläus repliciert: „Die Lutherisch Tauff hat nicht so krefftige wirkung als vnser Tauff, rnd das Sacrament des altars, empfahen die Lu'herischen nit wirdiglich noch zur seligkeit,... Sie haben auch nicht das recht Euangelium, sondern den text vom Luther an vil hundert orten gefelscht vnd vnrecht ausgelegt. Sie haben keyn vergebung der sunde, vnd all yhre Absolution ist nicht eins hellers wert ... Jr 


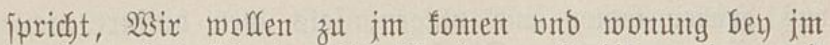

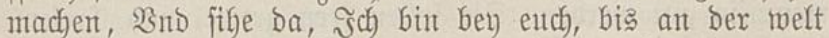
ende, Db aber ber Bapjt grewel nicht molt vnjer mort fúr bas recht wort halten, da ligt wns nicht an, Sie wiffens wol anders jun jrem gerwiffen, $\mathfrak{S i r}_{\text {ir }}$ find gleich wol gemis, das mir Grottes rort haben.

3no ob fie firt geben, die Reber jo gerwenget haben, fino Biffupue geweit, Darumb hat ber Bapit wno bie Beter ir \$Senfen Iaffen gelten, Das ijt mar, Sie fund Bifichoue geweit, aber nicht Furiten noch herrn, Son= [Q] bern wie Sanct らjeronymus aus Sanct \$aulo berweifet, ijt Biffichoff vno Sirarrber ein bing gemeit ${ }^{1}$ ), Bno Gaben folche Seber vnt antore Siffichoue auch), viel nicht io groffe \$farben obser (wie mans nentet) Biftumb gehabt, als ibt ein Sifarrber zu Iorgam, Lebpbig obder (5rymme, Kat, Denn eit igliche Stab hat einen Biff

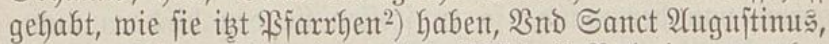

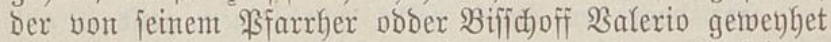
obser georbinirt waro zum \$rebiger, bno nach jeinem tobe, an jeine ftat Biffichoff maro, hat nicht eine groffer Bfarre gebabt, Denn vnjer $\mathfrak{B}$ farre zu 2 ittemberg ift, ift fie anders noch jo gros gemeft, Noch ift ber jelbe fleine Biffichoff obDer \$farrher zut Şippon Sanct 2luguftimus, groffer jum Der Ebriftenleit, weder fein Bapit, Earbinal

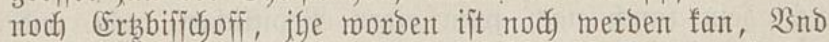

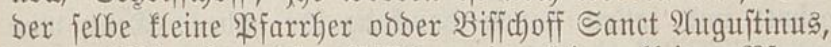
hat viel \$farrber obser Biffigue jun jeiner fleinen \$Farr= hen gemenhet uno georointixt (ba noch) fein wetbiffichoff noch Jitritenbiffichoff, jondern eitel \$farrber maren) bie vout andern Stedten begerb vno beruffen ruxben, Wie

pfarrampt ist ein verwüstung der kyrchen. - Jr gebet ist ein stanck vor Gott, wie des armen Judas . . y yre newe geseng vnd Deudsche lider sind ein lauter wolffsheulen, widder die schaff Christi ... was guts ynn seyner Sect befunden wird, das hat er der kyrchen abgestolen, geraubt vnd entpfirembdet." Bl. F 4 b.

1) Hieronymus Comment. in epist. ad Tit. 1, 7: „Idem est presbyter qui episcopus ... episcopi noverint, se magis consuetudine quam dispositionis dominicae veritate presbyteris esse majores."

${ }^{2}$ ) B besser "Pfarrherr". 
twir aus viljex Bjarben zu 2 ittemberg, andern Stebten, jo es begent und bet fich feine Gaben, orbinim vno jent= Den mugen, Dent orbinim fol heiffen und jein, beruffen vnd befelfen bas \$farrampt, h) $a=\left[Q^{b}\right]$ ben (Shriftus vno feine Rirche on allen (Erejem vnd Blatten, wo fie jun ber welt ift, jo wol als fie bas wort, tauffe, Sacrament, geift vno glauben haben mus.

Sno hie ift aber mal not zu mercfen untericheid zmiffchen bem gremel und Seeiliger itete, Denn bie Wintel herrn faren zu hoch bno zu weit, mit jrem 2 englen vno Erejem, gebent furr, als jeien fie bie Yeute, jo bas Sacra= ment machen obser 2 andren, quaji ex opere operato, dą ijt, Sie rbumten fich joldber gervalt, bas alts frafft jres Erejems odoer Wenge, Durch jr iprechen, vber bas brod und wein, als bald ber leib vnto blut Egrifti, (mie wol Durch rirfung (Sottes) Da fein muffe, Darumb fie audf) rhimten, das fein Engel noch die Mutter Bsottes, obder einiger Seilige auff erben fonne $23 a n d\left(e n{ }^{1}\right.$, vrjache ift, Sie find mit bem Erejem nidyt gewenget, vno haben feine platten, Wenn man aber grund von jnen fobdert, wo mit fie bemeijen wollen, bas ssott jeine madht aljo an jren Erejem (ba bsott nichts von meis) vnd an ir opus opera= tum gebunden habe, So weifen fie one jun $\mathrm{jr}$ Schlauraffent lanb vnd jagen, (Es jet) Die meinung Der Sirchen, Das ijt gar gutg, Dirffen nichts mehr.

1) So lehrt die dem Ende des Mittelalters angehörige Schrift "Lauacrum consciencie omnibus sacerdotibus perutile" in Cap. 5 ,de magna dignitate sacerdotum": „Deus sacerdotes exaltavit super omnes creaturas. Si conditione estis homines, dignitate estis super omnes homines. Nam sacerdos est altior regibus, sanctior angelis et creator sui creatoris. Sicut mundus nihil esset sine luce, sic ecclesia nihil esset sine sacerdotibus." Beliebt ist der Nachweis, dass ein Priester noch grössere Würde habe, als Maria. So lesen wir in dem .Novum beatae Mariae psalterium" (Druek aus dem 15.Jahrh.) folgende kräftigen Antithesen: ,Maria est mater Dei passive se habendo, sed sacerdos est pater active se habendo; Maria tantum semel genuit Jhesum parvulum, vos autem sacerdotes gignitis eum infinities ad nutum; Maria concepit octo verbis [Luc. 1, 38 Ecee ancilla Domini, fiat mihi secundum verbum tuum], sacerdos gignit quinque [Hoc enim est corpus meum] etc." 
Darumb fo merfe bu und miffe, das foldfe lere, Des grewels Yere ift, bas ein Frie $=[\mathcal{L}$ ij] fter aus frafft bes Erejems dober wenhe, das brod wandle jun den leib Shrifti, als ex opere operato, Durch) jr (prechen odoer thun, (s) ift alles io garitig exlogen vito exituncfen, als Der Ereiem jelbs ijt, Die Şeilige itete obser Sirche leret aljo, bas weder \$srieiter nod) Ehriften ein einiges Sacra= mtent madjen, auch bie heilige sfrrijtliche Sirche jerbs nicht, Bnjer ampt heifit, ond fol jein, nicft madyen noch $\mathfrak{W}$ anto= Yen, jondern alfein reiffen obser geben, $2(1$, , ein \$Ffarrher obser \$reoiger, madyt nicht bas Eruangelion, vno burch jein prebigen oboer ampt miro fein roort nicht zum Euan= gelion, Sonit muit es alles Euangelion fein mas er reben finte, Sondern ex reidft alfein vno gift burch fein pre= bigen Das Enangelion, Denn das Enangelion ift zunor

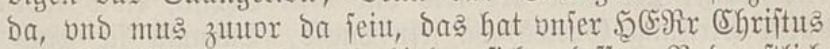
gemadyt, her gebracht vno finder fich gelaffen, \$no exitlich)

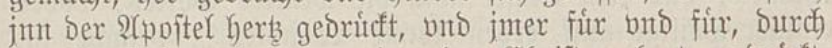
Der 2(poitel nach fomen jun ber EGriften Gerbs gebricft, ba neben auds eufferlich jun die butchitaben vno biloer rafien malen, 2Afjo bleift nichts im \$FFarr ampt odber \$rebigt ampt, bent bas einige wercf, Remlich, geben obder Darreichen Das Euangelion, von EGrifto befolfen zu Fre bigen, Der Bapit wno feine gremel Gaben tod viel Yere gemadyt aus jrem fopff, 2uber es heifien nicht brottes mort noch (Enangelion.

$\left[\Omega i^{b}\right]$ 2A[jo ber Teuffer macht feine Tauffe, Sondernt (Ehriftus hat fie zunor gemadyt, Der Teuffer reicht vno gibt jie alfein, Denn ba itehet Chrijtus oromung, Die ift, wie Sarct 2luguitimts ipricht, 2 fccebit verbunt ao element=

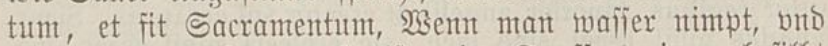
thut fein mort ba zu, io ifts eine Iauffe, mie er befilfyt Matthej am Yebten, Ssehet Gin, Yeret alle Sgeiden, vno Tenffet fie im namen des Baters, vno des Sons, vno des Şeifigen geifts. Diejer bejelf bnto einjebung, bie thuts,

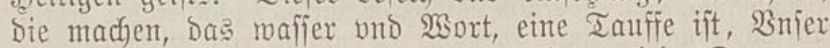
mercf oboer thun, ex opere operato, thuts nicht, Dent es heiffit nicht barumb eine Tauffe, bas ich Teuffe odoer bas werd thu, wemt idf audf heiliger bent Sanct Sobante? 
Doex ein Engel were, Condern barumb heifit mein Tenffen

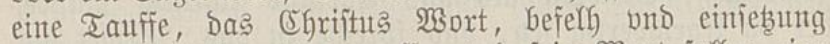

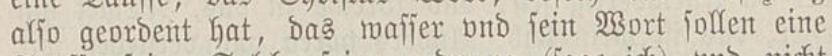
Tauffe jein, Soldge feinte oronung (jage idj) ond nicht unfer thun oboer opus operatum, macht die Tauffe, Snjex thun aber reidgt allein bno gibt joldje Tauffe, georbent vnd gemacht burch SGriftus befelf und einjebzung, Darumb ift bnd bleibt ex alfein, ber einige, rechte, emiger Tenffer, ber jeine Tauffe Durch bnjer thun odoer bienjt teglich auts teilet, bis an Den Jungiten tag, Das unjer teuffent billich folt Geiffen, ein barreichen obser geben ber tauffe Cgrifti, gleidf wie bit $=[\Omega i i j]$ jer prebigt, ijt ein barreidyen bes morts Ssottes, Man mags aber vnier prebigt obser tauffe nenten, Doch mit dent veritand, das nicht burch vnjer tyun eine tauffe obder Sottes twort merde, Sondern, das mirs bon Cgrifto empfangen wno andern geben obser aus teifen $\mathfrak{S}$ ie ein haus fnecht, mag bas brod jo ex aus teilet, jein brod beiffen, doch, das ers jeines berm brod beritebe, ond zutueriteben gebe.

Arljo auch, Das brod ond twein Cyriftus Yeib vnd blut merde, ifit nicht vniers thuns, iprechens, nod toerds,

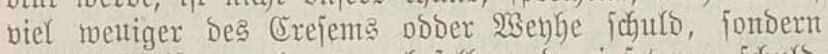
es ift chriftus oromung, befelf ono einjebung idfuld, Dex jelbe yat befolfen, (wie Sanct \$aulus jagt jum Dex eriten zun (Sorintbern am elfften) $\mathfrak{G e n t}$ wix zu famen foment, und jeine twort bber brod bno twein iprecten, io fol es jein leib ons blut jein, Das wir bie aud nidfyt mebr thun, denn reichent ond geben brod bnto twein mit

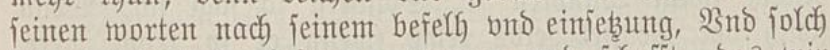
jein befelf bno einjebung vermag vno ichafft, bas twix nicht fiflecht brod bno wein, jondern jeinen leib uno blut Darreichen bno empfaben, wie feine twort Yauten, D2SS ijt mein Yeib, DथSS ift mein blut, Das nidyt vnjer mencf oboer iprectien, fondern ber befelf bno ordnung Egrifti, das brod zum Yeibe, bnd den wein zum blut macht, bon anfang bes exiten Arbenomals, bis an ber welt [ $\Omega_{i i j}{ }^{b}$ ] ende, und burch unjern bienit obser ampt teglidy gereidyt mirb, Denn wir Goren bieje wort DâS ift mein Yeib, nicht als jun ber perion Des \$farrbers oboer bieners 
geiprochen, Sondern als aus Égriftus eigentem munde,

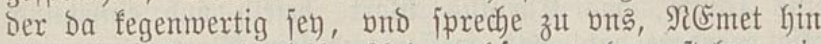
efiet, bas ift mein Yeib, 2Unders horen und veritehen wir fie nicht, wiffen twol, bas des \$farrhers odber bienters leib nicht im brod ift noch gereicht wird, So boren wir Den befelfy vno orbnung ba ex ipricht (Soldys thut zu meinem gedechtnis) auth nidyt als jun bes Pfarrbers perion geiprodien, Sondern horen Egriptum felbs, burchs Bfarrbers mund mit vns reben bno befelfen, das wir folfent brod bnt wein mit feinem toort (D)S ift mein leib zc.) nemen, vnd feinem befelh nach, barin feinen Yeib vnd blut efien bno trincfert.

Denn Das muifen mix gleuben vno gemis jein, bas Die Tauffe nicht vnjer, fonbern Egrifti jet), Das Enan= gefion nicht onjer, fonbern Efrifti jer), Das \$reebig ampt nicht vnjer, jombern (Efrifiti fet), Das Sacrament nicht vn= jer, jondern Ehrifti jey, bie ichliffel obder vergebung ond behaltung Der funden nicht vnjer, jondern Ehrifti ien, Summa bie ampt ond Sacrament find nicht vmjer, fon= Dern Cfyifti, Denn ex hat joldys alles geordent ond hin= Derfitch gelafien jum Der Sirchen, zu vben und [ [ 4] ge= braucjen, bis an ber welt ende, vno leuget noch treuget vuts nicht, Darumb fonmen wix auch nichtes anders braus madfen, Sondern miffien feinem befelf nad thun ond jold's galten, 230 mirs aber endern obder beffern, jo ijts nichts,

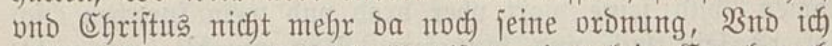
mil nidht jagen, wie bie \$apiften, Das fein Engel noch Maria fonme wanblen $2 c$, Sondern jo jage ich, Went gleich) ber Tenffel jelfo feme (ment ex jo from mere, bas ers thun wolte obDer fintste) 2(ber id jebse, bas icbs bernach erfitre, das ber teuffel fo Gerein jum das ampt geid)lichen were, odoer hette fich gleich lafjen, als jun mans geitalt, beruffen zum \$farrampt, vno offentlich jum Der Sirctien Das Euangelion gepredigt, getaufft, Meffe ge= falten, 2(bjoluirt, Sno jolche ampt vno Sacrament, al ein Bfarrber geubt vnd gereicht nach bem befelf vno orbmung (sfrifti, So mujten wix bennod) befenmen, das Die Sacrament recht weren, wir rechte tauffe ent= pfangen, recht Euangelion gefort, recht 2lbjolutio friegt, 
recht Sacrament bes reibs bno bluts Shrifti genoment letten.

Denn es mus vnier glaube vno Sacrament nicht auff ber perion ftehen, fie fen from obser boje, getwenget obder ongetwethet, beruffen obser eingejdylidyen, ber teuffel ober feine mutter, Sonbern auff SGrifto auff feintem $\left[\Omega 4^{\mathrm{b}}\right]$ mort, auff feinem ampt, auff feinem befelf bns ordnutitg, wo die jelbent gehen, da mus es recht gehen und ftefen, bie perion jet) wer und wie fie rodle odser fonne, Bnto jo man die perjon jolte anjeben, twas ifts fiur eine \$rebigt, tauffe ond Sacrament, fo Jubas vno alle jeine nach fomen, nach sfyriftus befelf, gethant ond gereidyt Gaben vns noch thun, anders, Denn bes teuffels prebigt, tauffe, Sacrament, das iit, Durchs teuffels glieder, vnts gereidbt bnd gegeben? Uber meil Das ampt, Wort, Sa=

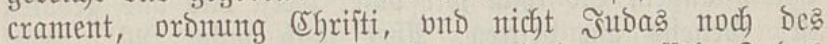

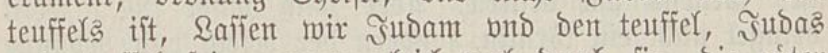
und tenffel jein, nemen gleich mor burch fie, bie gitter Chrifti, Denn Da ริubae zum teuffel fur, nam er fein 2lpoiter antpt nicht mit fich, fondern lies es fintor fich), bno friegts Mathias an jeine ftat, Die ampt bno Sacra= ment bleiben juter bar jnn Der Sirchen, bie perion endern fich teglich, Shan beruffe ond jebe nux brein bie fie fon= nen ausridbten, fo geben vno geidjeben fie getwis, Der gaul ijt gezeumet bno geiattelt, Sebze orauff audf). einen nacteten fnaben ber reiten fan, io gejet ber gaul eben io tool, als wenn in Der fieijex obDer Bapit ritte.

şch babe jun meiner jugent einte Sijtorien gebort, toie eins mals ber Prebiger jer ploblich frant morden als ex ibt hat follen prebigen, Da jet einer fomen zut jum und habe fich [M] exbotten firr jnen zu presigent, ond eilent bie bletter in bud Gerumb gemorffen, bnto eine prebigt gefafjet, Şat aber jo fóftlicf und exnjtyich ge= prebigt, Das die ganbe Sirche weynten muíte, $2(m$ ende hat ex gejagt, Wolt jr wiffen wex ich bint? Juch bin ber teuffer, und hab euch bumb aljo exnftlich gepredigt, auff bas ich euch beite billicher vnd herter verflagen fontu am כoungiten gericht zu etwrem grófiern verdamnis, went jre nicht gebalten Gabt, Sb dieje Şiftorij max jex obser 
nicht, las ich jun feinen wirben, Das meis ich aber wol, bas fie ber marbeit nicht vnefnulich ift, vno von ber heubt= jachen redjt jagt, Nemlich, bas ber tenffel mol fan bas mort, bie ampt bno Sacrament EGrifti Gabent ond geben, Denn ex fich junt einen (Engel Des Yiechts, vnt jum die Maiejtet Bottes jelbs veritelfen fan, Matthej am vierden

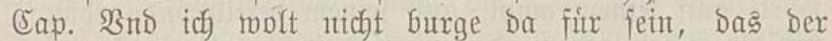
teuffel noch nie fet) \$farrher obder \$rebiger gemeit, (5: find wol io icheuffliche bing, burch ettlicbe \$farrber ond Bfaffen geicheben, mit zaubern vnd gaudfeln, vno ber gleichen teuffers geicheffte.

(Sebets Dod) autd) jun dent Creaturn ưlio zu, Das vnjer thun obber mercf nichts ichaffet, fondern alfein Siottes befelg vno orbmung, 2Ars, went wir pflugen, feen vito pflanken, So thun wir bujer mercf bas vns geboten

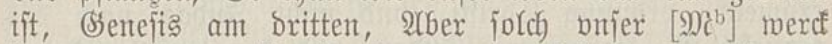
bringet nicht ein fómlin, jonbern ber befelf vno orbmung (sottes, Da ex zux exben ipricht, Benejts am exiten (anpite $\left.{ }^{1}\right)$, (5s bringe die exden gras, fraut ond afferfet) beumte, twie audf Sanct $\mathfrak{B a u t u s}$ inn Der exiten zun (Eho= rinthern am Dritten jagt ${ }^{2}$, Der ba pflants ijt nichts, Der ba begenfit ift audf nichts, Sondern Gott Ders gebeyen gibt, (5) thu mu ber Teuffel obser menjid, ein fabaldf odber fromer, joldh werct, ex pflanbe, jee obser begiffe, fo gebet gleich wol bie oromung bno befelly Srottes fír fich, vno bie eroe bringet jx frudbt, Sttem, Maan und $\mathfrak{B e i b}$

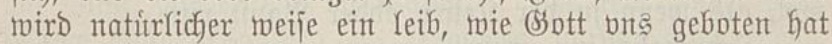
bno geichaffen, 2tber aus bem jelben mercf wird nimer mefyr fein frucfit ober finto, Sondern aus bem befelf ond orbuung, ba (Sott ipricht, Seid frutchtbar vno mebret euch), Senn mu gleich Der Teuffel Man vno meib zu jamen bringt, ars im ebebruch vno hurerey gejchicht, Dennoch gehet (Sidtes orbunng fúr fich, but twirb einte

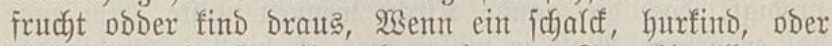
bieb, jun ein frembo erbgut fompt, So gilt alles gut eben jo viel, als ments ber rechte erbe hette, arfjo gehets
1) 1. Mos. 1, 11 .
2) 1. Cor. 3,7 . 
Gie mit ben Sacramenten audb, SBir thut waffer vno wort zu famen, wie er vns gebent, 2 (ber jolch vnier thun madyts nicht zux Tauffe, Sondern (Efriftus befelf ond oronung, SBir thun nach jeintem gebott, brod vnd twein

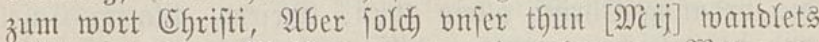
nicht, Sondern Shriftus mort vno orbnung, waent mu hie ber Teuffel odser jein glied, die oromung Egrijti Gielte und Darnach thette, fo were es gleich mol bie rechte Tauffe vno Sacrament, Dent Cofriftus roird vutbs Teuffels oboer bojer Yeute miflen fein lingner, nodg be= trieger jeiner Sirchen, fondern Teuffet fie, vno gibt jr jeinen leib vno blut, es fen bie Gant, ba burdh ers thut, mes bno wer fie wolle.

Befentent Doch die ßapiften jelbs, Das bie Tauffe im icherb oboer ipiels tweije gegeben, ier eine rechte Tanffe, wie jun Sifitoria Erctefiaftica von Sanct 21thanajio geid)rieben ftehet, das ex mit feinen gejellen vnd findern am meer ipielet, vno teuffet fie, wie evs hatte gejegen jut Der firchen vom Sififchoule, SHo Der Biffichoff Allerander, Gielts fir eine rechte Tauffe bno tauffet bie jelben finder nicht midoerumb, Des gleichen liejet man jun ben aegent= ben, bas ettliche ftod narren wolten ben beiden bofirm jum einem jpiel, vno ber (Efyriften fpotten mit ber Tauffe, als were es ein nerrijcher, lectgerlicher, glaube, burchs waffer wollen beilig werben 2 , Afber Dem einem erjobein mittem im ipiel ein jajrifft, bie fielt jm furr bieje toort

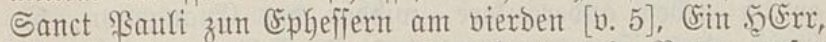
Ein glaube, Einte tauffe, Erin Grott ond Bater vnjer aller 2c. 2̂As jolcher ichrifftt mard er gleubig [M ij ${ }^{\mathrm{b}}$ ] bno nam bie ipiel Iauffe fur eine rechte Tauffe an, macht einen ennt braus ond befandte (Shriftum fret), Da aber bie Seiden fie alfe griffen ond meineten, bie ftocf=

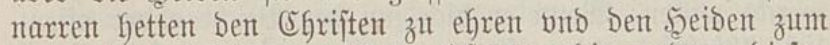
trob, foldh fpiel angerichtet, lefterten bie andern biejen einen jren gejellen wnd iprachen, Er were toll morben, (Fr aber blaib bey jeiner Tauffe vito glauben, vno lies fich oxuber martern, ond fur aljo vom jpiel gen Gimel. 2rber bie Bapijten find blind und blinben Yeiter, jeben alfein auff jre perjon und wercf, gerade als mujte 


\section{4}

das Sacrament barumb merben odber nicht, bas fie joldye perionen fint ond joldf werd thun, fragent nichts nad) Dex oromung obser einjebung (Shrifti, Bno es fan bod) ja vnjer perjon ono merd nichts ba zu thum, (5) mus Die oromung Ehrifti allein thun, Erejem, \$latte, Eajel vno bes gleidhent geprenge, hilffit nidht, Darumb wiffen fie fitr war jelbs nicht, fonnen audf) nicht wiffen, was fie macken jun jren Meffen, Bno bas ich ein mal auff bie frage antworte, bie ich brobent thet, Remlich, wie mant fich Galten folle gegen ben Bfarrbern im Bapitum, weil

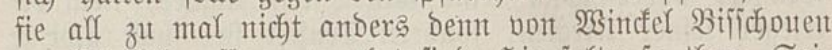
zur Sindel meffen gemenhet find, Site fortu fo thun, Sei=

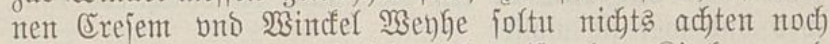
anjeben, als bie gemislich nityts ijt, ber Sirchen wno [Miiij] bir aud nichts nitbet nod) Dienet, Sondern, ba ichatw auff, bas ex bas \$farrampt jmen hat, weldys nicht jein, fondern Egrijti ampt ijt, $2 a$ S bich auch nicht jrrent, ob ex fey orbentlich beruffen, odoer habe fich Ginein ge= fauffit obser gebrungen, twie ex Ginein fomen iit, wber

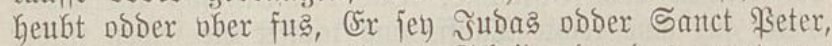
ba Yas bir nidyts an Yigen, Scheibe du das ampt von ber perionen, vnd bas Geiligthum vom gremel.

Wolan, Er ift \$farrber, und Errijtus gat arjo im Bapitum unter bem gremel fein heiliges liebes \$farrampt erhalten, Senn ex un predigt Den text Des Euangelij rein, fo iprich, bas ijt das heiligthum errijti, Frebigt er ba neben andere Yere, wiober bas Enangelion, So fprich, Das ift ber gremel bes Teuffels, Der Das twort veritoret, Went ex Teuffet und Gert darin bie oromung Egrijti (ob ex gleich) ber Tauffe rechten veritand nicht Gat) So iprich, Die Tauffe ift recht umb Efriftus ord =

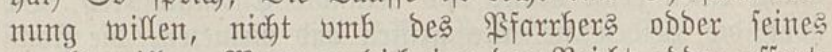
wercts willen, SSent ex Dich jun ber Beicht obser offent=

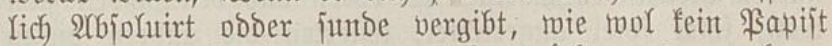
jun ber welt ijt, ber recht veriteben módgte was vergebunts Der jumben jer, Sie roffjen nidft (wie alfe jre butcher zeigen) ob fie fduld obser pein wergeben, Da fere ou bidf nichts an, went er bie mort vno meife helt, wnd bich jum

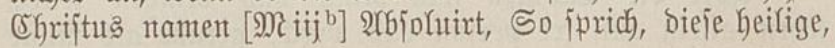




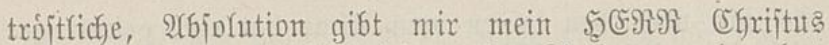
felbs Durch jeine ichlitifel, die ex ber firchen gegeben bat, $W_{D}$ ex bix ba nebent buffe auff legt, als ba mit bu folt fur beine junde gnug thun, So Dence, Sibe, bas ift Dex gremel, ber mix bie enbjolutio Egriti veritoren mil, als folt mir Shrijtus jeine gnabe umb mein verbienjt ver= feuffen, Meinem nebeiten firx ber welt, wil ich gung thun, too ich im zu nabe geweit bin, 2(ber fiur Srott, itehet meine gung thun, Shrijtus jelbs mit jeinen theuren blut, Da bet bleibe idf und barauff berlajie idg mich.

23enn er Mejije helt, fo merfe mit vleis biefent vnter= fdeid, So fern ex die ordmung bno eimjebung Shrifti Gelt, da zu bas Sacrament aud andern reicht vno gibt, fo wijie, bas ba gemis Shrijtus leib bno blut ijt, omb

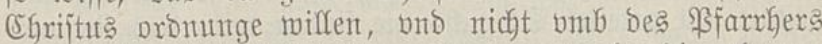
mercf obder Geiligfeit miflen, So fern ex aber bie orduntg but meinung Efrifti nidgt gelt, fonbern endert bnto ber= feret, ijt nicht not, das du gleubeit, es jen Ergrifus Yeib vno blut, ฐa du folts nicht gleuben, gleich wie von antoen

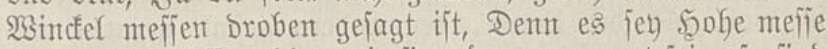
oboer Frute mefle, obder twie fie mitgen genentet fein, fo find

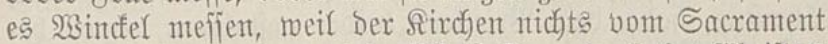
gereidft nod) gegeben wivd, [MM 4] Denn Da itehet Shrijtus ordmung ond einjebung flar, SDSObg thut zu meinem gebechtnis, 2 as follen wix thun? bno wie Geifft bas, Soldys? Remlick), das ex thut, bno mit wercfen bno wortent

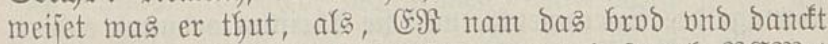

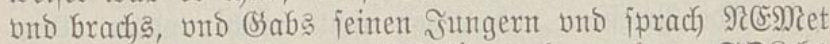

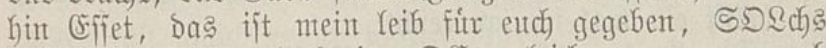
thut zut meinem gebechtnis, DES gleidjen nam ex auch

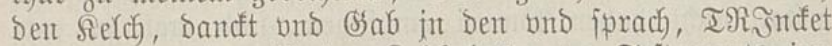
alle Drats, Das ijt ber fielch Des neme Teftaments inn meinem blut, Das firx eud vergoffen wird zur vergebung Der funden, SSldys thut jo offt jrs trindet zu meinem gedechtnis, Sol nu Egrijtus ordumng gebalten terben,

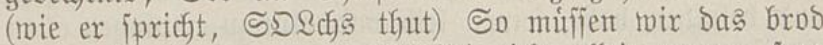

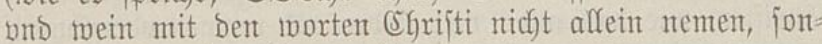
bern geben und andoent reichen.

Darumb toem ein Bfarrber in Diterfeit obder jonjt

L uther, Winkelmesse. 
Das jar wber ben Yeuten vom âltar hat eine geitalt ge= reicht, bas ift warhaffig das Sacrament, wie wol affeiu bie helffit gemeit, Die ander geitalt, jo er nicht gereicht, jonbern allein fur jich jelbe genoffen, halt ich jer nidjt bas Sacrament (bis fie es bemeijen) fondern ichlecter mein gemeit, らaben aljo nicht alfein Den হetjen bas halbe $\left[M\left\{4^{b}\right]\right.$ Sacrament geraubt, vnd bentoch jun forchem raub, als were es feine funde, Meffe gebalten, Sondern auds (iic) jelfs mit berautbt, vnd da zu jich jelbs juchendfich ge $=$ nerret bnto betrogen, vno wein fúr bas Sacrament ge= nomen, Wo bleibt bie jr faule aus rede, ba jie jagen, Ebriftus babe im Albentomal beiber geitalt allein ben \$rieitern gegeben, Dar nach hab Die Sirche, auffer Ehrijtus befelly, Durch eigene barmberbigfeit, Den Senen bie eine geitalt mit geteilet So jidbs hie finten wil, bas jie aud Den Friejtern wno jnen felbs, nicht mehr bent das halbe Sacrament Gaben gegeben, 2fuch mem die Friejter inn Der Marterwochen obser auch fonit im jar das Sacrament empfaben, vno nicht jelbs Meffe Gielten, muiten fie eben jo wol, als bie Seven, Der andern geitalt geraten vno emperen, vnangejeben vno vnbebacht, das fie jelbs jagen, Shriftus Gabe Den Friejtern beiber geftalt zu nemen bes folken, 2Ulfo feim reimen fich) jre eigen mort vno wercf zu famen, Summa, Sie mitgen aus der $\mathfrak{B s t h t e l}_{\text {meffen }}$ macken twas fie fornten, wir wollen ond jollen fie fur fein Sacrament halten, fondern fúr einen gremel vnd zer= itorunge bes Sacraments, weil fie Orriftus orbmung entort,

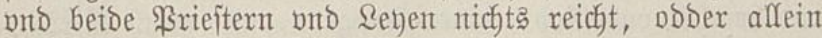
Die Gelfft ein mal im jar reicht.

Die Sirche obder gemeine EGriften, io [N] beider geitalt nicht haben fonten empfaben, find wol zul ent= ichutldigen, als bie betrogen vno verfíret finto burch ben Enodyrift, ono haben inen eine geftalt aflein laffen geben, Denn es ift gleich twol ber glaube feft ond rein blieben inn Der Sirctjen, das Shriftus im Sacrament eingejebst vno befolgen habe, feinen leib vno blut zu empfaben allen Ehriften, wie das affes viel Yieber vno retmen vberzengen,

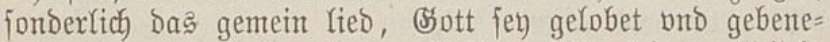
Deiet, Der vns jelber bat gejpeijet, shit jeinem fleijche 
ynd mit feinem blute, Bnd bar nach, Ş( heiligen warleidgnam, Der von beinter mutter Maria fam,

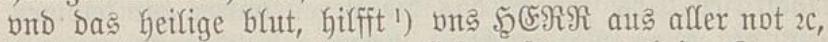
Mit biejem vno ber gleichen liebe, fo man bein Sacra= ment, ia inn proceffiton ond Sirchent gejungen, hat bie Sirche offentlich zeter und mivrbio vber Den (Endechrift vno

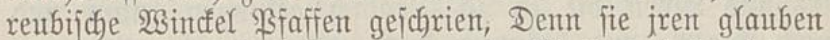
Gie mit offentlich befentet, das jx Egriftus beise feinen leib ons blut zux ipeije georbent onto gegeben habe, vno gebire ir nach (shriftus befelf zu empfahen, wie fie gleubet, befentet vnt Gerbilich begerd jun biejem Yiede, Fur war burch foldjen rechtent glauben begiro vno fret befentnis mibser bie Sirchen biebe onto reuber im Bapitumb? Gat Ehriftus feine aufferwelten exhalten, Sno barnach ire vnwiffenbeit, bas jie ber eirten gejtalt allein haben miffien braucben, Durch ber $=\left[\Re^{\mathrm{b}}\right]$ gebuntg ber junde, nicht zugeredjent, wie ex ben 2(pofteln viel gebrechen zu gut hielt.

Bnd wie miffen bie Shriften thum, jo jun ber Titrfen) gefangen, bas Sacrament nicht Gaben fommen, ond affeit ficf benigen laffen am glauben vno begirbe, fo jie zunt Sacrament und oxomung Efrifti haben, gleich wie bie ibenigen, io fur ber Iauffe fterben, bno boch Durch jrent glauben wnd begiro zur Tauffe jelig merden, Wie mutent Die finder s̃irael zu Babel thun, da fie gar feinten S5ottes bienft haben fundten zut serujalem, on allein im glaubent unt herblichem begirbe vnt jefnen, 2 flp went gleich bie Sirche were Durch Den Sapit, Des Sacraments gar be= raubt geweit, Nod) meil bie oromung (Efrifti jum jrent herben mit glauben nno begiro bliebe, mere fie dennoch ba Durch wol erfalten, wie Dent ibst zu vujer zeit viel fint, bie bes Sacraments Yeiplich gar emperen, ehe fie Des sapits gremel efren vnt ftercfen mollent jun ber einten geftalt, Dent Ehriftus oronung vno glaube, find zmen merct Sonttes, bie afles vermitgen.

1) Die Ausgabe von 1534 liest wohl richtiger: hilff. Vgl. Hoffmann von Fallersleben, Geschichte des Kirchenliedes. 3. Ausg. Hannover 1861 S. 205 f. Goedeke, Dichtungen von D. M. Luther, Leipz. 1883 S. 60 f. Schleusner Luther als Dichter. Wittenb. 1883 S. 117. 
Sibe aber bas genant lied an, obs nicht ein chrift= Yidf rein fein befentnis wno won einem redjten geijt ge=

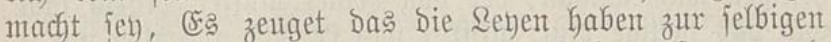

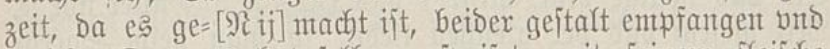
fpridyt, Der bns bat jelber geipeijet, mit jeinem fleifoche bnd mit jeinem brute, $\mathfrak{E e x}$ find fie, die, ßNS jagent?

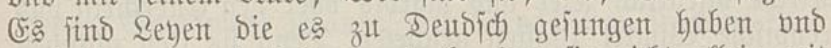
noch fingen, ond befennen Dod, Das fie nicht alfein mit einer gejtalt mit feinem fleifche (melchs fie mol muiten, bas es (mie bns Geute die jofraxfen Papijten fux Yegen) on blut nicht jein fan) jonbern aud mit ber andern ge= ftalt, mit feinem blut geipeijet find, Bno vber aus ijt Das grimblich vno (Egrijtbich gerest, Da ite jagen, Ehrijtus gabe fie felber geipeijet, Nidjt Der \$farther nod \$riejter, Son= bern Shrijtus jelbs jey ber fpeijer, dex alda Durch jeine oronung, bnd nidft Durchs \$rieiters merd, vns jeinent reib uns blut gebe. Sttent, das fie es nicht ein opffer noch gut rercf, wie es ber gretwel gelt, vno andern ver= feufft, jondern eine fpeije fix jee jeelent rhument $2 c$, alber id) mus auff horen dis Yied zu preijen, (5) jolten jonit die gremlidben, veritoditen, Sottes Yejterer, wo jue es exfuren, wol binfurt bas lied aud verbieten, bas fie sody jelbs bno alfe jre vorfaren gejungen haben, bns getwislich viel jar bor Dem Suther gemacht ift, wie fie fonit viel lieber berbieten, Do Doch eitel Bsottes mort vnd vnjer glaube jun gejungen wirb, auff bas fie fich jelbs, ja greifflich bar geben, als Den rechten grewel jun ber şeifigen itete, ober

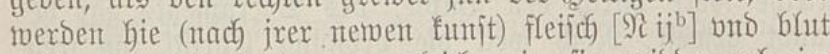
auff eine geitalt Deuten, gleich toie fie wibserumb im abentontal, eine gejtalt autif beibe Deuten, Denn mie jie es feren und machen, jo iits recht, Wrie es aber Gsott jerbs

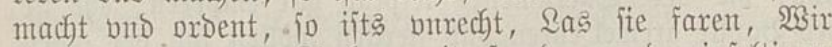
fungens jun vniex fircben mit freuben ond einfeltigem gewiffen, veritande bon beiber geitalt vom fleijch vno blut, wie bie roort flerlich lauten vin geben.

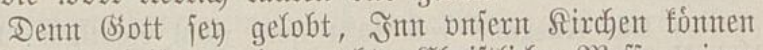
twix eintem Shrijten, eine rechte Shrijtliche Mrefje zeigent

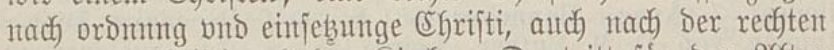
meinung Corijti uns Dex Sirchen, Da tritt fiur Den Sutar 
vilex Bfarther, Biffctioff, obser Dienter im Bfarrampt, recht vno redfich bnt offentlich beruffen, zuutor aber imt Der Tauffe gerwenket, gejalbet, ono geforn zum Frieiter Ebrijti, ungeadyt Des 23 incfer Erejemts, Der jingt offentlich

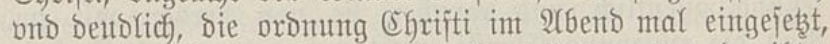
Simpt bas brod und wein, Dandt, teilets aus bno gibts,

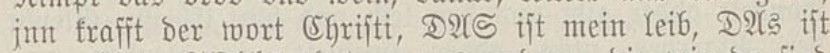
mein blut, SDldbs thut $2 c$, bnts andern, bie wir ba find vno empiahen mollen, Sno twir, jonderfich, jo bas Sacra= ment nement wollen, fnyen neben, Ginder, und vmb ju ber, man, weib, jung, alt, Gerr, fnecht, fraw, mago, eltern, finder, wie buts Ssott alsa zu famen bringet, alle jampt, rechte, heifige mit [ [N iij] Srrejter, Durch Shrijtus blut ge= heifiget, vno burch Den heifigen geift gejalbet und gemenhet jun ber Tauffe, Bno jut joldyer onjer angeborner, erb= licher, \$riejterlichen ebre und ichmucf finto wir ba, Gabent (mie 2lpocalypjits am vierben Eapitel [v. 4] gebilbet ift) vnjer guldon fromen auff ben Geubten, Garffen jut ber Gant vito gurben reuchfeffer, Bno lafjen vnjern \$Farrber midft fíx fich, als fír jeine perjonen, bie oromung (5hrifti iprechen, Sondern ex ijt vnjer affer muto, bnto wir alfe iprechen jie mit jm von Kerbुen, ono mit auffgeridgtem glauben, zu Dem \&am (Sottes, Das da fír vns vno bet) vns ijt, ons jeiner promung nach ons ipeijet mit jeintent leibe vno blut, Das ijt vnjer Meffe, uno bie rechte Meffe, Die vn's nidft fenlet.

Denn bie gehets eritlich, alfes nach ber orbunt - vnd befelf Chritt, das es ber Sirchén audd int beiber geitalt gereidyt vno gegeben wird, Durch bie mort (sfyrifti,

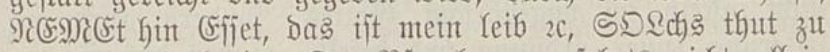
meinem gedechtnis, Der \$Ffarrher empfehets nidjt alleint fír fich, twie Der Bapft gremel thut, Er opffert? aud nicht Csotte firr onjer junbe vno afferlety not, wie ber Bapft gremel thut, Err teilets vnts nicht mit, verfeuffits vns audf) nidft, als ein gut mercf (sott zu verjinten, wie ber Bapit grewel thut, wno jolchen lefterfichen jar mareft

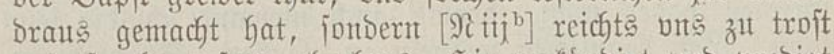
und iterfe vmiers glaubens, Şie berfindigt vno prebigt man bon (Ehrifto, Şie fan fein geib noch 2lbgótteret fein, 
Şie Gaben twir bie meinung Shrifti vnd Der Sirchen getwis, Şie Dirffen wir nicht jorgen ob dex \$Ffarrher bie mort heimlich iprectye obser of er autch Wandele, obser ob ex audf gleube, Dent twir horen bie moxt ber ein = jebung offentlich ond iprechen fie von herben mit im, Bnt bie einfebung Syrifti (nidgt onjer thun nody (Erejem)

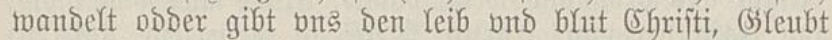
Der \$ffarrber nicht odoer zmeiult, jo gleuben wir, Stratchelt ex jun Den morten, Dober wird jure bno ver= giffit, ob ex die wort geiprochen habe, So find wir ba, horen zu, Galten feft und fino gemis, das fie geiprocken find, Darumb fontent twir nicht betrogen merben, Mno meil bie orbmung wo rechter glanbe ba iit, mus es ge= wis fein, Das wir ben waren Yeib wno blut Egrijti em=

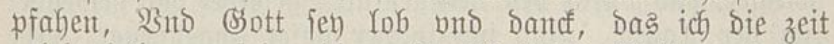
erlebt habe, zu fehen bie rechte Chriftliche Mefie, und Den reinten Egrijtlichen braud bes heiligen Sacraments, Jch jebe es mit luit und freuden meines berben, nach Dem gremlichen, ichrectlichen misbraudb), io id) Yeiber hab helffen treiben vnter Dem Bapit gremel, jo viel jar.

Denut ich offt ba fur exjefrecte, ment idy bran bentefe,

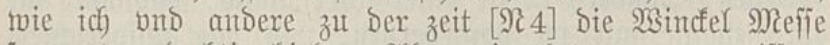
fo gants andechtig bielten, Arber wix thetents aus vnififen= heit, Darumb Gats vne Der liebe man shejus Shrijtus zu gut gebalten und vergeben, Denn wir twolfents autch nimer thun, 2Uber ibt wiffents die \$apiften, rollents aber nicht miffen, beharren mutwilliglich jnn jrem gremel, geben freulel vno thiritig ba Gin, vno verferen Ehriftus ord = mung, madjen eine netwe andere oronutg, Galten Mefie nicht alfein im ongeforjam Gsottes, fonbern auch jun Yejterung jeiner oronung und befelf, reichen das Sacra= ment niemano, bebaltens alfein, fonnen ba zu nidgt gemis fein, of fie eitel brod und wein obser den Yeib vnt blut Ehrifti nemen, weil fie es nidgt nach) Chriftus oromung, fonbern nad) eigener oronung wibder Chritus oromung handeln, 2Auch fan niemand gewis jein, of fie bie wort

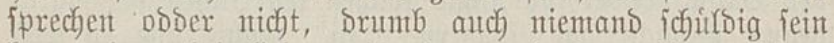
fant, irem beimlichen twispeln zu gleuben, So predigent fie audf feintem mentichent etras, wie Doch (Shrijtus be= 
folfen hat, ess iit audy vnminglich, bas fie folten recht

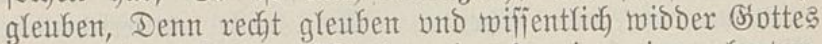
wort toben, itebet nidgt bey einander junt eintem herben, Der balben formen fie aud nidjt beten nodh dandfen, Das

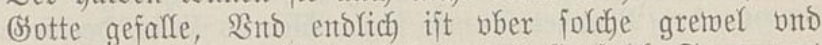
fremer, jr Gobeiter Ssottes bienjt, bas fie foldh Sacrament (iits anders ein Sacrament) mit io viel gremeln $\left[\Re_{4} 4^{\mathrm{b}}\right]$ gejchendet uno geleitert, Sott opffern vno andern CGrijtent vmbs gelo mit teiren ono berfeuffen, Segen joldye berben, ift fein itahl nod) eijen, fein fels noch itein, bart zu rechen, bie wiffentlidy junt joldfem gremel bleibent. ${ }^{1}$ )

(ङ) ijt mix aber bis buch onter ben henden grofier gemachien, Dent idj gebacht fyab, vno mus es ein wentg einziehen, bis idf obder bie vnjern ein ander mal weiter ba von jebreiben, Dent weil bie \$arapiften junt jren gremel verzweiuelt und veritoct, nicht auff horen wollen, beibe mit Yiegen wiober bie erfante warheit, ono mit morben bie unichitloigen, fromen Egriften, miffent wir himfurt bis ftucf offt und vleiffig hanbeln, da mit bie vnjernt einent flaren uno gemifijen vntericheio baben mitgen, zmifichen Dex rechten Seifigen Sirchent uno Dem Bapitum, zwifichent

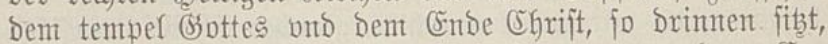
jun ber andern Epiftel zu Tefijalonichern am andern $\mathrm{C}_{\mathrm{a}}=$

1) Gegen diese Kritik der Winkelmessen ruft Cochläus das Schwert der Obrigkeit anf: ,die Oberkeyt hat warlich hoch zubedencken, wie sie Gott dauon rechenschafft gebe, wo sie nicht mit höchstem vleys vnd ernst so schwere Gotteslesterunge verbeut, verbrennet vnd vertylget, so viel der selbigen lesterbüchlin ynn yhrem gepiete mögen erfunden werden. Denn sie tregt das schwert nicht vmb sonst, wie Paulus spricht. Da solt sie Tausent mal ernstlicher yhr schwerdt gebrauchen, Denn wo Türcken odder Heyden die Christen bekriegen oder belegern, denn sie verdirbt die Seel ewiglich, dort alleyn der leyb zeytlich." Bl. D 4. „W ir halten vns festiglich an die kyrchen ... vnd glauben sicher vnd vngezweyfelt, das wenn ein rechter Priester diese wort der tyrmung spricht vber brod vnd wein, das warhafftiglich dadurch die wandlung gescheh, wie wol es ynn der gantzen Bibel nirgend geschrieben steht.... [Christus vnd die Apostel] habens die kirchen mündtlich gelernt, wie auch viel andere mysteria, die man für die hund vnd schweyn ynn offentlichen schrifften nicht werffen sol." Bl. Eijb. 
pitel [․ 4], zwifichen Der Şeiligen ftete vno Dem gremel brimen, wie uns Ehriftus jelbs Geifit, ontericheiden, Miatthei am vier vno zmentigiten [v. 15], Went ir jeben merdet ben gremel ber verjtorunt itehen jun Seiliger itete, ba von ber \$rophet Daniel jagt, Wex es Yiejet, Der jebe zu Das ers veritehe, Denn wir Iaffen Das Şapitum nidyt fein bie Keilige Sirche, noch) ettrwa ein ftitce Da von, und fontens auch nicat thun, Sonbern es ift ber wijpte gremel und En[D]Dechrijt, Der feino vno wiober wertiger, ber bie Sirche, Sottes mort vno orbmung zerftoret, wno jich jelbs wiboer wno briber jebt, als ein Ssott bber alle Bsotter, mie Daniel vnt Sanct \$aulus getweiffagt haben, Snd bie meil es nidft jein fan, Das wix obser Die heilige Rirdje, fich) leiblich icheibe obser abjondere, von bem gremel, Bapitum odser Endechrift, bis an Den singiten tag (Denut Der gremel for wno mus (mie Égriftus leret) nicht auffer, jonbern jun ber Geiligen itete jteben, ono Der Endechrijt nicht auffer, fonberit jin bem tempel (Sottes fitzen, vno bas Bapitum nicht auffer, fondern jun Der Sirchen jein) jo miffjen wir boch wns wiffen geifflich wno mit rechtem bexitand, von im zu icheisen, vnd uns firr feinem veritoren Gitten vnt bemaren, ba mit wix in rechten glauben Ebrijti rein blei= ben, vnto wiober fein geidhmeis vno vulifer uns wehren vno vertet)bigen.

2Uljo wil ich ibst bas funffit uno jechjt itucfe iparen, Remlicf), bie ichliffiel obser vergebung, vno bas gebet, twie fie ba mit geipielet, vno bie rechte vergebung vno gebet zeritoret Gaben, Bno boch Shriftus fie, alle beide wum= Derbarlich bno mit macht exhalten hat, wil bie mit an=

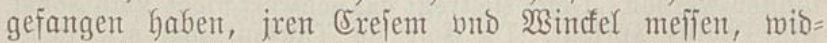
Derumb zuteritoren vno fold exgernis belffen aus bem Reicf Shrifti jamlen, vnd den beruff obder rechte saenhe $\left[S^{b}\right]$ vno orbinim zum \$farrampt, witberumb bex Sirchen zu iprectjen vno ein reumen, wie fie von anfang gehabt hat, welche bie groffen Bifichoue zu fict) alfein ge= riffen, ben fleinen Biffchouen obser Sfarrhern gentmen haben, Denn bas ijt vno mus vnjer gruno vno gerwiffer fels jein, $\mathfrak{W}_{\mathrm{D}}$ bas Euangelion redat wno rein gepresigt mirb, da mus einte heilige Ebriftliche Sirche jein, Sno 
wer baraut ziveiuelt, bex mag eben io mebr audh ztweiuteln aut Dent Enangelion obs Sottes wort jer), $\mathfrak{S 0}$ aber eine beifige Shriftliche Siuche ijt, Da mifien alle Sacrantent jein, Shriftus jelbs ond jein seifiger geift, Solten wix nu eine Geilige Shriftiche Sirche jein, ono bie groiten und nottigiten itucf Gaben, als Sottes \$ort, Shrijtum, S'eijt, SSlauben, SSebet, Tauffe, Sacrament, Schlitifel, 2tmpt $2 c$, ond folten nicht aud bas geringit- jticf Gaben, Remrlich), bie macht und recht attliche zum ampt beruffen, Die uns bas 2 bort, Tauffe, Sacrament, Rergebung, (fo bereit $D a$ find) Darreichtent nno Drinnen Dieneten, $29 a$ were mix bas fin eine firche? 230 bliebe fie Éfrifus wort ba ex pridft, $\mathfrak{S D}_{\mathrm{D}}$ zmeen obder brey jum meinem namen verjamlet fints, da bin ich viter inen? Bno aber= ntal, 250 zween vnter euch eins werden auff erden, warumb es ift, Das fie bitten mollen, das jol jut roibserfaren won meinem $\mathfrak{B}$ ater im Gimel, şaben zmeen oboer bren forke getwalt, wie viel mehr eine ganbe firche?

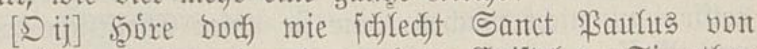
Dem orbinim rebet, inn ber andern Epijtel zu Timotheo an Dem andern Capitel [v.2], $\mathfrak{B a s}$ but von mix gebóret Gajt burch biel zeugen, Das befilly tremen menidgen, Die ba tudftig find audf andere zu leren, Şie ijt weber Srejem noch putter, (5s ijt allein Der befelf zu Yeren Ssottes toort, Wer Den Gat, Den Gelt Sanct $\mathfrak{B a u l}$ (us fix $\mathfrak{B}$ farther, Biffchoff und Bapit, Denn es ligt auch alles ant wort Ssottes, als am hobeiten ampt, Das Ehriftus felbit fur jein eigen und bas Góbeit hat wollen Gaben, Mafifen boch alle Sacra= ment burchs toort twerben, als burchs fuir nemeit ititcfe jun affen Sacramenten, wie es die \$apiten ielbs, For= mant Sacrantenti, nemen, Bno Shrijtus bat aud forjento= (ich vergeffen bes Erejems Mattbej am lebsten, Da ex ipricht, Sebet fin, reret alle jeeiben Galten alles, was ich) elich geboten habe, $\mathfrak{3 a s}$ hat ex juen aber geboten? Frenlich das (Enangelion zu predigen, zu Teltfen, Sacra= ment zu reichen, funbe vergeben $2 c$, Sollen nu alle şetbent joldjes haltent, So miffen fie frenlidy madyt nno recht Gaben zu Frebigen, Teuffen, Sacrament reichen, funde vergeben $2 c$, ja $e s$ ift inen bie mit geboten, bas fie es 
thut follen, Wsie Sant ßaulus audy zun (Eorintbern

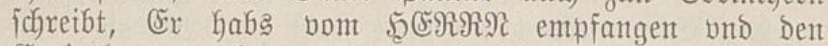
corinthern gegeben, und gebenctt feines Crejems, jondern allein bes ampts vnto befelfs. 1)

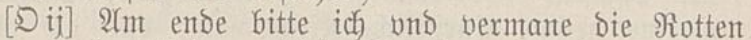
geijter, auch ettliche ruchloje Bapijten, bie jrem 216gott jelbs nicht tratwen, Sie wolten biejes mein buth onge= brautcht Iafjen, Denn bas ich bie Keilige Rirche entichitloige, twie fie aus vnwiffentheit gejundigt hat jun ber einen geitalt, (mie mol nicht bie ganbe Chrijtentheit fierin ge= fundigt) ba mit hab id nicht erfeubt nody bejtettigt, Den frentel bere, fo ibst miffentlich beiber geitalt berbamnen, 2(uch) feinem fottengeijt hierin gebientet ijt, ba ich) bom brod ond wein ber Wincfel meffen gejagt babe, Sondern icf wil ben unjern meinen bienjt exzeigt, ond bie $\mathfrak{B}_{\text {incfer }}$ menbe ond Wincfer mefie angegriffen, bno einten vnterjajeis zmiffichen Der Rirchen uno Bapitum gegeben Gaben, Denn

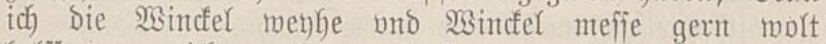
helffen zut nicht machen, twie fie vnjer (Efrijtliche wethe ono Mefie zut nicht gemadyt hat, Soldye jache gehet bie

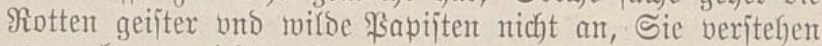
es aud gar nichts, Darumb jollen fie jre fache nicht da mit jodmincfen.

Wenn ich wiober fome, wil ich weiter angreiffen bie

1) Cochlïus erwidẻrt hierauf Bl. Fb: „Vom heyligen Cresem stehet wol nichts da [scil. in der Bibel], ob sie jn darzu gebraucht haben oder nicht, Es ist nicht alles geschryben ... Es hette sich auch nicht gezymet, alle heymligkeyt vnd hohe mysteria vnsers glaubens ynn offne vnd gemeyne bücher der Bibel zu setzen, denn Juden, Heyden, Tiurcken, Ketzer vnd Apostaten (wie ytzt Lnther vnd sein anhang thun) hetten solche mysteria verhönt, verspot, vbel aus gelegt vnd mit füssen getretten. Darumb verbot es Christus im Euangelio, das man das heylig den hunden nicht geben solt etc." Und weiter unten: "Welcher text saget, das die apostel alle y $\mathrm{n}$ die hende auffs heubt gelegt vnd gebetet haben? Wo steht das wörtleyn, Allein, darbey? Ach der ehrlose felscher wil das wörtleyn allenthalben hynzu schantzen, da es nicht stehet noch stehen sol, vnnd mit solchem falsch die kirchen straffen vnd vmbstossen, Es wird yhm aber nicht gelingen." Bl. Hiij. 
gantbe Wenhe in Bapitum, als ba fie fieben weble haben, ehe fie eintent Wintfel \$faffen machen, Nemtlich, Foitiarium, Rectorem, Errorciftam, Âcolvtum, Subbiacomumt, Diaconum, Fresbrterum, 2 nto bar nach bie hoben Wenthe,

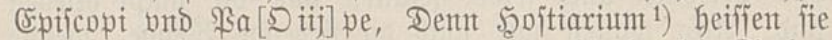
Dent io zum ftrange getwenhet war, Das ijt, ber bie Rirchen ichlieffen und glocten Yeuten folt, welche wenhe ibst bet) ineut felfs langes gefallen, ßno bock jolds ampt, on alle Wenhe, Der Ciriter, jein meib, mago, ber fnecht ats ridjten, beibe jun Dórffern wno Stedten. Rector ${ }^{2}$ ) hies ber jum Der Rirchen Yejen mujte die Section jun Dex Metten odber Bigilien, vnto \$Falmen fingen, Welchs ampt ibt autch auts=

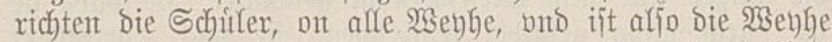
gar gefallen, wno bas amtpt Glieben. (Exprcifta ${ }^{3}$ ) Gies, Der ben Teuffel befdyweret fitr ber Iauffe, weldys ibst

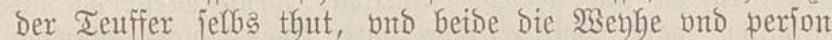
folchs naments meg, affein bas ampt bliebent ijt. 2lcoly =

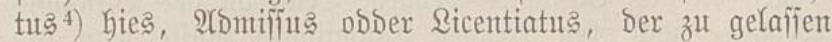
mar bmb ben Âttar Dem \$riejter zu Dienen, als bie Dent 2litax zn richten, Yiecht bno ferben anzundeten, vnd zux Mefie bulffen, barumb fie jolche Ceroferarios biefien,

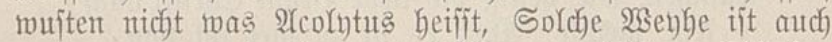
vntergangen, bno thun ibt joldy ampt (eifter, Schuler, Ciriters weib, todjter, mago, on alle Wrenke, beibe jun Stesten und Dorffern, Dieje mititen auch alle Crerici, Die geiftlichen Keifient.

Irfo Evifteler und Enangelier, maren bie jo jun ber Mefie die Epifter uno Enangelion Yajen, Eorporal wno

1) „Primus [Ordo] est ostiariatus, cujus est custodire locum confectionis sacramentorum ab immundis $\mathrm{s}$. infidelibus et excommunicutis." "Tractatus sacerdotalis de sacramentis" Argentinae, Mart. Flach. 1490. Bl. G 6b․

${ }^{2}$ ),Secundus est lectoratus, cujus est legere prophetias ad instruendum illos, qui volunt credere."

$\left.{ }^{3}\right)$,Tercius est exorcistarum, qnorum est artare demones per adiurationem, ne dominentur in corpore nondum baptizato."

4) "Quartus est accolitorum, quorum est presentare materiam vrceolum cum aqua et vino et lumen accendere." ibidem. [áxó 


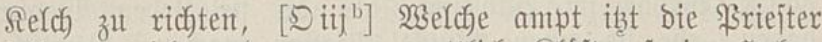

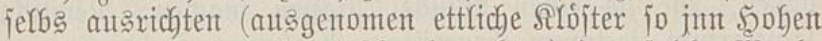

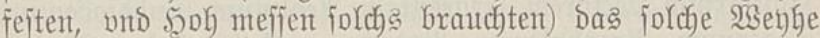
und pexjonten aucf felbs gefalfent bno die ampt bliebent

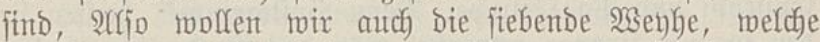

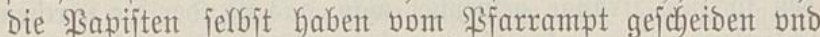
zut nicht gemacht mit jrem 2 intfel wenhen, weg gethan vnd Das ampt beitettigt Gaben, Das alfo alle fieben weybe uns mit jrem gleifien nicht jren jollen jun ben

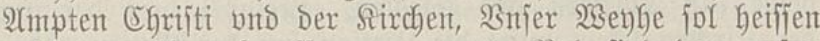
orbinitut odser beruffen zum ampt, 2 nti find ber perjon Die fintger mit Dem Erejem nicht gejchmirt, io jollen fie ba burch gung gefalbet fein, wemt fie das Sacrament angerint baben, gleich twie Die Reldye wno Corporal bie Bapiften da mit geweblyet Gielten, went Meffe ba mit gebalten ward, wie ettliche vnter inen folchs thuxiten mogen on bes Bifjchoffes menken, Denn on Des Biffchoffes wenken (nach jren ftrengen Cantnibus) muite man jun feinem vngemengeten Corporal oboer feldhe Mieffe halten, Durfft auch jolche gemengete Corporal feine Nome nicht mafichen, wie heilig bie liebe Braut Efrifti auth jein mochte, 2rber es iit z"t viel ibst won bem unzelichen gremel Des wenken zu jagen, Ein ander mal mebr Da von, vnt ob (Ś)tt wil, gut, $\mathfrak{A} \mathfrak{M}[\mathfrak{S}$. 

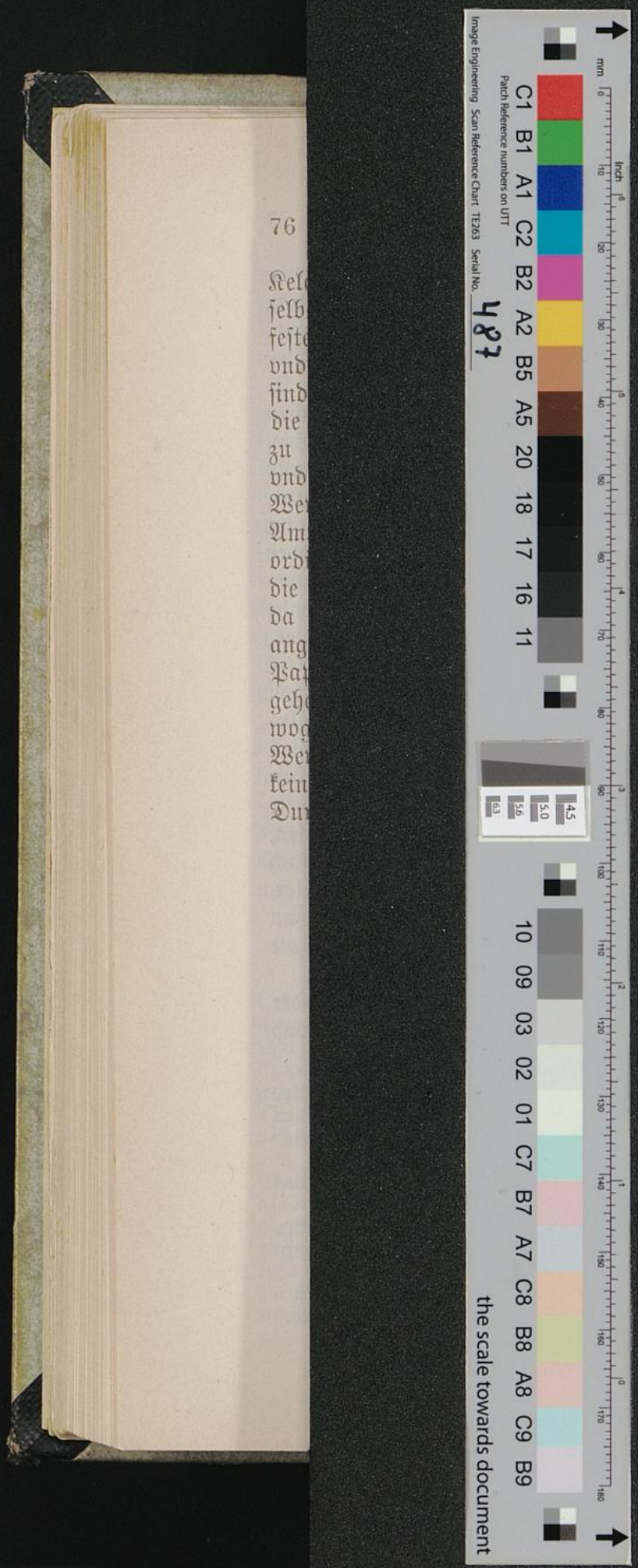

ie Ssrieiter jun Sobert (che 23 enge unt bliebent he, melche fretiont vito weg gethant alle fiebent ent jint ben fol Geiffent Der perion b jollen fie Sacrament prporal die efie da mit 5 thuritent Bififdoffis man jun eile Gartent, corme nicht (i aucle ont 